\title{
New Air Cleaning Strategies for Reduced Commercial Building Ventilation Energy
}

\author{
Meera Sidheswaran, Hugo Destaillats, \\ Douglas P. Sullivan and William J. Fisk
}

Environmental Energy Technologies Division Indoor Environment Department

E.O. Lawrence Berkeley National Laboratory

Berkeley, CA, USA

October 27, 2010

This work was supported by the Assistant Secretary for Energy Efficiency and Renewable Energy, Building Technologies Program of the U.S. Department of Energy under Contract No. DE-AC02-05CH11231. 


\section{ACKNOWLEDGEMENTS}

The authors thank Jerome Lam and Colin McCormick of DOE for program management, R. Maddalena, M. Sleiman, M. Russell, T. Hotchi, M. Spears, A. Montalbano, J. Larsen, X. Song, W. Lukens, Q. Fu, Ken Reichl, and Marc Fischer (LBNL) for technical assistance, and L. Gundel and M. Apte for reviewing this report. 


\section{Table of Contents}

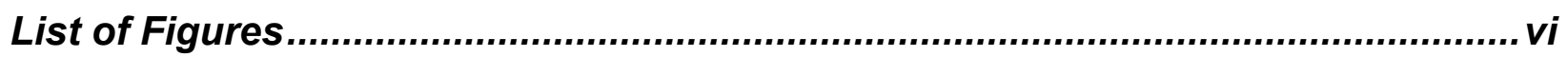

List of Tables ......................................................................................................... viii

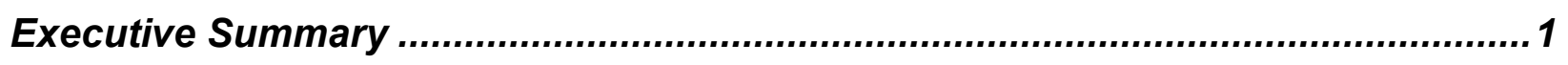

1 Evaluation of in-situ regeneration of Activated Carbon Fiber (ACF) filters ...... 5

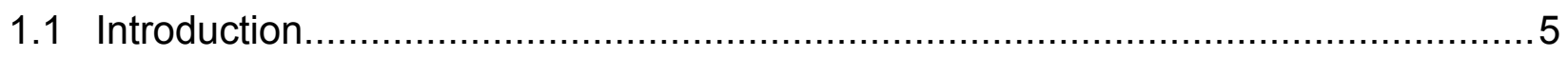

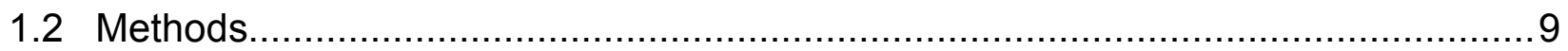

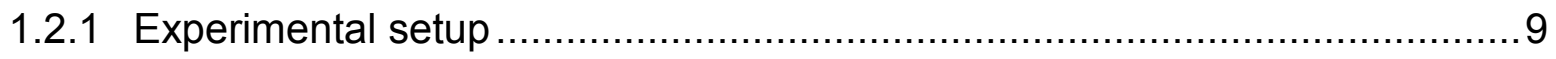

1.2.2 Adsorption (air cleaning) Period ……................................................. 11

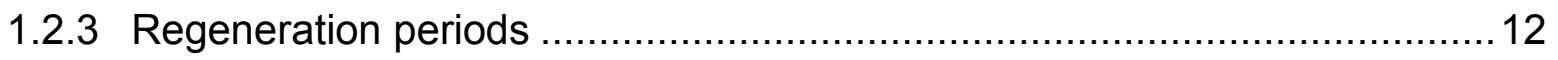

1.2.3.1 Unheated outdoor air regeneration ............................................. 13

1.2.3.2 Electro-thermal regeneration .................................................... 13

1.2.4 Determination of removal and regeneration efficiencies ...........................13

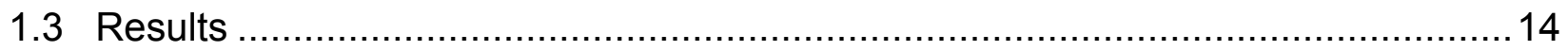

1.3.1 Continuous adsorption period to evaluate VOC holding capacity of ACF .... 14

1.3.2 Evaluation of VOC air cleaning with different regeneration methods ...........17

1.3.2.1 Adsorption - regeneration cycles: Method 1 - regeneration with room temperature outdoor air ..................................................................... 17

1.3.2.2 Adsorption - regeneration cycles: Method 2- regeneration with heating ..

1.3.2.3 Adsorption - regeneration cycles: Methods 1 and 2 with shorter

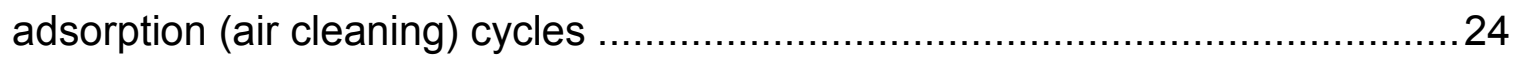

1.3.3 Evaluation of the effect of relative humidity on regeneration .....................26

1.3.4 Prediction of impacts on indoor VOCs: Mass balance model .....................27

1.3.4.1 Scenario 1: Moderate initial ventilation rates ...................................27

1.3.4.2 Scenario 2: High initial ventilation rates .........................................28

1.3.5 Energy consumption costs for using ACF filter bed system:...................... 31

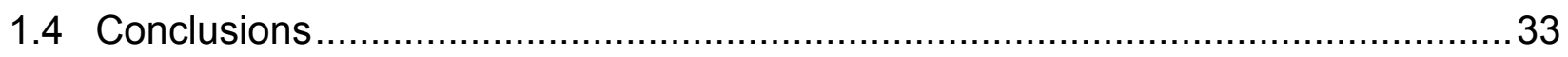




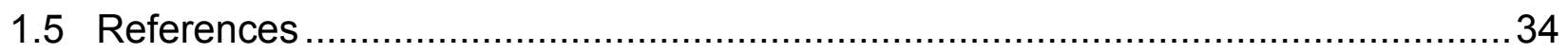

2 Formaldehyde removal with manganese oxide-based room-temperature

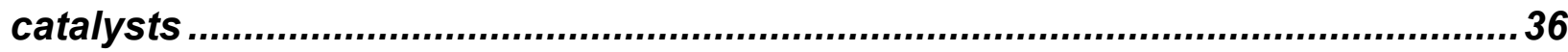

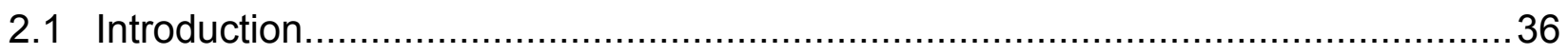

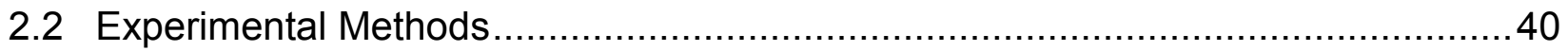

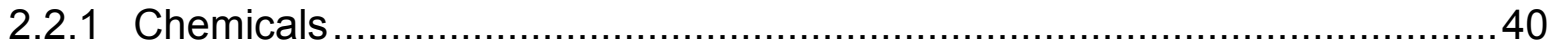

2.2.2 Preparation of manganese oxide catalysts ........................................... 40

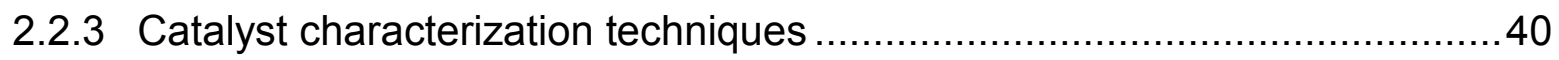

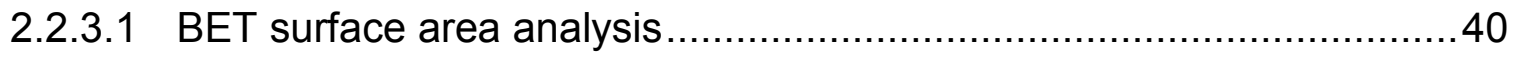

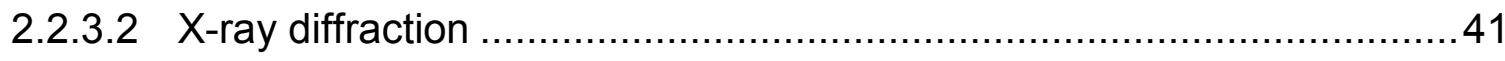

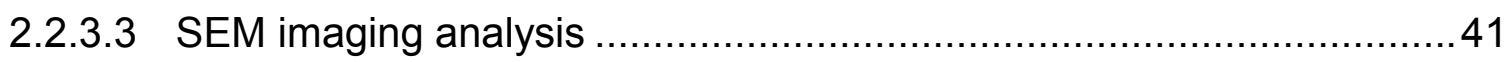

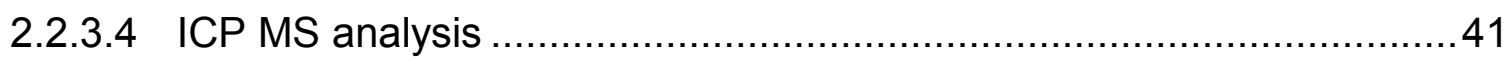

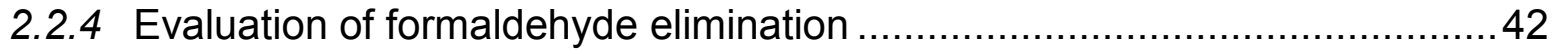

2.2.4.1 Preparation of supported catalysts ............................................. 42

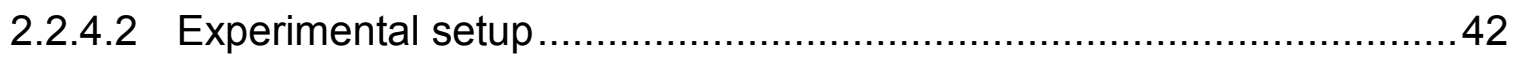

2.2.4.3 Sampling and analytical methods ............................................... 43

2.2.4.4 Evaluation of the extent of mineralization ....................................... 43

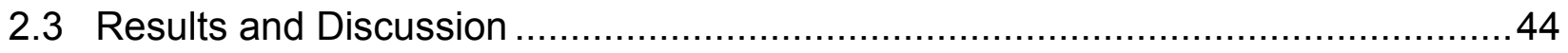

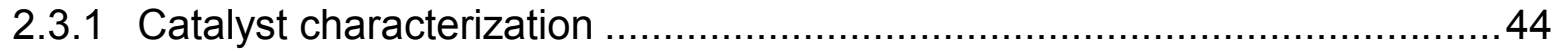

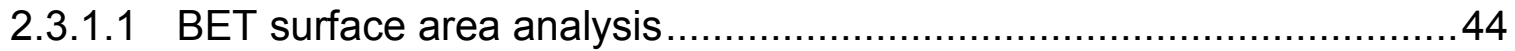

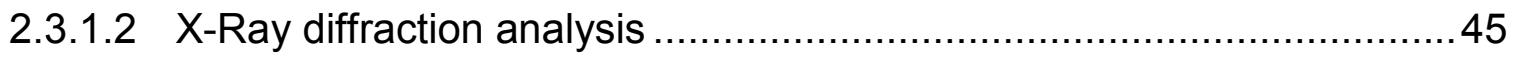

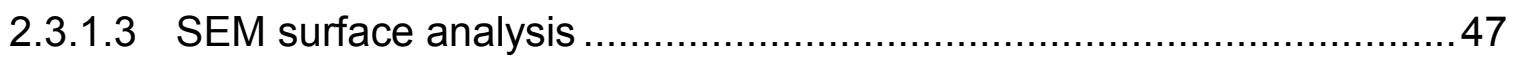

2.3.1.4 Determination of empirical formulae ........................................... 49

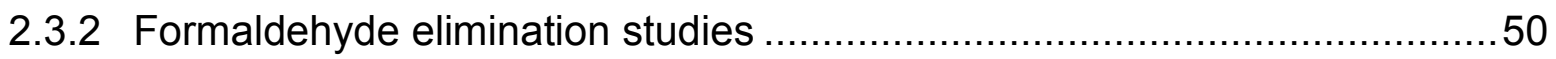

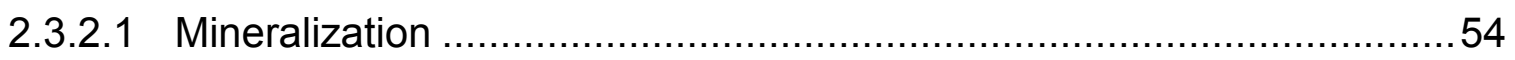

2.3.3 Predicted impact on indoor formaldehyde concentrations .........................55

2.3.3.1 Scenario 1: Moderate initial ventilation rates ....................................55

2.3.3.2 Scenario 2: High initial ventilation .................................................55

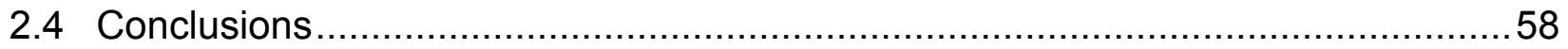

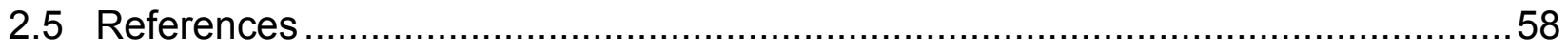


3 Evaluation of passive formaldehyde removal by ceiling tile and wallboard...63

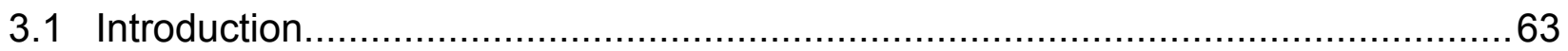

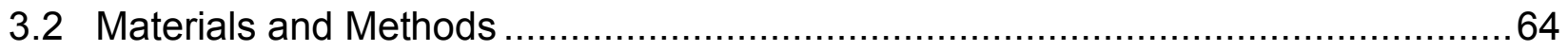

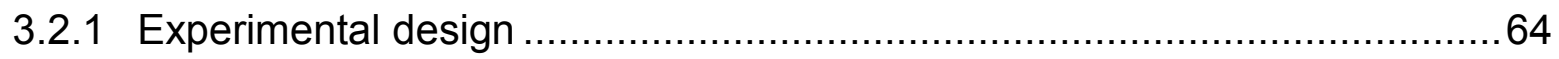

3.2.1.1 Surface area of ceiling tile per unit air volume .................................. 64

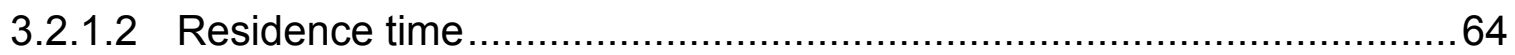

3.2.1.3 Composition and concentrations of pollutants in the air ..................... 65

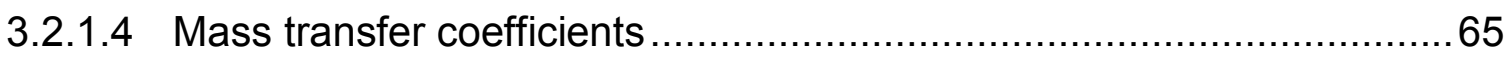

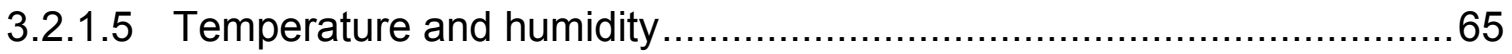

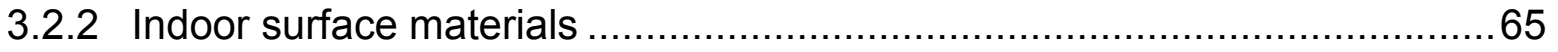

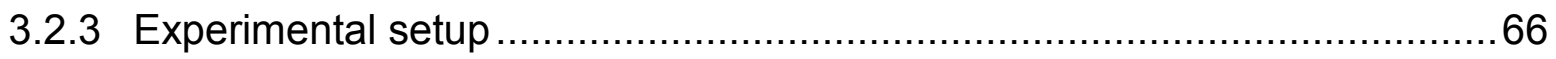

3.2.4 Sampling and Analytical Methods ...................................................... 68

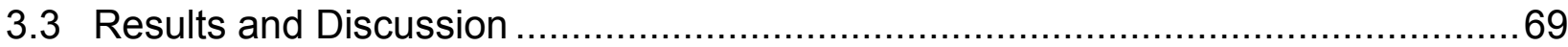

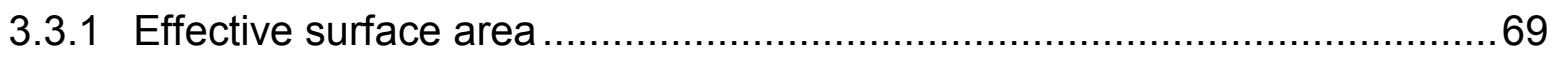

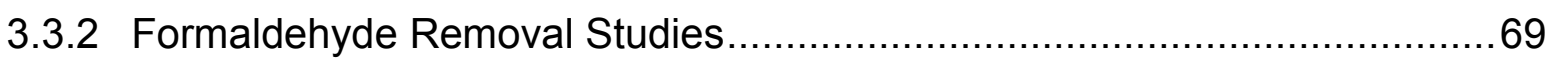

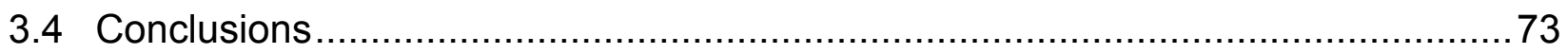

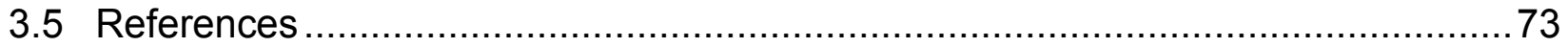




\section{List of Figures}

Figure 1-1.Two possible retrofit configurations using activated carbon fiber air cleaning

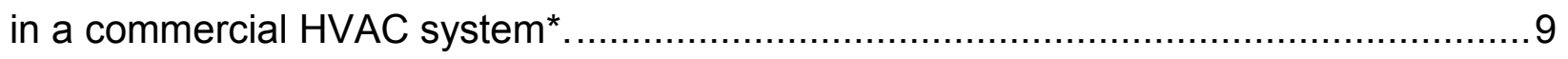

Figure 1-2. Flow setup showing adsorption and regeneration periods ........................ 10

Figure 1-3. Dimensionless adsorption profile for different VOCs on the surface of ACF

Figure 1-4. Removal percentage time profile for (a) Benzene, (b) 1-Butanol, (c) Toluene, (d) O-Xylene, (e) Formaldehyde, (f) Undecane for different adsorption - regeneration cycles with adsorption face velocity of $31.3 \mathrm{~m} / \mathrm{min}$ and regeneration face velocity of 6.3 $\mathrm{m} / \mathrm{min}$

Figure 1-5. VOC Percent removal efficiency for 24 hour adsorption period with a room temperature outdoor air regeneration air stream of $0.3 \mathrm{~m} / \mathrm{min}$. Negative values indicate downstream levels higher than upstream concentrations due to ACF saturation. 20

Figure 1-6. VOC Percent removal efficiency for 24 hour adsorption period with different electro-thermal regeneration air stream face velocities and a regeneration temperature of $150^{\circ} \mathrm{C}$ for two hours.

Figure 1-7. VOC percent removal efficiency for 12 hour adsorption cycle with ambient air regeneration at $25^{\circ} \mathrm{C}$ and air face velocity of $4.2 \mathrm{~m} / \mathrm{min}$ for 6 hours 25

Figure 1-8. VOC percent removal efficiency for 12 hour adsorption period with electrothermal regeneration at $150{ }^{\circ} \mathrm{C}$ and air face velocity of $1.1 \mathrm{~m} / \mathrm{min}$ during 15 minutes ...26

Figure 1-9. Comparison of Adsorption period VOC removal efficiency at the end of Cycle 3 for wet regeneration and ambient air regeneration at $6.3 \mathrm{~m} / \mathrm{min}$ and 12 hours.. 27

Figure 1-10. Mass balance model flow system 29

Figure 2-1. Flow System. 43 
Figure 2-2 X-Ray Diffraction spectrum of $\mathrm{MnO}_{\mathrm{x}}$ treated at $100{ }^{\circ} \mathrm{C}$. 46

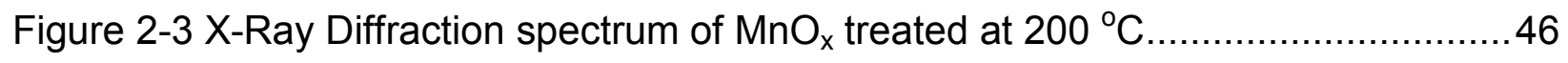

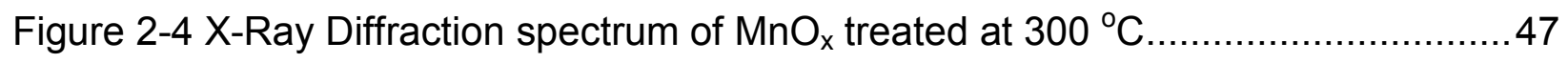

Figure 2-5. SEM Images of manganese oxide particles synthesized and treated at (a) $100{ }^{\circ} \mathrm{C}$; (b) $200{ }^{\circ} \mathrm{C}$; (c) $400{ }^{\circ} \mathrm{C}$; and (d) commercially available $\mathrm{MnO}_{2}$. 48

Figure 2-6. Percent formaldehyde removal $\eta_{f}$ vs. time. 51

Figure 2-7. Cumulative formaldehyde elimination. 51

Figure 2-8. Plot of percent formaldehyde removal vs. time for high face velocity of 31 $\mathrm{m} / \mathrm{min}$. .53

Figure 2-9. Formaldehyde elimination at two different face velocities. 54

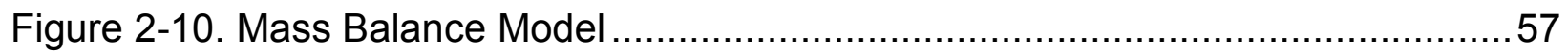

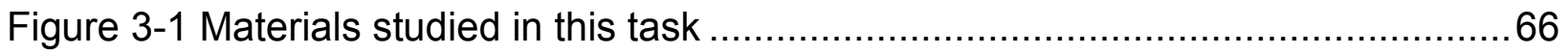

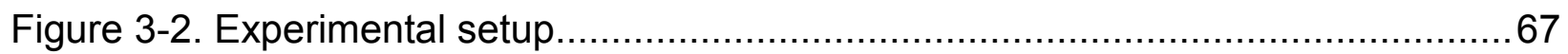

Figure 3-3. Chamber (upstream) concentrations ................................................. 70

Figure 3-4. Formaldehyde percent removal and cumulative uptake for different materials 72

Figure 3-5. Formaldehyde cumulative mass uptake by each material. .72 


\section{List of Tables}

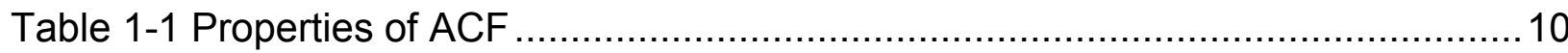

Table 1-2. Physical properties and concentration of the selected VOCs ......................11

Table 1-3. Multi-component Freundlich Isotherm parameters for VOCs....................... 16

Table 1-4. Regeneration efficiency $\eta_{r, i}$ for different compounds using room temperature outdoor air for regeneration (face velocity during regeneration $=6.3 \mathrm{~m} / \mathrm{min}$ ). 18

Table 1-5. Regeneration efficiency $\eta_{r, i}$ of different compounds under different face velocities using electro-thermal method with a $150{ }^{\circ} \mathrm{C}$ regeneration temperature for two hours. 23

Table 1-6. Percent removal efficiency and air cleaning effectiveness ratio for ACF filter fiber system with different regeneration techniques.

Table 1-7 Annual regeneration energy cost estimates for the electro-thermal regeneration system and savings obtained from ventilation costs.

Table 2-1 BET surface area of different ceiling tile materials. 44

Table 2-2 Composition of manganese oxide prepared in the laboratory 45

Table 2-3. Analysis of manganese oxide sample treated at $100{ }^{\circ} \mathrm{C}$ using ICP-MS 50

Table 2-4 Formaldehyde and Carbon-dioxide upstream and downstream concentrations .

Table 3-1 Indoor surface materials analyzed in this study 66

Table 3-2. BET surface area of different ceiling tile materials*. 69 


\section{Executive Summary}

\section{Introduction}

Approximately ten percent of the energy consumed in U.S. commercial buildings is used by HVAC systems to condition outdoor ventilation air. Reducing ventilation rates would be a simple and broadly-applicable energy retrofit option, if practical counter measures were available that maintained acceptable concentrations of indoorgenerated air pollutants. The two general categories of countermeasures are: 1) indoor pollutant source control, and 2) air cleaning. Although pollutant source control should be used to the degree possible, source control is complicated by the large number and changing nature of indoor pollutant sources. Particle air cleaning is already routinely applied in commercial buildings. Previous calculations indicate that particle filtration consumes only $10 \%$ to $25 \%$ of the energy that would otherwise be required to achieve an equivalent amount of particle removal with ventilation. If cost-effective air cleaning technologies for volatile organic compounds (VOCs) were also available, outdoor air ventilation rates could be reduced substantially and broadly in the commercial building stock to save energy. The research carried out in this project focuses on developing novel VOC air cleaning technologies needed to enable energy-saving reductions in ventilation rates. The minimum required VOC removal efficiency to counteract a $50 \%$ reduction in ventilation rate for air cleaning systems installed in the HVAC supply airstream is modest (generally $20 \%$ or less).

\section{Project Status and Outcomes}

Activated Carbon Fiber Filters: Granular activated carbon has long been used in industry to adsorb VOCs from polluted air and water but the cost, weight, and pressure drop of granular activated carbon systems preclude their widespread use in buildings. Activated carbon fiber cloths have recently become available. They can be deployed in a similar fashion to particle filters. This study evaluated the use of ACF cloth media to remove a broad range of VOCs from the indoor air with periodic, e.g., nightly, 
regeneration. The regeneration process removes the adsorbed VOCs from the ACF media and vents these VOCs outdoors, allowing for recycling of the ACF media for indoor air cleaning. We evaluated regeneration of the ACF media with room temperature outdoor air passing through the ACF media at velocities as low as $15 \%$ of the velocities used during air cleaning. We also evaluated ACF media regeneration by heating the ACF to $150{ }^{\circ} \mathrm{C}$ for periods as low as 15 minutes, and using much lower air velocities, e.g., $1 \%$ of the velocity during air cleaning. With every regeneration approach, we employed sequential 12 to 24 hour periods of air cleaning, each followed by a regeneration period. The primary outcomes of interest were the efficiency of removing the various VOCs during each air cleaning cycle and the regeneration conditions (flow rates, temperatures and durations), which determine the energy consumption of ACF air cleaning. The results of testing under various regeneration regimes were very promising. In one condition using unheated outdoor air for regeneration, VOC removal efficiencies were in the $40 \%$ to $60 \%$ range for all VOCs except formaldehyde, which was removed with $15 \%$ efficiency. With heated regeneration air, VOC removal efficiencies were in the $60 \%$ to $85 \%$ range for all VOCs except formaldehyde, and $20 \%$ for formaldehyde. Calculations accounting for fan energy and regeneration heating energy (when employed), indicate that the cost of energy required to provide a unit of VOC-free air with the ACF system is only $2-15 \%$ of the cost of energy required to obtain the same amount of indoor VOC removal with ventilation. Mass balance modeling indicates that the combination of ACF air cleaning and $50 \%$ reductions in ventilation will substantially reduce concentrations of indoor VOCs (except formaldehyde) compared to today's conventional practices. The modeling predicts that indoor formaldehyde may decrease or increase moderately depending on the initial ventilation rate and the operational conditions of the ACF system. Further research is needed to evaluate system performance over a broader range of conditions, to confirm the lifetime of ACF systems and to determine media costs.

Manganese oxide based catalyst: Recently, manganese oxides have been used in the high-temperature catalytic oxidation of formaldehyde in air. The catalytic activity of 
manganese oxide depends on the crystal structure, effective surface area and oxidation state of $\mathrm{Mn}$ present. If these properties are modified appropriately, room temperature oxidation of formaldehyde in air can be achieved. We synthesized nano-particulate manganese oxide-based catalysts with favorable properties using precipitation methods. The precursors and synthesis process are inexpensive. When these materials were characterized using scanning electron microscopy, X-ray diffraction and porosimetry techniques, it was observed that the laboratory-synthesized manganese oxide catalysts exhibited a much higher surface area ( $>2$ orders of magnitude) and lower particle size compared to commercially available manganese oxide. The catalytic activity of the laboratory-synthesized manganese oxide was evaluated in formaldehyde removal tests. The catalyst was loaded on HVAC particle filters, and the formaldehyde removal efficiency of the system was tested with two different formaldehyde concentrations under two different flow conditions at room temperature. In both sets of experiments, the catalyst maintained a consistent formaldehyde removal efficiency of more than $80 \%$. Further, the pressure drop across the system was very low, suggesting that there would be insignificant fan energy costs when the catalyst is deployed in the HVAC system. A mass balance model similar to that used with the ACF filter bed suggests that, when the catalysts is deployed and ventilation rates are reduced by $50 \%$, indoor formaldehyde concentrations can be reduced by $80 \%$. Additional research is required to study the optimal operating conditions and to determine the catalyst lifetime.

Passive formaldehyde removal: Zeolite-containing ceiling tiles have recently been introduced into the European market for indoor formaldehyde control by the German manufacturer Knauf. Zeolites are highly porous aluminosilicates with a strong affinity for certain gases and organic vapors. Research has shown that formaldehyde adsorbs strongly to zeolites, where its oxidation can be catalyzed. Ceiling tiles and wallboards are well suited for passive air cleaning application due to their wide spread use in commercial buildings and large surface area. Passive air cleaning processes have low operational costs and do not consume energy. However, we were unable to identify any prior studies that documented the formaldehyde removal performance of these 
products. Chamber tests were conducted to evaluate the formaldehyde-removal performance of zeolite-containing ceiling tiles, compared to standard mineral fiber ceiling tiles and gypsum wallboard. All products initially adsorbed formaldehyde, as expected, but none was promising as a long term means of removing formaldehyde passively.

Summary of Technical Potential: Calculations indicate that application of ACF systems and simultaneous reductions in ventilation rates by $50 \%$ could decrease total ventilation energy costs by 35 to $48 \%$, while also decreasing the indoor concentrations of a broad range of VOCs and reducing or maintaining unchanged formaldehyde concentrations. When necessary, the ACF system can be supplemented by the manganese oxide catalyst for formaldehyde, for which there are negligible energy costs. Total product costs have not yet been evaluated and will depend on system lifetimes. However, the manganese oxide nanocatalysts are expected to be inexpensive because the precursors are inexpensive and the synthesis process is simple. The U.S. supplier of ACF cloth is interested in this application of their product. Particle filter suppliers are expected to be very interested in applying the manganese oxide catalysts on their filters. Thus, there is a ready path to market these two promising VOC air cleaning technologies. 


\section{Evaluation of in-situ regeneration of Activated Carbon Fiber (ACF) filters}

\subsection{Introduction}

Ventilation with outdoor air is required to maintain acceptable indoor concentrations of indoor generated air pollutants. Based on recent analyses of data from Benne et al. 2009 and Griffith et al 2008, in the U.S. commercial building stock approximately ten percent of energy is used to condition ventilation air provided mechanically and via air leakage. To reduce energy use in buildings, reductions in the energy required for ventilation are highly desirable. One option is to reduce ventilation rates, e.g., by $50 \%$, and compensate for the diminished rate of pollutant removal using energy efficient air cleaning systems. In commercial buildings with a VOC air cleaner installed in the supply airstream consisting of outdoor air and a larger quantity of recirculated indoor air, approximately a 15 to $20 \%$ VOC removal efficiency would be required to prevent VOC concentrations from increasing from a $50 \%$ reduction in outdoor air supply.

In most commercial buildings, there are insignificant indoor sources of inorganic gaseous pollutants and the primary indoor-generated pollutants affected by ventilation are particles and volatile organic compounds (VOCS). The particle filters already used in buildings remove indoor generated particles using far less energy than ventilation. To complement particle filtration, effective and energy efficient air cleaning methods are needed for VOCs. This document describes evaluations of the use of activated carbon fiber systems to remove VOCs from indoor air during work hours, with periodic, e.g., nightly, in-situ regeneration of the carbon fiber media. Regeneration would allow the filter to provide effective VOC air cleaning during the subsequent period of occupancy. The regeneration process drives previously adsorbed VOCs off the carbon fiber media and exhausts those VOCs outside the building. 
While there has been prior research, as described below, on VOC removal using active carbon fiber media and media regeneration those studies have utilized high concentrations of VOCs (parts per million) and generally only single compounds. However, to enable a reduction in ventilation rates an air cleaning system needs to be effective in removing a broad spectrum of VOCs that are present simultaneously in the indoor air at low ppb-level concentrations. In this project we investigated ACF performance in those realistic conditions.

A much larger body of research exists on the air cleaning performance of granular activated carbon (GAC), documenting effective adsorption of a broad range of indoor VOCs at the low concentrations typically present buildings. Activated carbon media in granular form is generally poured into trays through which air passes. Large quantities of granular activated carbon are generally used with infrequent, e.g., yearly, replacement. These activated carbon systems are expensive, heavy, and often impose large pressure drops on the airstreams; thus, they are not commonly used in typical building applications. Our review of sorbent air cleaning for DOE (Fisk 2007) found that the VOC removal capacity and corresponding lifetime of granular activated carbon systems are very uncertain for indoor air applications where many VOCs are present simultaneously at low concentrations. Although activated carbons can remove a broad range of VOCs from indoor air, their capacity to adsorb VOCs varies among compounds. Activated carbons have a relatively low capacity for formaldehyde - an important indoor pollutant. Hence activated carbon systems may need to be supplemented by other air cleaning systems for formaldehyde. Alternately, formaldehyde source control measures may be employed.

A little noticed study (Liu 1992) found that desorption of VOCs is very rapid in activated carbon systems that use fine carbon fibers, as opposed to in the usual granular carbon media. Liu's studies showed that 90 to $95 \%$ of the toluene adsorbed on an activated carbon fiber (ACF) system could be driven off with a reversed direction flow of ambient outdoor air (at temperatures in the range $7.2-18.3^{\circ} \mathrm{C}$ and relative humidity in the range 50 to $80 \%$ ) in less than two hours. The flow rate required was only $20 \%$ of 
the supply airstream flow rate. More recent studies showed that ACF filters are very good VOC adsorbent material under dynamic conditions, showing better performance than granular activated carbon, zeolites and silica gel under identical operation conditions (Das et al, 2004). Effective regeneration of the ACF filter was achieved by direct current (DC) electrical heating (Das et al, 2004; Subrenat and LeCloirec, 2004). ACF filters are prepared from fabric precursors and have the appearance of cloth. Their specific surface area (BET) is typically higher than $1000 \mathrm{~m}^{2} / \mathrm{g}$ (Das et al, 2004).

Lorimier et al (2005) and Yao et al (2009a, 2009b) further explored the performance of ACF filters using toluene as a probe. A mathematical model was developed to predict adsorption and regeneration performance of ACF (Yao et al, 2009c). For toluene, an adsorption capacity of $120 \mathrm{mg} / \mathrm{g}$ was determined, which was not affected by changes in relative humidity (RH) (Lorimier et al, 2005)

The prior study by Liu (1992) suggests that ACF systems with periodic, e.g., nightly, regeneration using outdoor air are promising. The fan energy needed for a regeneration period using outdoor air at one fifth of the supply air flow rate for only 60 minutes per day, and with much less than the total supply airstream pressure drop, would be only a few percent of the normal supply fan energy consumption. However, that study was performed using toluene at an elevated concentration and only for ten adsorption-desorption cycles. To further assess the potential of this technology, we have evaluated performance for the range of indoor VOCs, with realistic indoor VOC concentrations, and for periods that included multiple adsorption-desorption cycles.

The prior studies of Yao et al (2009a, 2009b) suggest that short periods of DC electrical heating of the carbon to 150 or $200{ }^{\circ} \mathrm{C}$ is another promising option for periodically regenerating activated carbon systems. During the heating period, air flows through the ACF at a low flow rate and is exhausted outdoors. This air transports the desorbed VOCs outside the building. As an alternative to DC heating of the ACF media, regeneration might be accomplished by passing heated air through the ACF media. However, if ACF systems that regenerate with heat are to save energy the amount of heating energy must be small relative to the energy required to obtain the same amount 
of indoor VOC removal using the traditional ventilation process. Thus, it is necessary to limit the period of heating and the regeneration air flow rate while still providing sufficient regeneration to enable effective air cleaning during periods of building occupancy.

Figure 1-1 shows two possible configurations of hardware for $\mathrm{VOC}$ air cleaning using activated carbon fiber (ACF) cloth installed in a HVAC system, dampers, and a fan and duct system. These retrofits would allow for periodically removing VOCs from the ACF cloth and recycling for VOC air cleaning. The ACF cloth can be installed downstream of a particle filter, with air passing through the ACF cloth and supplied to the building interior. During periods of air cleaning, VOCs are removed from the air passing through the ACF cloth by adsorption on the ACF cloth. Periodically, e.g., each night, the adsorbed VOCs can be removed from the ACF cloth by passing heated or unheated outdoor air through the cloth. The VOCs desorbed during regeneration are vented outdoors. Configuration 1 requires less hardware, and configuration 2 avoids passing heated high-VOC regeneration air through the particle filter where some VOCs might adsorb and subsequently be released to indoor air. During periods of air cleaning, air passes through the blue shaded airflow paths and VOCs are adsorbed on the activated carbon fiber filter. When the activated carbon fiber filter is regenerated, fan 1 is turned off, fan 2 is turned on, the heater (when used) is turned on, damper 6 (configuration 1) or damper 5 and damper 6 (configuration 2) are opened, damper 2 and damper 4 are closed (configuration 1) or dampers 2-4 are closed (configuration 2), and VOCs are desorbed from the activated carbon fiber filter and vented to outdoors. 
Figure 1-1.Two possible retrofit configurations using activated carbon fiber air cleaning in a commercial HVAC system*.

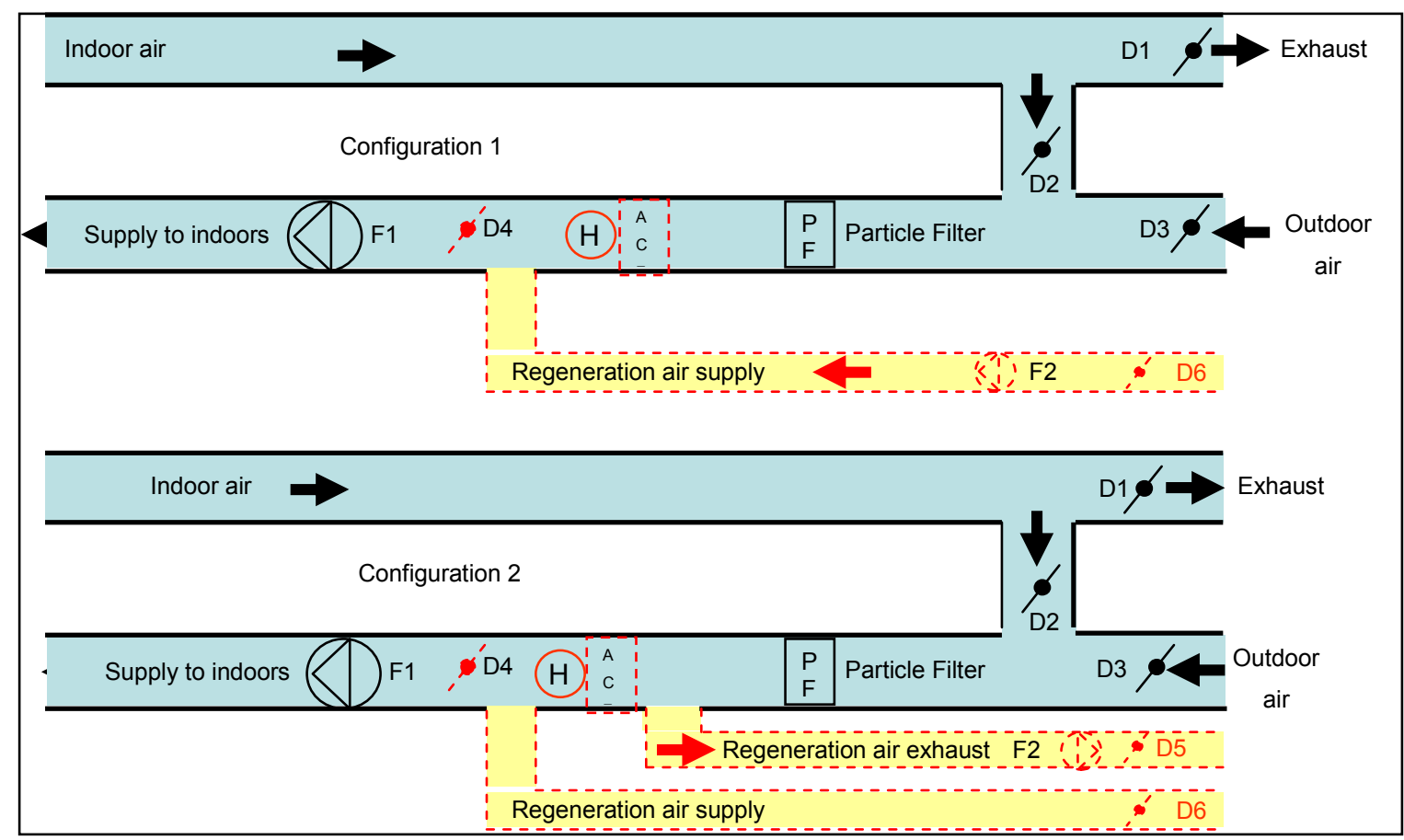

* Items in red are added when ACF air cleaning is used. D1 - D6: dampers (D1 - D3 existing HVAC systems); F1: normal supply air fan; F2: added regeneration air fan; PF: normal particle filter; ACF: added activated carbon fiber filter; H: heater

\subsection{Methods}

\subsubsection{Experimental setup}

Experiments were conducted with a 1.4-g single-layer specimen of activated carbon fiber (ACF) cloth of $80 \mathrm{~mm}$ diameter and $0.4 \mathrm{~mm}$ thickness (Calgon Corp., Type FM10) with an exposed area to air flow of $9.5 \mathrm{~cm}^{2}$. The properties of the ACF reported by the manufacturer are listed in Table 1-1. The adsorption and desorption capacities of the ACF were tested using a mixture of volatile organics (VOC) that are commonly present in indoor air. The physical properties and concentrations of the selected compounds are listed in Table 1-2. A homogeneous liquid mixture of the desired VOCs was prepared and injected at a constant rate using a syringe pump into a 19- $\mathrm{m}^{3}$ stainless steel chamber. The liquid droplets emerging from the syringe evaporated and the gaseous VOCs were dispersed into the chamber at a constant rate using a blower. 
The temperature and $\mathrm{RH}$ in the chamber were monitored using an APT logging system (Automated Performance Testing, TEC, Minneapolis) and these parameters were maintained at $\sim 29^{\circ} \mathrm{C}$ and $30 \% \mathrm{RH}$. Outdoor air was delivered to the chamber through a GAC filter at an air exchange rate of $1 \mathrm{~h}^{-1}$. Chamber air was well mixed using fans, and also recirculated using an external loop fitted with a blower to maintain uniform recycle rates. The system is shown in Figure 1-2.

Figure 1-2. Flow setup showing adsorption and regeneration periods

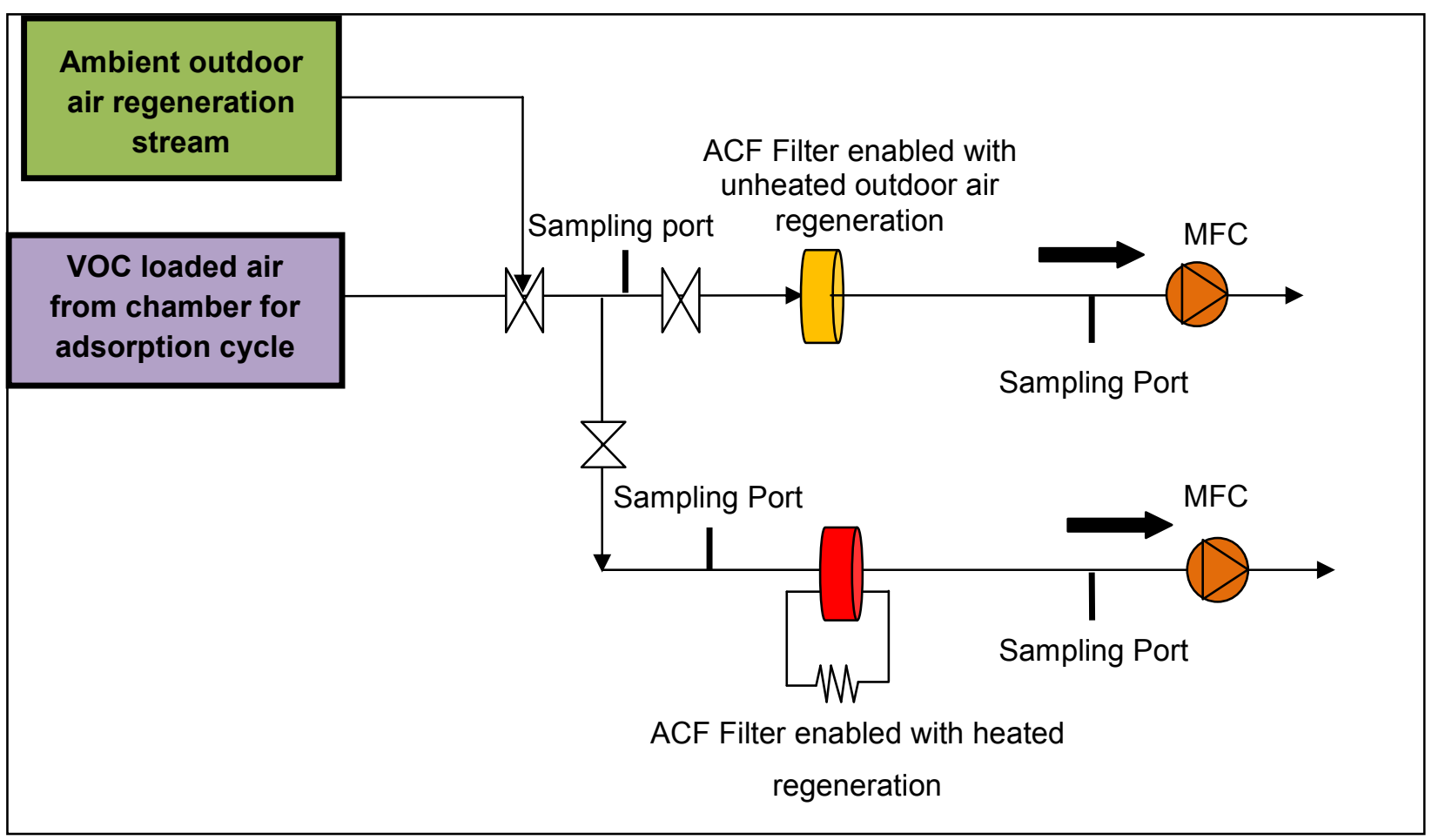

Table 1-1 Properties of ACF

\begin{tabular}{|c|c|c|c|c|}
\hline Type & Specification & $\begin{array}{c}\text { Surface Density } \\
\left(\mathbf{g} / \mathbf{m}^{2} \mathbf{)}\right.\end{array}$ & $\begin{array}{c}\text { Thickness } \\
\mathbf{( m m})\end{array}$ & $\begin{array}{c}\text { Surface Area } \\
\left(\mathbf{m}^{2} / \mathbf{g}\right)\end{array}$ \\
\hline Zeroflex FM 10 & $1 / 1$ plain weave & 120 & 0.4 & $1000-2000$ \\
\hline
\end{tabular}


Table 1-2. Physical properties and concentration of the selected VOCs

\begin{tabular}{|c|c|c|c|c|}
\hline Compound & Molecular Weight & $\begin{array}{c}\text { Boiling Point } \\
\text { (K) }\end{array}$ & $\begin{array}{c}\text { Vapor Pressure } \\
\text { (mm Hg) }\end{array}$ & $\begin{array}{c}\text { Upstream } \\
\text { concentration } \\
\text { (ppb) }\end{array}$ \\
\hline Benzene & 78 & 353 & 100 & $12-15$ \\
\hline 1-Butanol & 74 & 391 & 8.8 & $14-20$ \\
\hline Toluene & 92 & 384 & 28.4 & $40-50$ \\
\hline o-Xylene & 106 & 418 & 6.7 & $5-10$ \\
\hline Undecane & 156 & 469 & 0.41 & $35-40$ \\
\hline Limonene & 136 & 449 & 20 & $2-10$ \\
\hline Formaldehyde & 30 & 252 & (gas at room T) & $15-30$ \\
\hline
\end{tabular}

\subsubsection{Adsorption (air cleaning) Period}

The ACF filter was subjected to a 24-h or a 12-h VOC adsorption period followed by a shorter desorption period (regeneration period). The adsorption period corresponds to a period of air cleaning in an occupied building and the regeneration period to the period when VOCs are removed from the ACF media and vented outside, making the $A C F$ ready for $\mathrm{VOC}$ air cleaning on the subsequent cycle. The air flows through the ACF were controlled using mass flow controllers (MCR-50SLPM-D/5M, DS, Alicat Scientific) and were maintained to provide a $31.4 \pm 0.1 \mathrm{~m} / \mathrm{min}$ face velocity during the adsorption period. This face velocity is typical of the velocity expected in a real-world application of ACF media as a pleated filter in the supply airstream of a heating, ventilation, and air conditioning system.

In order to avoid VOC contamination during experiments, the mass flow controllers were placed downstream of the ACF filters, and vacuum was applied to pull VOC-laden air from the chamber through the ACF filters (Figure 1-2). Initial adsorption tests were performed on ACF fibers to obtain the maximum capacity of the media to adsorb VOCs. The cloth was subject to continuous adsorption period lasting $\sim 100$ 
hours and the resulting data allowed a calculation of the adsorption capacity and determination of parameters for a modified multi-component Freundlich isotherm for the different VOCs on the surface of ACF. Subsequent to saturation studies, alternative adsorption and desorption studies were conducted to evaluate the performance efficiency of the ACF media.

An adsorption and regeneration cycle can be defined as one adsorption phase of the ACF and one regeneration phase following the adsorption phase. Hence Cycle $\mathrm{i}$ represents the $\mathrm{i}^{\text {th }}$ adsorption phase and subsequent $\mathrm{i}^{\text {th }}$ regeneration phase that follows the adsorption phase. Durations of 24 hours and 12 hours were used for the adsorption period and different types of ambient air and heated media regeneration techniques were studied. To measure the VOC removal efficiency of the ACF, simultaneous samples were collected upstream and downstream of the ACF filter. Samples for VOCs (except formaldehyde) were collected periodically on Tenax-Carbosieve sorbent tubes using a peristaltic pump for a period of 1 hour at the rate of $\sim 30 \mathrm{~mL} / \mathrm{min}$. The samples were analyzed using a gas chromatography (HP 6890 series GC) system equipped with a Gerstel TDSA2 sampler and a mass selective detector (HP 5973). Aldehyde sampling was also conducted periodically on DNPH cartridges (Waters Sep-Pak, \# WAT047205) using a peristaltic pump operating at $\sim 1 \mathrm{~L} / \mathrm{min}$ for a duration of 1 hour. The samples were analyzed using a HPLC-UV (Agilent 1200) equipped with a photodiode array detector. DNPH cartridges were extracted with 2-mL aliquots acetonitrile, and the extracts were analyzed by HPLC with UV detection ( $\lambda_{\max }=360$ $\mathrm{nm})$. A calibration curve for quantification was carried out using authentic standards of the DNPH hydrazone of formaldehyde.

After the initial saturation tests, the ACF was subject to sequential adsorption and desorption cycles while monitoring VOCs and aldehydes upstream and downstream of the ACF media.

\subsubsection{Regeneration periods}

Two different types of ACF regeneration were evaluated: 


\subsubsection{Unheated outdoor air regeneration}

Unheated outdoor air was passed through the ACF filter after the completion of an adsorption period. Two different air face velocities $(6.28 \mathrm{~m} / \mathrm{min}, 0.31 \mathrm{~m} / \mathrm{min})$ were utilized. Periodic Tenax and aldehyde samples were collected and analyzed by methods described above in Section 1.2.2 (Adsorption period).

\subsubsection{Electro-thermal regeneration}

The electro-thermal regenerative unit was created by clamping the activated carbon cloth between two Teflon flanges. The mating surfaces of the flanges were covered with electrical grade copper sheets in such a way that a voltage could be maintained across the carbon cloth. A Powerstat variable autotransformer, (Type 3PN116C, Superior Electric Co.) was used to apply the desired potential difference across the copper sheets. Temperature on the surface of the ACF media was monitored and recorded using a thermometer data logger (Extech Easy View 15). The voltage was measured with a multimeter (Keithley 177 Microvolt DMM) and the current across the cloth was measured with an amp meter. The ACF was heated to $\sim 150{ }^{\circ} \mathrm{C}$ for all of the electro-thermal regeneration tests. Three different face velocities $(5.24 \mathrm{~m} / \mathrm{min}, 0.52$ $\mathrm{m} / \mathrm{min}$ and $0.11 \mathrm{~m} / \mathrm{min}$ ) were explored to identify the optimum conditions to achieve high regeneration efficiency with minimal energy consumption.

\subsubsection{Determination of removal and regeneration efficiencies}

The VOC percent removal efficiency of a given cycle, $n_{a, i}$ was calculated as indicated in equation 1-1. The regeneration efficiency of a given cycle $n_{r, i}$ was calculated as the ratio of the mass of $\mathrm{VOC}$ desorbed during a regeneration run to the net mass of VOC accumulated on the ACF from all of the previous adsorption periods using equations $1-2 \mathrm{a}$ and $1-2 \mathrm{~b}$. The average mass accumulated $M_{a, i}$ or removed $M_{r, i}$ during a single adsorption / regeneration cycle was calculated using equations 1-3a and 1-3b.

$\eta_{a, i}=\left[\frac{C_{0, i}-C_{a, i}(t)}{C_{0, i}}\right] \times 100$ 
$\eta_{r, i}=\frac{M_{r, i}}{M_{a, i}}$

$M_{a, i}=\sum_{k=1}^{i} M_{a, k}-\sum_{k=1}^{i-1} M_{r, k}$

$M_{a, i}=\frac{\int_{0}^{t}\left(C_{0, i}-C_{a, i}(t)\right) d t}{\int_{0}^{t} d t}$

$M_{r, i}=\frac{\int_{0}^{t}\left(C_{r, i}(t)\right) d t}{\int_{0}^{t} d t}$

where, $\eta_{a, i}$ is the percent removal efficiency, $\eta_{r, i}$ is the regeneration efficiency, $M_{r, i}$ is the mass of VOC desorbed during the $\mathrm{i}^{\text {th }}$ regeneration period, $M_{a, i}$ is the mass of the VOC adsorbed in the ACF filter during the $\mathrm{i}^{\text {th }}$ adsorption period, $C_{0, i}$ is the inlet concentration of the $\mathrm{i}^{\text {th }}$ adsorption period of the VOC under study, $C_{a, i}$ is the outlet concentration obtained downstream of the filter during the $\mathrm{i}^{\text {th }}$ adsorption period.

\subsection{Results}

\subsubsection{Continuous adsorption period to evaluate VOC holding capacity of ACF}

The ACF was first subject to continuous adsorption to estimate the net capacity of the ACF for VOC uptake. For this purpose, the ACF was subject to continuous flow of VOC-laden air (face velocity $=31.4 \mathrm{~m} / \mathrm{min}$ ) until ACF saturation was achieved (i.e., VOC removal rates fell to near zero). VOC samples were collected periodically at the end of 24 hours. The saturation time was estimated to be $\sim 97 \mathrm{~h}$. When challenged with the mixture of VOCs, the maximum adsorption capacity of the ACF cloth for the compounds under study was determined experimentally by integrating the area under adsorption 
concentration profile for each of the compound. The values were estimated to be 3.1 $\mathrm{mg} / \mathrm{g}, 4.8 \mathrm{mg} / \mathrm{g}, 24.2 \mathrm{mg} / \mathrm{g}, 7.8 \mathrm{mg} / \mathrm{g}, 48.2 \mathrm{mg} / \mathrm{g}, 2.6 \mathrm{mg} / \mathrm{g}$ for benzene, 1-butanol, toluene, o-xylene, undecane and formaldehyde respectively (total VOC mass accumulated $=90.7 \mathrm{mg}$ of $\mathrm{VOC}$ mixture $/ \mathrm{g}$ of $\mathrm{ACF}$ ).

Figure 1-3. Dimensionless adsorption profile for different VOCs on the surface of ACF

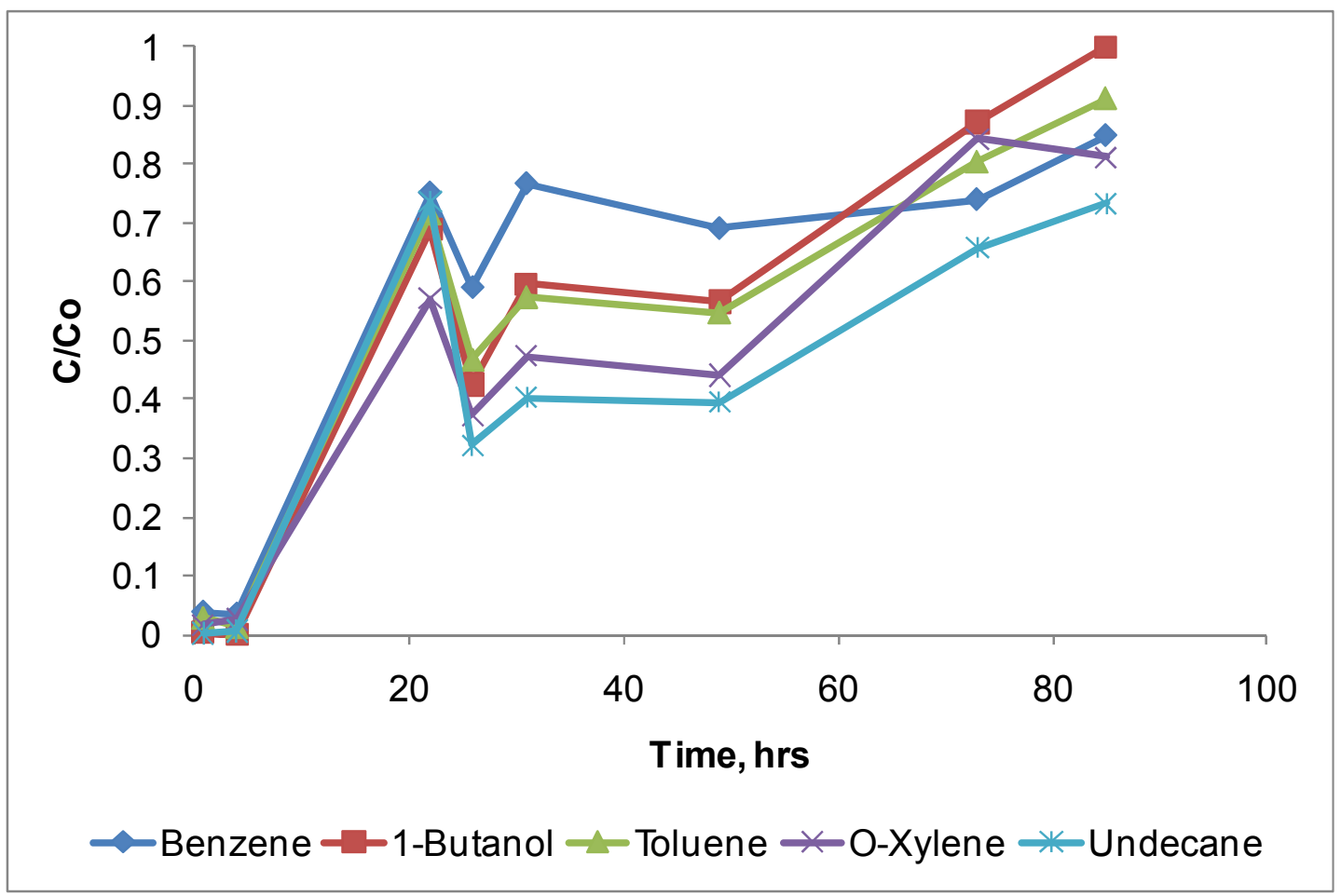

Figure 1-3 shows the dimensionless concentration profile of the different VOCs adsorbed on the surface of ACF. The results obtained from the continuous adsorption study are in agreement with the study by Yao et al., 2009 in which they show integrated adsorption of $81.6 \mathrm{mg}$ of toluene $/ \mathrm{g}$ of ACF over a saturation period of 197 hours. The lower saturation period obtained in this study may be due to the presence of other components in our mixture that had a lower vapor pressure and a higher tendency to adsorb to the ACF than toluene (e.g., undecane, o-xylene and butanol).

A Freundlich multi-component isotherm model (Sheindorf et al., 1981) was adopted to develop an isotherm for the different VOCs studied in this project. There are numerous studies (Cal., et al, 1997, Singh et al., 2002, Ramirez et al., 2005, Yao et al., 
2009c) that have modeled the single component adsorption isotherm for activated carbon; however, very little work has been done on the modeling of multi-component interaction on activated carbon fiber cloth. Yao et al., 2009 have developed isotherms for toluene adsorption and modeled the mono-component adsorption parameters. The multi-component adsorption isotherm expressed in terms of weight of sorbate as described by Sheindorf et al., 1981 is written in the form as follows:

$$
q_{i}=K_{i} C_{i}\left(\sum_{j=1}^{k} a_{i j} C_{j}\right)^{n_{i}-1},
$$

where $q_{i}$ is the weight adsorbed of the component i per unit mass of media (expressed in $\mu \mathrm{g} / \mathrm{g}), K_{i}$ is determined as the mono-component Freundlich adsorption constant for the component $\mathrm{i}, a_{i, j}$ is a dimensionless adsorption competition coefficients for multicomponent system which is equal to unity when $i=j\left(a_{i, i}=1\right), n_{i}$ is the isotherm exponent of the component $i, C_{j}$ is the concentration of the component $j$, and $k$ is the total number of components in the system. This model is valid only for compounds where the monocomponent adsorption Freundlich isotherm is applicable. The adsorption constant $K_{i}$ for the different compounds under study was either obtained from or determined by methods listed by Yao et al., 2009. The isotherm parameters estimated for benzene, 1butanol, o-xylene, toluene, undecane and formaldehyde are listed in Table 1-3.

Table 1-3. Multi-component Freundlich Isotherm parameters for VOCs

\begin{tabular}{|c|c|c|c|c|c|c|c|c|}
\hline \multicolumn{7}{|c|}{$a_{i, j}$} & \multirow[t]{2}{*}{$\begin{array}{c}K_{i} \\
(\mathrm{mg} / \mathrm{g})\end{array}$} & \multirow[t]{2}{*}{$n$} \\
\hline${ }^{\mathbf{j}}$ & Benzene & $\begin{array}{c}1- \\
\text { Butanol }\end{array}$ & Toluene & $\begin{array}{c}0- \\
\text { Xylene }\end{array}$ & Undecane & Formald & & \\
\hline Benzene & 1 & 1.2 & 0.7 & 1.3 & 1.4 & 0.3 & 7.6 & 0.192 \\
\hline 1-Butanol & 0.9 & 1 & 1.7 & 0.4 & 1.3 & 0.2 & 92.3 & 0.413 \\
\hline Toluene & 1.8 & 0.61 & 1 & 0.8 & 0.4 & 0.5 & 123 & 0.721 \\
\hline o-Xylene & 0.8 & 1.9 & 1.3 & 1 & 0.7 & 0.3 & 259 & 0.802 \\
\hline Undecane & 0.7 & 0.81 & 2.4 & 1.6 & 1 & 0.7 & 454 & 0.814 \\
\hline Formaldehyde & 2.9 & 4.7 & 2.4 & 3.2 & 1.8 & 1 & 1.8 & 0.103 \\
\hline
\end{tabular}


One of the main aims of this isotherm study is to determine the bed life, i.e., the time before the ACF bed becomes saturated and will no longer remove VOCs. Bed life $\left(T_{B}\right)$ can be defined as follows (Yao et al., 2009):

$$
T_{B}=\frac{M_{A C F}}{Q}\left(\sum_{i} \frac{q_{i}}{C_{i, i n}}\right)
$$

where, $M_{A C F}$ is the mass of activated carbon fiber $(\mathrm{g}), q_{i}$ is the weight adsorbed of component i per unit mass of media, $Q$ is the flow rate of the air stream to be treated (L/min), $C_{i, i n}$ is the inlet concentration of the component $i$ of the multi-component VOC stream. Hence, we could verify the consistency of the experimental results by estimating the bed life of a mass of $1 \mathrm{~g}$ of ACF used to remove benzene, butanol, toluene, xylene, undecane and formaldehyde at average concentrations of $4 \mu \mathrm{g} / \mathrm{m}^{3}$, with an air flow of $1.8 \mathrm{~m}^{3} / \mathrm{hr}$ through the ACF from equation $1-5$. For these conditions the estimated bed life is approximately $103 \mathrm{hrs}$, which is consistent with the values estimated from the experiments. The replacement of the ACF media every 103 hours of operation is impractical, and hence periodic in-situ regeneration is necessary for this scenario.

\subsubsection{Evaluation of VOC air cleaning with different regeneration methods}

\subsubsection{Adsorption - regeneration cycles: Method 1 - regeneration with room temperature outdoor air}

Regeneration with outdoor air at $6.28 \mathrm{~m} / \mathrm{min}, 0.31 \mathrm{~m} / \mathrm{min}$

ACF performance after a 12 hour regeneration period using two different regeneration air flow rates was evaluated to identify the optimum method to obtain efficient VOC removal from supply air after the ACF was saturated initially. Figure 1-4 shows the VOC removal percent achieved for different cycles for different VOCs with an adsorption period face velocity of $31.4 \mathrm{~m} / \mathrm{min}$. The levels of the VOCs in this study were maintained below $50 \mathrm{ppbv}$. It was found that the ACF had a removal efficiency of $40-$ $70 \%$ in the first cycle and the efficiency decreased to $20-45 \%$ in the subsequent cycles, which was maintained in 6 additional cycles. All of the adsorption-regeneration 
cycles studied with a $6.28 \mathrm{~m} / \mathrm{min}$ regeneration air stream are not shown in Figure 1-4 $((a)-(f))$ to eliminate overlap of data points for a clear demonstration. Limonene was added to the VOC mixture in cycles $6-12$ and showed an average removal efficiency of $\sim 35 \%$. Formaldehyde was not present in the adsorption period 4 and it was found that there was a very high initial adsorption of $>90 \%$ for all of the VOCs when formaldehyde was absent from the mixture. However, with increase in time to 24 hours, the removal percentage decreased to a value lower than the previous cycles for all of the organics under study.

Table 1-4 lists the regeneration efficiency obtained for various VOCs for the different adsorption - regeneration cycles. It was noted that the regeneration efficiency increased in the second cycle and reduced subsequently. This behavior can be explained as a result of initial strong adsorption properties of the volatiles on the ACF under study. This strong initial adsorption leads to multilayer adsorption of VOCs in the ACF cloth leading to a concentration buildup during the adsorption phase of the second cycle. As the concentration of the VOCs on the surface increases, the VOC amount that can be retained by the cloth decreases, leading to lower adsorption removal percent (Figure 1-4) and improved regeneration efficiency in the second cycle. Subsequent cycles show lower regeneration efficiency as can be seen from Table 1-4.

Table 1-4. Regeneration efficiency $\eta_{r, i}$ for different compounds using room temperature outdoor air for regeneration (face velocity during regeneration $=6.3 \mathrm{~m} / \mathrm{min}$ ).

\begin{tabular}{|c|c|c|c|c|c|}
\hline Compound & Cycle 1 & Cycle 2 & Cycle 3 & Cycle 4 & Cycle 5 \\
\hline Benzene & 0.05 & 0.76 & 0.13 & 0.19 & 0.12 \\
\hline Butanol & 0.03 & 0.11 & 0.12 & 0.15 & 0.30 \\
\hline Toluene & 0.01 & 0.40 & 0.30 & 0.12 & 0.28 \\
\hline O-xylene & 0.10 & 0.73 & 0.32 & 0.17 & 0.11 \\
\hline Undecane & 0.04 & 0.22 & 0.20 & 0.11 & 0.08 \\
\hline Formaldehyde & 0.05 & 0.56 & 0.04 & 0.01 & 0.54 \\
\hline
\end{tabular}


Figure 1-4. Removal percentage time profile for (a) Benzene, (b) 1-Butanol, (c) Toluene, (d) 0Xylene, (e) Formaldehyde, (f) Undecane for different adsorption - regeneration cycles with adsorption face velocity of $31.3 \mathrm{~m} / \mathrm{min}$ and regeneration face velocity of $6.3 \mathrm{~m} / \mathrm{min}$

(a)

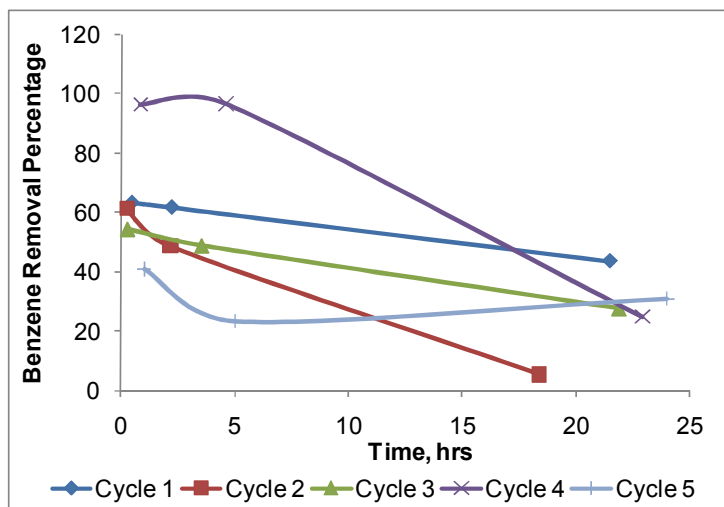

(c)

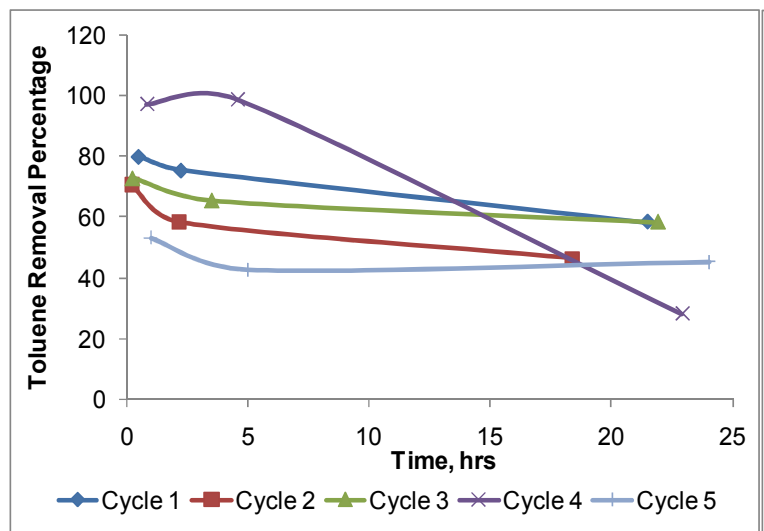

(e)

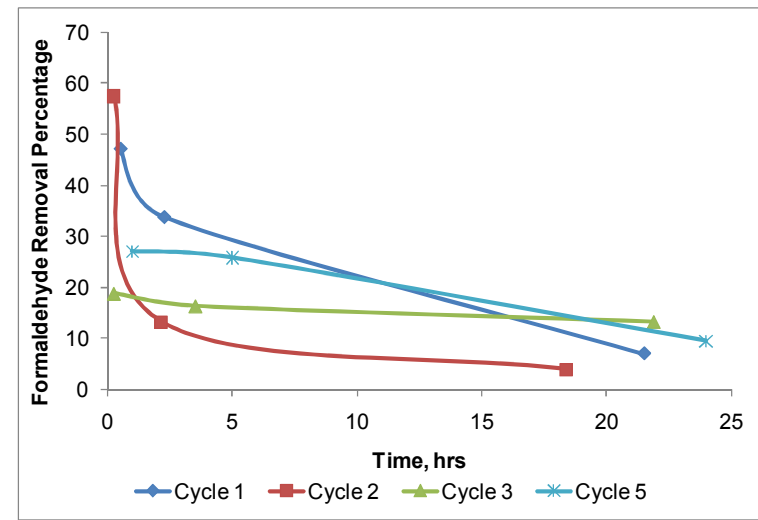

(b)

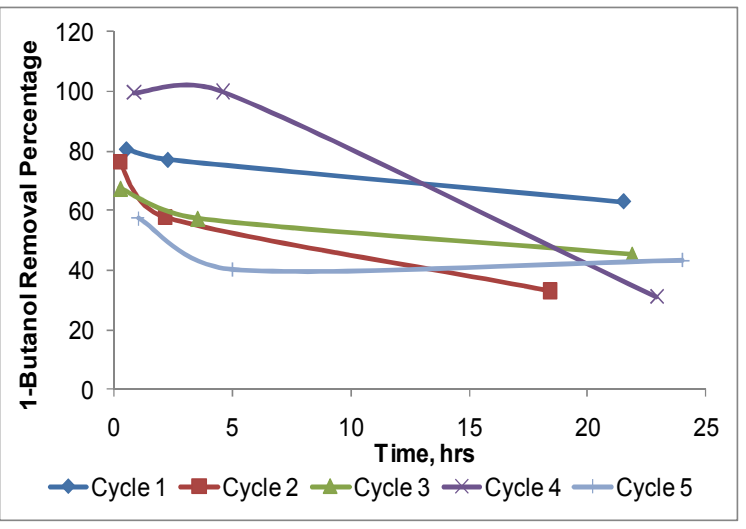

(d)

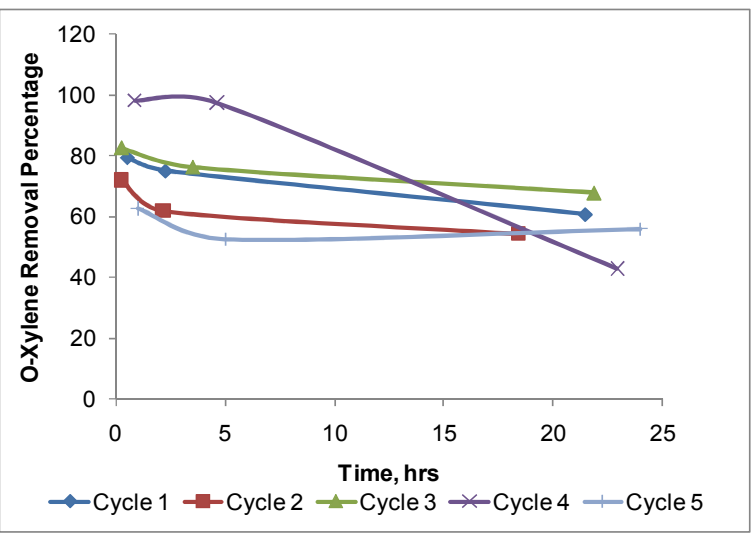

(f)

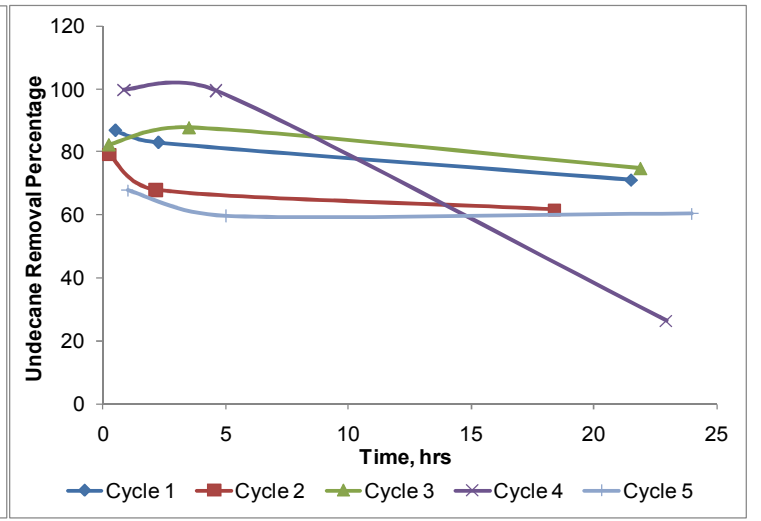


Additional experiments at the end of 10 cycles with outdoor air regeneration of $6.3 \mathrm{~m} / \mathrm{min}$ were performed after regenerating the ACF cloth for 53 hours at the same air face velocity of $6.3 \mathrm{~m} / \mathrm{min}$. The adsorption periods of 24 hours duration were followed by regeneration cycles with face velocities of $0.3 \mathrm{~m} / \mathrm{min}$ for a period of 12 hours for these experiments. The cycles will be named as Cycle' to distinguish from the cycles with a regeneration face velocity of $6.3 \mathrm{~m} / \mathrm{min}$. Cycle'1 follows the 53 hour regeneration after Cycle 12 of the $6.3 \mathrm{~m} / \mathrm{min}$ regeneration system discussed above. It was found that the adsorption of more sorptive species improved significantly when preceded by the prolonged regeneration time (Cycle'1). Subsequently, the regeneration efficiency decreased rapidly and a breakthrough (release of VOCs by the ACF media during the air cleaning cycle) was achieved at the end of the $4^{\text {th }}$ cycle showing that decreasing the regeneration rate decreases the adsorption capacity of the ACF fiber to an unacceptable level. The results obtained in these experiments are shown in Figure 1-5.

Figure 1-5. VOC Percent removal efficiency for 24 hour adsorption period with a room temperature outdoor air regeneration air stream of $0.3 \mathrm{~m} / \mathrm{min}$. Negative values indicate downstream levels higher than upstream concentrations due to ACF saturation.

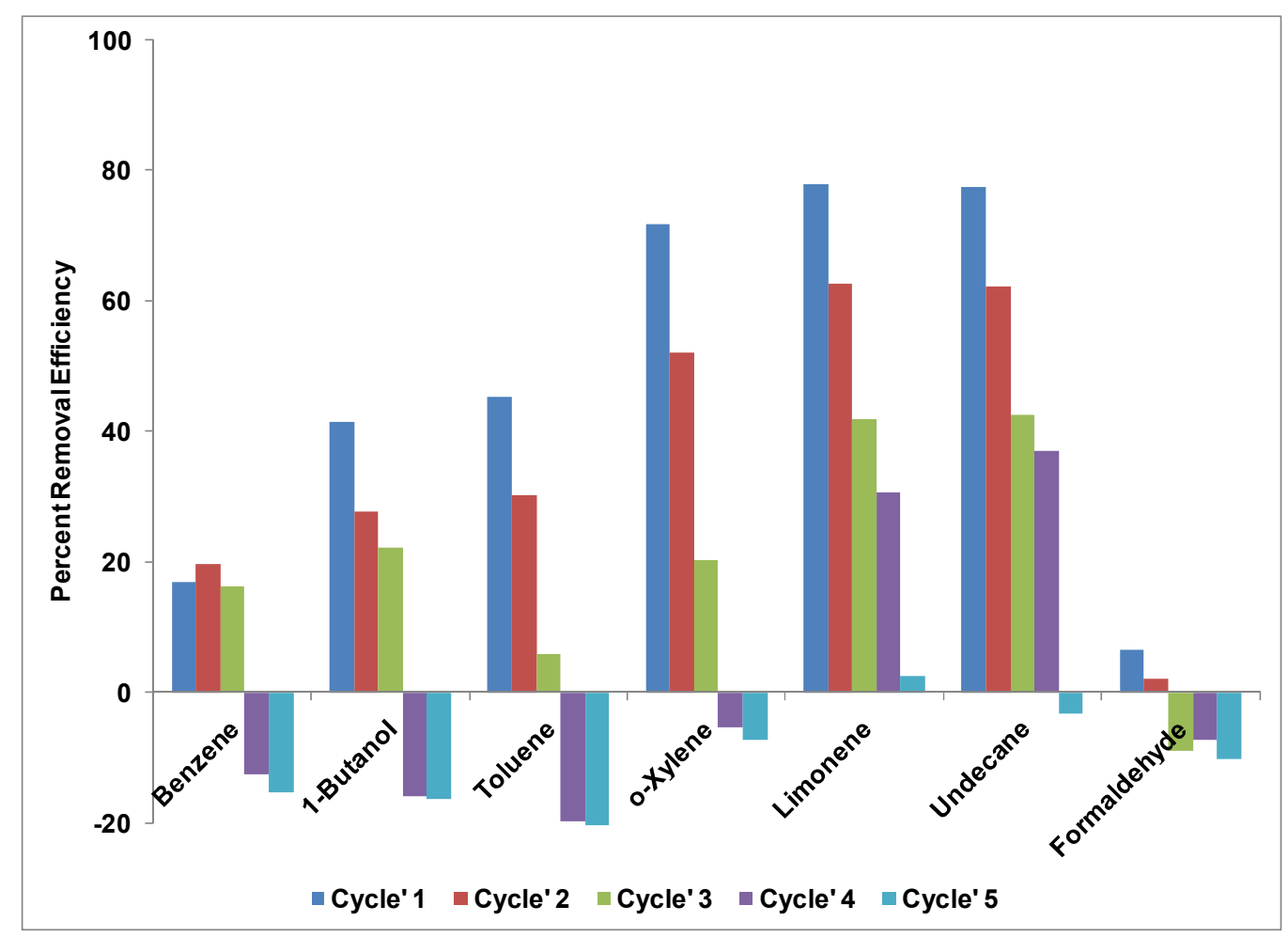




\subsubsection{Adsorption - regeneration cycles: Method 2- regeneration with heating}

Electro-thermal regeneration at $150^{\circ} \mathrm{C}$ with ACF cloth using three different regeneration face velocities:

The electro-thermal regeneration method has been explored in a number of studies to obtain optimal loading and regeneration conditions for ACF fiber systems (Yao et al., 2009, Sullivan et al., 2001, Dombrowski et al., 2004). These studies utilized a single VOC at different concentrations. Our study concentrates on optimizing electrothermal regeneration process for multi-VOC system to obtain an ACF system that is energy efficient.

The adsorption period face velocity of the polluted air stream was maintained at $31.4 \mathrm{~m} / \mathrm{min}$ for all of these experiments. The temperature of the ACF fiber during regeneration was maintained at $150{ }^{\circ} \mathrm{C}$ for 2 hours and the regeneration air flow rates were varied. Three face velocities of $5.24 \mathrm{~m} / \mathrm{min}, 0.52 \mathrm{~m} / \mathrm{min}$ and $0.11 \mathrm{~m} / \mathrm{min}$ were studied to obtain the optimum regeneration efficiency. Figure 1-6 shows the VOC percent removal efficiency plot for different adsorption regeneration cycles. The three flow regimes are marked on the plot in Figure 1-6. The regeneration face velocity of $5.24 \mathrm{~m} / \mathrm{min}$ was maintained for Cycles $1-4$. The regeneration face velocity of 0.52 $\mathrm{m} / \mathrm{min}$ was maintained for Cycles $5-7$ and the regeneration face velocity of $0.11 \mathrm{~m} / \mathrm{min}$ was maintained for Cycles $8-12$. 
Figure 1-6. VOC Percent removal efficiency for 24 hour adsorption period with different electrothermal regeneration air stream face velocities and a regeneration temperature of $150{ }^{\circ} \mathrm{C}$ for two hours.

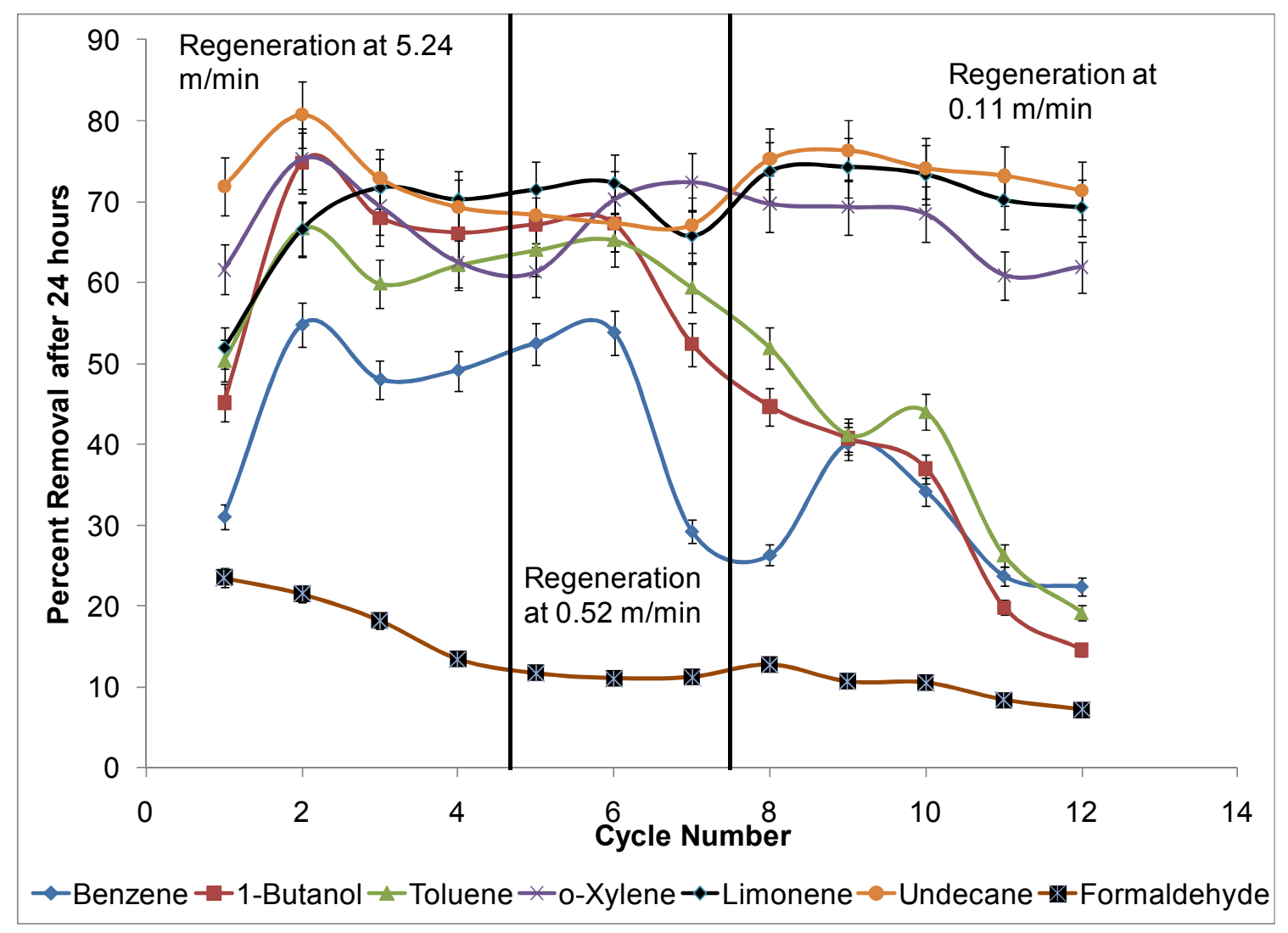

Varied VOC percent removal trends for different organics was been observed for regeneration face velocities using the electro-thermal regeneration method. The percent removal of formaldehyde decreased consistently for regenerations with low face velocities. For low molecular weight organics like benzene, 1-butanol, and toluene with weak adsorption profiles on ACF fiber (Yao et al., 2009), the percent removal efficiency decreased with decrease in regeneration flow. o-Xylene, limonene and undecane show a consistent performance with high percent removal efficiency for each cycle being almost constant ( $62 \%$ for o-Xylene, $71 \%$ for limonene and $74 \%$ for undecane). oXylene, limonene and undecane have a high Freundlich adsorption capacity constant $\left(K_{i}\right)$ (Table 1-3) compared to benzene, toluene and 1-butanol. Those heavier and less volatile molecules adsorb strongly on the carbon fiber surface and displace the 
lighter/more volatile molecules like benzene and toluene, leading to a decrease in percent removal efficiency of these compounds as shown in Figure 1-6. Removal of formaldehyde is consistently low in all regeneration conditions.

The regeneration efficiency of the electro-thermal desorption system was studied for $5.24 \mathrm{~m} / \mathrm{min}$ and $0.52 \mathrm{~m} / \mathrm{min}$ regeneration velocities and the results are listed in Table 1-5. It was found that the regeneration efficiency depends on the flow rate of the regeneration stream, very similar to the results found in Method I discussed earlier in this study. It was inferred from the regeneration efficiencies and the trends in Figure 1-6 that the decrease in regeneration efficiency of the high molecular weight compounds such as limonene, undecane and o-xylene cause competitive adsorption, which leads to displacement of low molecular weight and less adsorptive compounds such as benzene, toluene and butanol.

Table 1-5. Regeneration efficiency $\eta_{r, i}$ of different compounds under different face velocities using electro-thermal method with a $150^{\circ} \mathrm{C}$ regeneration temperature for two hours.

\begin{tabular}{|c|c|c|c|c|c|c|c|}
\hline \multirow{2}{*}{ Compound } & \multicolumn{6}{|c|}{ Regeneration Face Velocity } \\
\cline { 2 - 8 } & \multicolumn{5}{|c|}{$\mathbf{5 . 2}$ min } & \multicolumn{3}{c|}{$\mathbf{0 . 5 2} \mathbf{~ m / m i n ~}$} \\
\hline & Cycle 1 & Cycle 2 & Cycle 3 & Cycle 4 & Cycle 5 & Cycle 6 & Cycle 7 \\
\hline Benzene & 0.41 & 0.42 & 0.43 & 0.44 & 0.45 & 0.36 & 0.31 \\
\hline Butanol & 0.61 & 0.62 & 0.64 & 0.65 & 0.66 & 0.42 & 0.36 \\
\hline Toluene & 0.64 & 0.61 & 0.58 & 0.55 & 0.52 & 0.45 & 0.37 \\
\hline o-xylene & 0.85 & 0.83 & 0.81 & 0.79 & 0.68 & 0.58 & 0.59 \\
\hline Undecane & 0.86 & 0.84 & 0.82 & 0.84 & 0.68 & 0.57 & 0.55 \\
\hline limonene & 0.88 & 0.84 & 0.84 & 0.84 & 0.71 & 0.70 & 0.72 \\
\hline formaldehyde & 0.87 & 0.83 & 0.80 & 0.76 & 0.73 & 0.70 & 0.68 \\
\hline
\end{tabular}




\subsubsection{Adsorption - regeneration cycles: Methods 1 and 2 with shorter adsorption (air cleaning) cycles}

Shorter Adsorption and Regeneration Cycles

One main aim of this project was to identify an optimum cycle to implement ACF filter system to remove VOCs in HVAC units as energy retrofit in office buildings. For this purpose, we studied shorter adsorption and regeneration cycles. The duration of the adsorption period was reduced to 12 hours from 24 hours. In a building with only workday occupancy, periods of HVAC operation are often approximately 12 hours. Both outdoor ambient air regeneration and electro-thermal regeneration were studied for with 12 hours adsorption periods. The outdoor air regeneration was carried out at air face velocities of $4.2 \mathrm{~m} / \mathrm{min}$ for duration of 6 hours and the electro-thermal regeneration by heating the ACF cloth at $150{ }^{\circ} \mathrm{C}$ was carried out at air face velocities of $1.1 \mathrm{~m} / \mathrm{min}$ for duration of 15 minutes.

Regeneration with outdoor air at a face velocity of $4.2 \mathrm{~m} / \mathrm{min}$

Figure 1-7 shows the VOC percent removal efficiency for 12-h adsorption periods with outdoor air regeneration. It was found that the filter showed consistent removal efficiency for all of the VOCs studied. The formaldehyde removal was however found to be low $(\sim 16 \%)$ but still close to the $20 \%$ target needed to compensate for a $50 \%$ reduction in outdoor air. (In many situations, less than a $20 \%$ efficiency is necessary.) The VOC removal efficiency at the end of 12 hour cycles were much higher than the VOC removal efficiency observed for 24 hour cycles. 
Figure 1-7. VOC percent removal efficiency for 12 hour adsorption cycle with ambient air regeneration at $25{ }^{\circ} \mathrm{C}$ and air face velocity of $4.2 \mathrm{~m} / \mathrm{min}$ for 6 hours

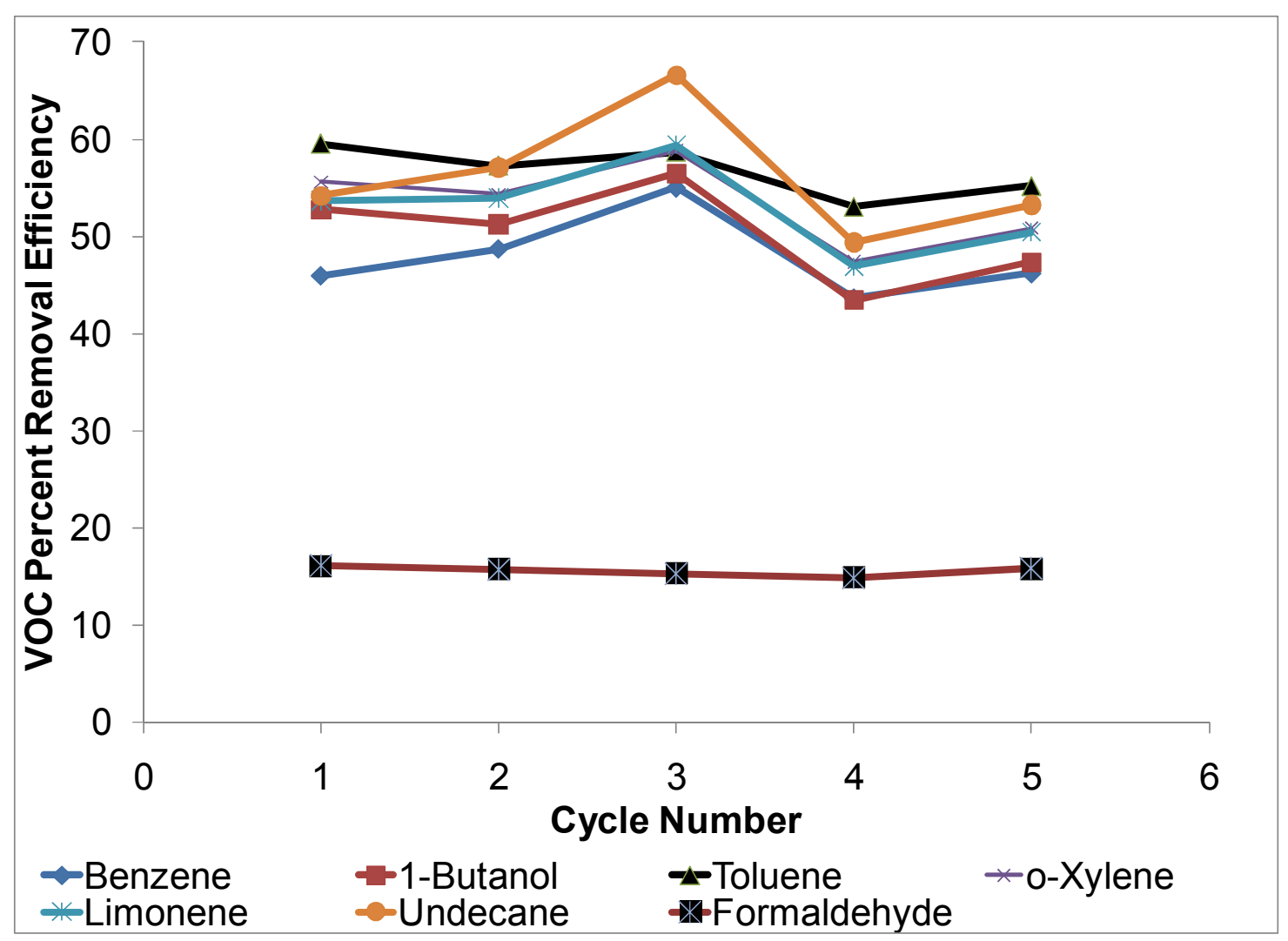

Electro-thermal regeneration

Figure 1-8 shows VOC percent removal efficiency obtained at the end of 12 hours with electro-thermal regeneration. The VOC removal efficiency was found to be higher than observed at the end of 24 hours with a comparable regeneration flow rate. Further, the removal efficiency was also consistent for all of the VOCs studied unlike what was observed earlier (Figure 1-6). The formaldehyde removal efficiency was low as observed in the previous case (Figure 1-6), but still approximately equally to the target of $20 \%$. Further the duration time of regeneration was also comparatively small. 
Figure 1-8. VOC percent removal efficiency for 12 hour adsorption period with electro-thermal regeneration at $150{ }^{\circ} \mathrm{C}$ and air face velocity of $1.1 \mathrm{~m} / \mathrm{min}$ during 15 minutes

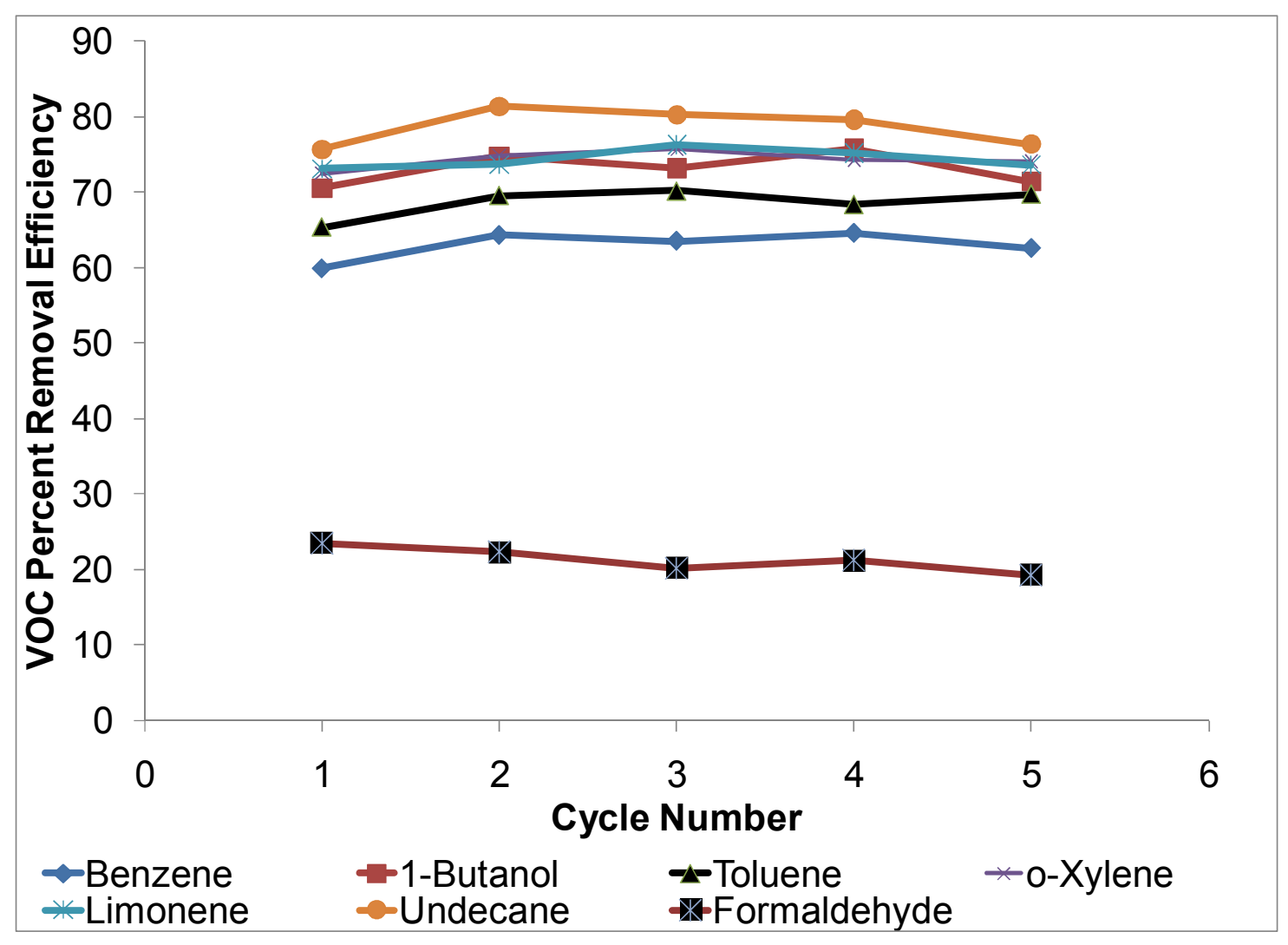

\subsubsection{Evaluation of the effect of relative humidity on regeneration}

Two additional experiments were conducted to explore the possibility of using humidified air as to enhance regeneration efficiency and improve percent removal efficiency. Results obtained were not encouraging and water was also observed to be a competing adsorbent. Hence this method of regeneration was not explored further. A comparison between regeneration under ambient and high humidity conditions is presented in Figure 1-9. 
Figure 1-9. Comparison of Adsorption period VOC removal efficiency at the end of Cycle 3 for wet regeneration and ambient air regeneration at $6.3 \mathrm{~m} / \mathrm{min}$ and 12 hours.

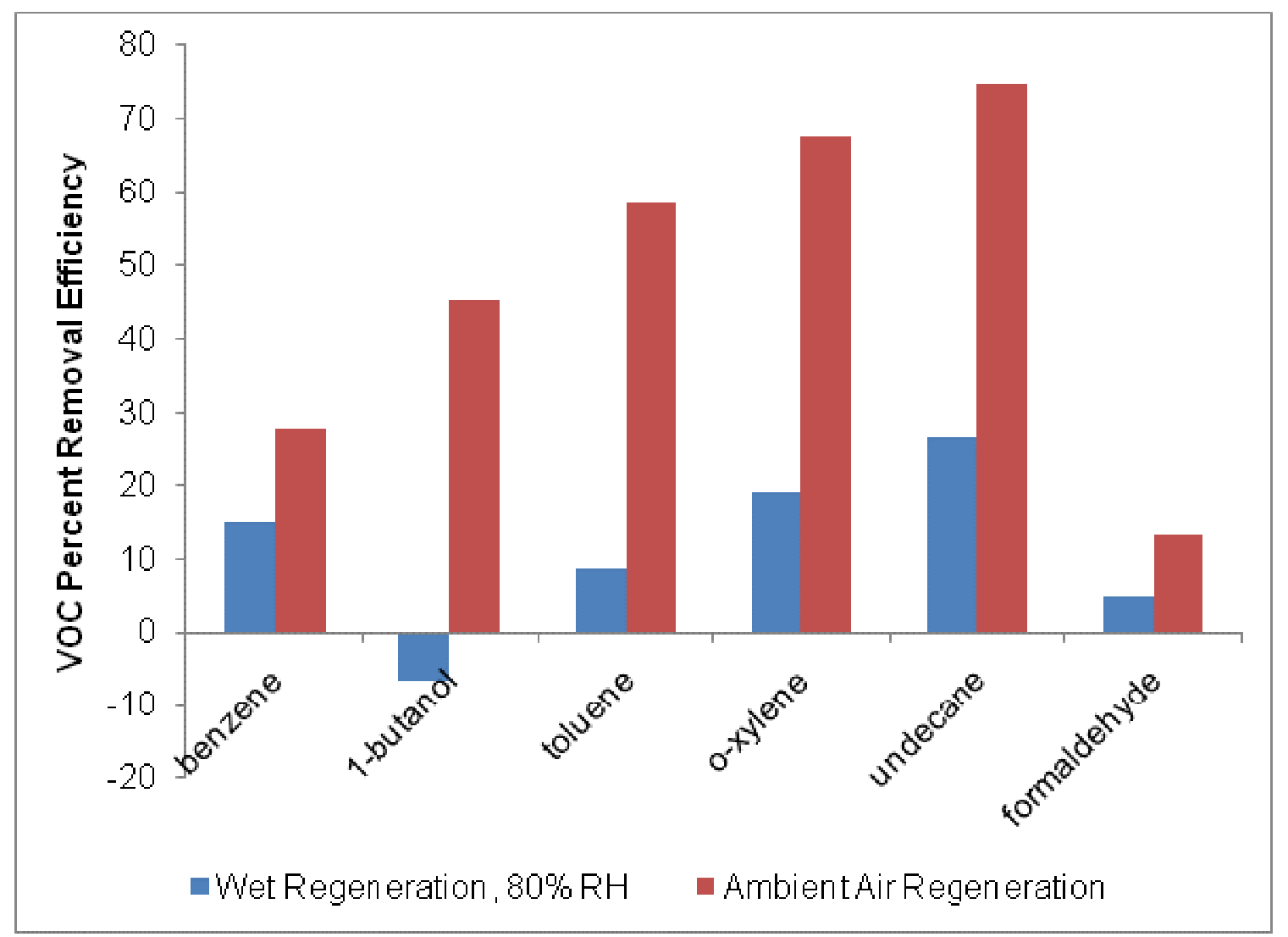

\subsubsection{Prediction of impacts on indoor VOCs: Mass balance model}

A simple mass balance model has been developed to analyze the effect of using ACF media to remove VOCs from indoor air. Scenarios with two different initial ventilation rates were studied to evaluate the performance of ACF when ventilation rates are subsequently reduced.

\subsubsection{Scenario 1: Moderate initial ventilation rates}

Base Case: Air handling system with no ACF filter bed air cleaning unit and an outdoor air ventilation rate of $0.8 \mathrm{~h}^{-1}$ and a volume-normalized VOC source emission rate of $6.4 \mathrm{ppb} / \mathrm{h}$ for each VOC 
- Case 1.1: Air handling system with ACF filter bed air cleaning unit with heated outdoor air regeneration and outdoor air ventilation exchange rate of $0.4 \mathrm{~h}^{-1}(50 \%$ reduction in ventilation).

- Case 1.2: ACF filter bed air cleaning unit with unheated outdoor air regeneration and outdoor air ventilation rate of $0.4 \mathrm{~h}^{-1}$ (50\% reduction in ventilation).

\subsubsection{Scenario 2: High initial ventilation rates}

Base Case: Air handling system with no ACF filter bed air cleaning unit and an outdoor air ventilation rate of $1.2 \mathrm{~h}^{-1}$, and a volume-normalized VOC source emission rate of $6.4 \mathrm{ppb} / \mathrm{h}$ for each VOC.

- Case 2.1: Air handling system with ACF filter bed air cleaning unit with heated outdoor air regeneration and outdoor air ventilation rate of $0.6 \mathrm{~h}^{-1}(50 \%$ reduction in ventilation).

- Case 2.2: ACF filter bed air cleaning unit with unheated outdoor air regeneration and outdoor air ventilation rate of $0.6 \mathrm{~h}^{-1}$ (50\% in ventilation)

Figure 1-10 shows the flow diagram for the steady state mass balance model. A VOC air cleaning ratio $\left(R_{i}\right)$ for a given VOC $\mathrm{i}$, was defined as the ratio of the indoor VOC concentration with an air handling unit with the ACF filter bed installed in the system to the indoor VOC concentration with an air handling unit without the ACF filter bed. $R_{i}$ is given in equation 1-6. A lower air cleaning effectiveness ratio denotes a better performing ACF unit. $R_{i} \leq 1$, signifies that the air cleaning technology maintains a lower indoor VOC concentration than the base case system with twice the ventilation rate. The air cleaning effectiveness ratio can also be calculated from the air exchange rates and VOC removal efficiency of the ACF system as shown in equation 1-7.

$$
\begin{aligned}
& R_{i}=\frac{\left[C_{i}\right]_{A C F}}{\left[C_{i}\right]_{n o-A C F}} \\
& R_{i}=\frac{\left[S_{r, i}+N_{v, A C F}\left(1-\eta_{i}\right)\right] N_{v}}{\left(N_{v}+\eta_{i}\left(N_{r}-N_{v, A C F}\right)\left(S_{r, i}+N_{v} X_{0, i}\right)\right.}
\end{aligned}
$$


where $\left[C_{i}\right]_{\text {no-ACF }}$ is the indoor concentration of the VOC species $i$ with an air handling unit without ACF filter bed, $\left[C_{i}\right]_{A C F}$ is the indoor concentration of the VOC species $i$ with an air handling unit with an ACF filter bed, $S_{r, i}$ is the emission rate source concentration per unit volume of $\mathrm{VOC} \mathrm{i}, N_{r}$ is the air exchange rate, $N_{V}$ is the number of air changes with the outdoor air in the scenario without ACF filter bed, $N_{V-A C F}$ is the number of air changes with the outdoor air in the scenario with ACF filter bed, $X_{0, i}$ is the concentration of $\mathrm{VOC}$ entering from outdoors through ventilation (assumed to be $2 \mathrm{ppb}$ for all our model calculations), and $\eta_{i}$ is the removal efficiency of the ACF filter system for a given species i.

Table 1-6 shows the percent removal efficiency of different VOCs tested in our experiments and the corresponding $R_{i}$ values for different ventilation scenarios and corresponding cases. It was observed that in both the scenarios of low and high ventilation rates, the system equipped with $\mathrm{ACF}$ filter bed and $50 \%$ reduced ventilation performed better than the system without ACF filter bed. This was true even in the case of formaldehyde where the removal percent was significantly lower than the other organic compounds studied in this project. It was also observed that cases in which ACF was regenerated by heating have lower $R_{i}$ values compared to the corresponding cases in which ACF was regenerated with unheated outdoor air. This shows that the heated regeneration method improves ACF VOC-removal performance compared to the unheated outdoor air regeneration method.

Figure 1-10. Mass balance model flow system

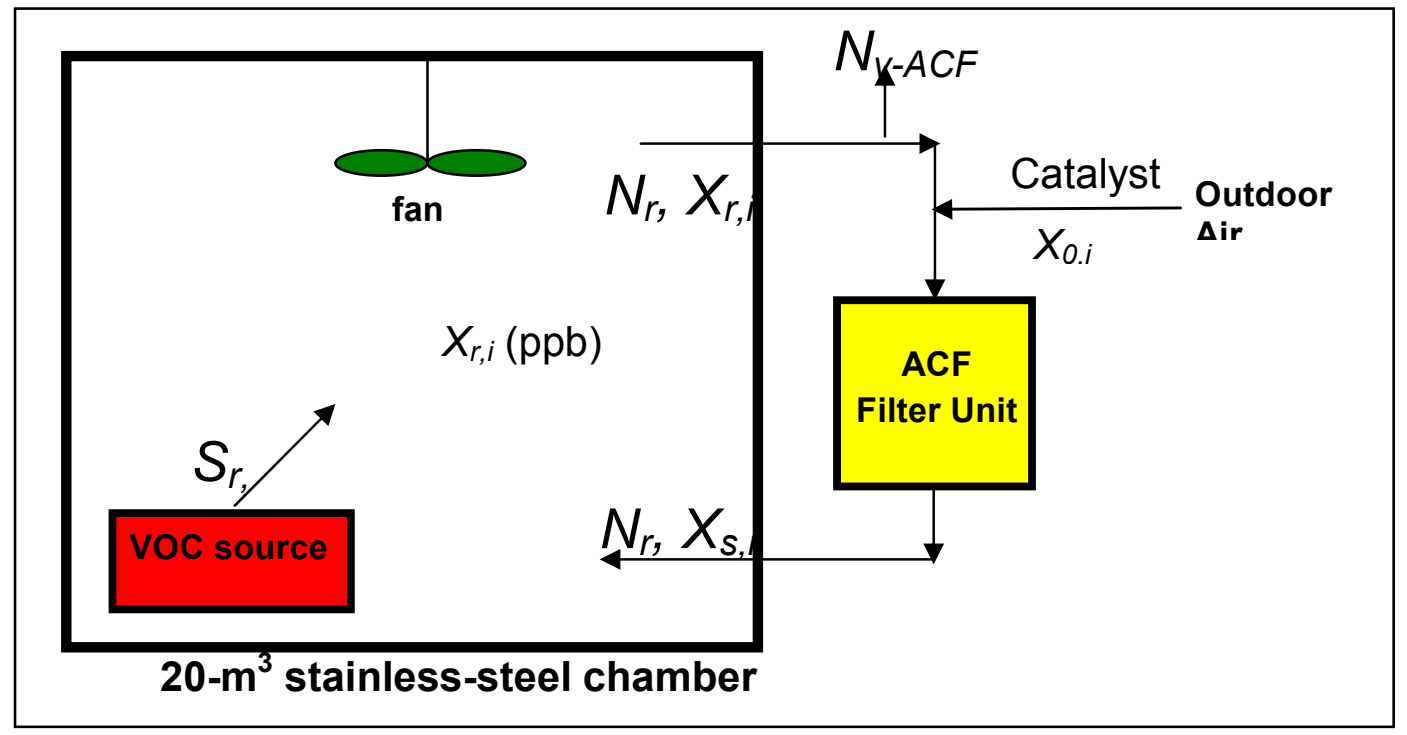


Table 1-6. Percent removal efficiency and air cleaning effectiveness ratio for ACF filter fiber system with different regeneration techniques.

\begin{tabular}{|c|c|c|c|c|c|c|c|}
\hline Scenario & Case & Compounds & $\begin{array}{c}\text { Percent } \\
\text { Removal } \\
\text { Efficiency* }\end{array}$ & $\begin{array}{c}N v \\
\left(h^{-1}\right)\end{array}$ & $\begin{array}{c}\text { Nv,ACF, } \\
\left(h^{-1}\right)\end{array}$ & $\begin{array}{c}\mathrm{Sr} \\
(\mathrm{ppb} / \mathrm{h})\end{array}$ & $\mathbf{R i}$ \\
\hline \multirow{14}{*}{$\begin{array}{l}\text { Low ventilation } \\
\text { rate }\end{array}$} & \multirow{7}{*}{1.1} & Benzene & 60 & \multirow{14}{*}{0.8} & \multirow{14}{*}{0.4} & \multirow{14}{*}{6.4} & 0.26 \\
\hline & & 1-Butanol & 71 & & & & 0.23 \\
\hline & & Toluene & 65 & & & & 0.24 \\
\hline & & o-Xylene & 73 & & & & 0.22 \\
\hline & & Limonene & 73 & & & & 0.22 \\
\hline & & Undecane & 76 & & & & 0.21 \\
\hline & & Formaldehyde & 24 & & & & 0.56 \\
\hline & \multirow{7}{*}{1.2} & Benzene & 46 & & & & 0.33 \\
\hline & & 1-Butanol & 53 & & & & 0.29 \\
\hline & & Toluene & 60 & & & & 0.26 \\
\hline & & o-Xylene & 56 & & & & 0.28 \\
\hline & & Limonene & 54 & & & & 0.29 \\
\hline & & Undecane & 54 & & & & 0.29 \\
\hline & & Formaldehyde & 16 & & & & 0.72 \\
\hline \multirow{14}{*}{$\begin{array}{l}\text { High ventilation } \\
\text { rate }\end{array}$} & \multirow{7}{*}{2.1} & Benzene & 60 & \multirow{14}{*}{1.2} & \multirow{14}{*}{0.6} & \multirow{14}{*}{6.4} & 0.36 \\
\hline & & 1-Butanol & 71 & & & & 0.31 \\
\hline & & Toluene & 65 & & & & 0.33 \\
\hline & & o-Xylene & 73 & & & & 0.30 \\
\hline & & Limonene & 73 & & & & 0.30 \\
\hline & & Undecane & 76 & & & & 0.29 \\
\hline & & Formaldehyde & 24 & & & & 0.71 \\
\hline & \multirow{7}{*}{2.2} & Benzene & 46 & & & & 0.44 \\
\hline & & 1-Butanol & 53 & & & & 0.40 \\
\hline & & Toluene & 60 & & & & 0.36 \\
\hline & & o-Xylene & 56 & & & & 0.38 \\
\hline & & Limonene & 54 & & & & 0.39 \\
\hline & & Undecane & 54 & & & & 0.39 \\
\hline & & Formaldehyde & 16 & & & & 0.88 \\
\hline
\end{tabular}

*Determined experimentally 


\subsubsection{Energy consumption costs for using ACF filter bed system:}

The main cost of operating an ACF filter bed in an HVAC system is the energy required to regenerate the ACF cloth. The energy consumption costs were computed for different regeneration face velocities and temperatures. Net energy required to regenerate the system was estimated as a sum of the energy required to heat the ACF cloth, heat the regeneration air passing through the cloth and the energy consumed by a fan to circulate air through the system. The energy consumption and cost estimates for different ratios of adsorption to regeneration face velocity and regeneration temperature are listed in Table 1-7. An U.S. average annual ventilation cost in offices was also estimated by analyzing data from Benne et al,, 2009, Grifith et al., 2009, Persily and Gorfain, 2008. It was estimated that the unheated outdoor air regeneration, indicated by the green highlighted row in Table 1-7, consumed the least energy. The most realistic condition for optimal operation with heated regeneration would be operating the ACF at $150^{\circ} \mathrm{C}$ at regeneration air velocities that are $1 / 30$ of the velocities during air cleaning adsorption periods. This condition has been highlighted in orange in Table 1-7. With this operational strategy, the annual energy cost estimate for providing a unit of VOC free air with an ACF filter systems is $15 \%$ the estimated U.S. average cost of providing the same amount of VOC removal by ventilation. Thus, with a $50 \%$ reduction in outdoor air, total building ventilation energy cost is reduced by approximately $35 \%$. With unheated outdoor air regeneration, which also yielded good VOC control performance, the total building ventilation energy cost is reduced by almost $50 \%$, as the regeneration energy is insignificant. These preliminary energy cost estimates for operating an ACF system show that incorporating the ACF filter bed in a HVAC system can effectively contribute substantially towards reducing ventilation energy consumption. 
Table 1-7 Annual regeneration energy cost estimates for the electro-thermal regeneration system and savings obtained from ventilation costs.

\begin{tabular}{|c|c|c|c|c|}
\hline $\begin{array}{l}\text { Ratio of } \\
\text { adsorption to } \\
\text { regeneration } \\
\text { face velocity }\end{array}$ & $\begin{array}{c}\text { Regeneration } \\
\text { temperature } \\
{ }^{\circ} \mathrm{C}\end{array}$ & $\begin{array}{l}\text { Net energy required } \\
\text { to produce } 1 \mathrm{~m}^{3} / \mathrm{s} \text { of } \\
\text { VOC free air per } \\
\text { regeneration period } \\
\left(\mathrm{KWH} /\left(\mathrm{m}^{3} / \mathrm{s}\right) / \mathrm{cycle}\right)\end{array}$ & $\begin{array}{c}\text { Annual regeneration } \\
\text { cost per unit rate of } \\
\text { VOC free air } \\
\left(\$ / \mathrm{m}^{3} \mathrm{~s}^{-1}\right)\end{array}$ & $\begin{array}{c}\text { Annual } \\
\text { Ventilation cost } \\
\text { per unit rate of } \\
\text { VOC free air } \\
\left(\$ / \mathrm{m}^{3} \mathrm{~s}^{-1}\right)\end{array}$ \\
\hline \multirow{2}{*}{300} & 150 & 0.35 & 9 & 389 \\
\hline & 200 & 0.48 & 13 & 389 \\
\hline \multirow{2}{*}{30} & 150 & 2.15 & 56 & 389 \\
\hline & 200 & 2.99 & 78 & 389 \\
\hline \multirow{3}{*}{6} & 20 & 0.22 & 6 & 389 \\
\hline & 150 & 10.4 & 270 & 389 \\
\hline & 200 & 14.3 & 371 & 389 \\
\hline
\end{tabular}

Assumes 260 regenerations in a year 


\subsection{Conclusions}

The ACF system has been studied for a mixture of typical indoor VOCs and results obtained so far are very promising. ACF cloth media has a long adsorption life time and can be effectively used for removing indoor VOCs with periodic regeneration. The isotherm data obtained for the ACF cloth show that it will take about $\sim 100$ hours to fully saturate the ACF media when challenged with air containing realistic concentrations of a range of indoor VOCs. The results from periodic adsorption and desorption experiments show that the ACF media can be easily regenerated after a 12 or 24 hour period of air cleaning. From the experiments conducted so far, it was inferred that regeneration of the media at $150^{\circ} \mathrm{C}$ proved to be effective in improving the VOC air cleaning efficiency relative to regeneration with unheated outdoor air. The VOC removal efficiencies were increased when the adsorption time was reduced to 12 hours from 24 hours. A mass balance model shows that an HVAC system equipped with an ACF filter bed, with either unheated or heated outdoor air regeneration, can reduce indoor VOC concentrations even when ventilation rates are reduced by $50 \%$. Calculations indicated that reducing ventilation rates by $50 \%$ and using of ACF air cleaning with heated or unheated outdoor air will result in substantial energy savings. Additional studies are needed to establish optimal regeneration conditions, system lifetime and overall costs. 


\subsection{References}

Benne, K., B. Griffith and e. al (2009). "Assessment of the energy impacts of outside air in the commercial sector." NREL/TP-550-41955. Golden, CO, National Renewable Energy Laboratory.

Das, D., V. Gaur and N. Verma (2004). "Removal of volatile organic compound by activated carbon fiber." Carbon 42(14): 2949-2962.

Dombrowski, K. D., C. M. B. Lehmann, P. D. Sullivan, D. Ramirez, M. J. Rood and K. J. Hay (2004). "Organic vapor recovery and energy efficiency during electric regeneration of an activated carbon fiber cloth adsorber." Journal of Environmental Engineering-Asce 130(3): 268-275.

Cal, M.P.; Rood, M.J.; Larson, S.M. Gas Phase Adsorption of Volatile Organic Compounds and Water Vapor on Activated Carbon Cloth; Energy Fuels 1997, 11, 311-315.

Fisk, W. J. (2007). "Can sorbent-based gas phase air cleaning for VOCs substitute for ventilation in commercial buildings? ." Proceedings of the IAQ 2007 Healthy and Sustainable Buildings. ASHRAE, Atlanta.

Griffith, B., N. Long and e. al (2008). "Methodology for modeling building energy performance across the commercial sector, ." NREL/TP-550-41956. Golden, Co. National Renewable Energy Laboratory.

Liu, R. T. (1992). "An in-situ regenerative adsorber for the control of indoor VOCs activated carbon fibers." Proceedings of IAQ'92, pp. 257 - 261. ASHRAE, Atlanta.

Lorimier, C., A. Subrenat, L. Le Coq and P. Le Cloirec (2005). "Adsorption of toluene onto activated carbon fibre cloths and felts: Application to indoor air treatment." Environmental Technology 26(11): 1217-1230.

Persily, A. K. and Gorfain J (2008). Analysis of ventilation data from the U.S. Environmental Protection Agency Building Assessment Survey and Evaluation (BASE). http://www.fire.nist.gov/bfrlpubs/build04/art043.html

Ramirez, D.; Qi, S.; Rood, M.J. (2005) Equilibrium and Heat of Adsorption for Organic Vapors and Activated Carbons; Environ. Sci. Technol. 39, 5864-5871.

Sheindorf, C., M. Rebhun and M. Sheintuch (1981). "A FREUNDLICH-TYPE MULTICOMPONENT ISOTHERM." Journal of Colloid and Interface Science 79(1): 136-142. 
Singh, K.P.; Mohan, D.; Tandon, G.S.; Gupta, G.S.D. (2002) Vapor-Phase Adsorption of Hexane and Benzene on Activated Carbon Fabric Cloth: Equilibria and Rate Studies; Ind. Eng. Chem. Res., 41, 2480-2486.

Subrenat, A. and P. Le Cloirec (2004). "Adsorption onto activated carbon cloths and electrothermal regeneration: Its potential industrial applications." Journal of Environmental Engineering-Asce 130(3): 249-257.

Sullivan, P. D., M. J. Rood, K. J. Hay and S. Qi (2001). "Adsorption and electrothermal desorption of hazardous organic vapors." Journal of Environmental EngineeringAsce 127(3): 217-223.

Yao, M., Q. Zhang, D. W. Hand, D. L. Perram and R. Taylor (2009). "Investigation of the Treatability of the Primary Indoor Volatile Organic Compounds on Activated Carbon Fiber Cloths at Typical Indoor Concentrations." Journal of the Air \& Waste Management Association 59(7): 882-890.

Yao, M., Q. Zhang, D. W. Hand, D. Perrarn and R. Taylor (2009). "Adsorption and Regeneration on Activated Carbon Fiber Cloth for Volatile Organic Compounds at Indoor Concentration Levels." Journal of the Air \& Waste Management Association 59(1): 31-36.

Yao, M., Q. Zhang, D. W. Hand and R. Taylor (2009). "Modeling of Adsorption and Regeneration of Volatile Organic Compounds on Activated Carbon Fiber Cloth." Journal of Environmental Engineering-Asce 135(12): 1371-1379. 


\section{Formaldehyde removal with manganese oxide-based room-temperature catalysts}

\subsection{Introduction}

Ventilation with outdoor air is required to maintain acceptable indoor concentrations of indoor generated air pollutants. Based on analyses of data from modeling carried out at NREL (Griffith et al. 2008; Benne et al. 2009), in the U.S. commercial building stock approximately ten percent of all energy consumption is for conditioning of ventilation air provided mechanically and via air leakage. To reduce energy use in buildings, reductions in the energy required for ventilation are highly desirable. One option is to reduce ventilation rates, e.g., by $50 \%$, and compensate for the diminished rate of pollutant removal using energy efficient air cleaning systems. In commercial buildings with the VOC air cleaner installed in the supply airstream consisting of outdoor air and a larger quantity of recirculated indoor air, approximately a 15 to $20 \%$ VOC removal efficiency would be required to prevent VOC concentrations from increasing if the outdoor air supply rate is reduced by $50 \%$. In most commercial buildings, there are insignificant indoor sources of inorganic gaseous pollutants and the primary indoor-generated pollutants affected by ventilation are particles and volatile organic compounds (VOCs). Particle filters already used in buildings remove indoorgenerated particles using far less energy than ventilation. To complement particle filtration, effective and energy efficient air cleaning methods are needed for VOCs. In the previous chapter, we described our evaluation of a promising $\mathrm{VOC}$ air cleaning technology based on activated carbon fiber (ACF) systems. While VOC removal performance of ACF was very acceptable for most compounds studied, the removal efficiency of formaldehyde is expected to be marginal relative to requirements, when initial high ventilation rates are reduced by $50 \%$. Due to serious concerns about health effects associated with indoor formaldehyde (described below), ventilation rate reductions may be possible only if the ACF system is complemented by formaldehyde 
air cleaning. Additionally, there are many buildings in which existing ventilation rates exceed the requirements specified in standards but indoor formaldehyde concentrations are above guidelines. Reducing ventilation rates in these buildings could pose liabilities given that formaldehyde has been declared a human carcinogen. In these buildings, formaldehyde-specific air cleaning could enable reduced ventilation and energy savings. For that reason, we explored here a different technology aimed specifically at formaldehyde removal from indoor air. This technology uses a manganese oxide catalyst for removal of formaldehyde at room temperature.

Formaldehyde $\left(\mathrm{CH}_{2} \mathrm{O}\right)$ is a ubiquitous indoor pollutant emitted by wood-based building products and furnishings, among other sources (Hodgson et al. 2002). It can also be formed by the oxidation of volatile organic compounds (VOCs) with ozone and $\mathrm{OH}$ radicals (Destaillats et al. 2006; Singer et al. 2006). Residential exposure to $\mathrm{CH}_{2} \mathrm{O}$ is associated with increased risks of asthma and allergy (Mendell 2007). Additional concern about chronic exposures to indoor formaldehyde arises from its listing by the US EPA as a probable human carcinogen (group B1, US EPA) and its classification by the World Health Organization as a known human carcinogen (Cogliano et al. 2005). Mean indoor $\mathrm{CH}_{2} \mathrm{O}$ concentrations of $11 \mathrm{ppbv}$ and $17 \mathrm{ppbv}$ were determined in surveys of US commercial buildings ( $n=100)$ (Girman et al. 1995; USEPA 2003) and of US homes $(n=190)$ (Hodgson and Levin 2003), respectively. Those concentrations are higher than the 8-h reference exposure level recently proposed by the California Environmental Protection Agency (7 ppbv), and are close to the 8-h recommended level for occupational exposure in the US (16 ppbv) (NIOSH, 1992). Current indoor air pollutant exposure scenarios may worsen if tighter building envelopes and lower air exchange rates adopted with energy efficiency purposes are not compensated by additional pollution abatement measures.

Manganese dioxide $\left(\mathrm{MnO}_{2}\right)$ is a relatively abundant and inexpensive material, and $\mathrm{Mn}$ is considered a non-toxic metal. The potential use of $\mathrm{MnO}_{2}$-based materials as a room temperature catalyst for elimination of indoor formaldehyde was recently 
demonstrated in bench scale studies (Sekine 2002; Xu et al. 2008), and deserves further attention. In particular, Xu et al. (2008) used the results of bench scale experiments to predict formaldehyde removal efficiency for coated honeycomb substrates with various dimensions. Manganese oxide based nano-particles have been used for the purification of water (Prasad and Chaudhuri 1995). The redox properties of manganese oxide minerals make them useful catalysts in industrial processes. Naturally occurring manganese oxide mineral has a basic $\mathrm{MnO}_{6}$ octahedron structure that assembles into a large variety of structural arrangement yielding a mineral with high surface area. Another favorable property of the manganese oxide crystals is the multiple valance state exhibited by $\mathrm{Mn}$ in a single mineral which facilitates oxidation reactions (Post 1999). Modeling results of $\mathrm{Xu}$ et al (2008) indicate that $20 \%$ formaldehyde removal efficiency could be obtained using a coated honeycomb media with very low pressure drop (about 2 to $3 \mathrm{~Pa}$ ) with face velocities typical of air filter systems. Higher formaldehyde removal efficiencies were predicted for systems with higher but still very acceptable pressure drops. Assuming typical ratios of outdoor air flow to total supply air flow in commercial HVAC systems, $15 \%$ to $20 \%$ formaldehyde removal efficiency in the supply airstream is adequate to counteract the expected indoor level increases associated with a $50 \%$ reduction in minimum outdoor air supply. Given that total supply airstream pressure drops are often $500-1000 \mathrm{~Pa}$, the predictions of $\mathrm{Xu}$ et al 2008 suggest that the pressure drops and associated fan energy requirements of manganese oxide-coated honeycomb media air cleaning may be negligible.

In addition to active air cleaning applications, there is some additional evidence of $\mathrm{Mn}$-based catalyst efficacy in passive applications. In a residential setting, deployed manganese oxide within wallboard was reported to reduce $50 \%$ to $80 \%$ of indoor formaldehyde throughout a 7-month long study period (Sekine and Nishimura 2001).

A great deal of attention has been placed recently on the synthesis of novel $\mathrm{MnO}_{2}$-based catalysts for the removal of formaldehyde and other volatile organic compounds (VOCs) at room or low temperatures $\left(<100{ }^{\circ} \mathrm{C}\right.$ ). Doping of $\mathrm{MnO}_{2}$ with other transition metals and synthesis of mixed oxides showed improved formaldehyde 
removal efficiencies. For example, $\mathrm{MnO}_{x}-\mathrm{CeO}_{2}$ catalysts had improved performances than $\mathrm{MnO}_{2}$ synthesized by the same method (Tang et al. 2006; Tang et al. 2008). Also, other authors showed good performance of manganese oxides doped with other transition metals, such as vanadium (Tang et al. 2010) and tin (Wen et al. 2009). Several manganese oxide nano and meso structures (e.g., pyrolusite, cryptomelane) have been shown to have very high catalytic activity in the complete oxidation of formaldehyde (yielding $\mathrm{CO}_{2}$ and $\mathrm{H}_{2} \mathrm{O}$ ) at low temperatures, explained by its porosity, degree of crystallinity, reducibility and average oxidation state of the manganese atoms (Chen et al. 2009). Further, nano-structured mixed valence oxides (such as $\mathrm{Mn}_{3} \mathrm{O}_{4}$ ) were shown to effectively catalyze the oxidation of formaldehyde at room temperature (Ahmed et al. 2010). A simple synthetic approach to produce nano-structured mixed valence oxides by reduction of $\mathrm{KMnO}_{4}$ to yield products of general formula $\mathrm{K}_{\mathrm{x}} \mathrm{MnO}_{2}$ has also been described (Chen et al. 2007). In most of the cases mentioned here, low temperature oxidation of formaldehyde likely takes places via a similar Mars-van Krevelen (MvK) mechanism, as is usually described for high temperature catalysis, in which lattice oxygen atoms from the catalyst participate in the initial step of the reaction, and are subsequently replenished by atmospheric $\mathrm{O}_{2}$ (Doornkamp and Ponec 2000; Cellier et al. 2006):

$$
\begin{aligned}
& \mathrm{MnO}_{\mathrm{x}-1} \mathrm{O}(\mathrm{s})+\mathrm{CH}_{2} \mathrm{O} \text { (ads) } \rightarrow \mathrm{MnO}_{\mathrm{x}-1}(\mathrm{~s})+2 \mathrm{H}(\text { ads })+\mathrm{CO}_{2}(\mathrm{~g}) \\
& \mathrm{MnO}_{\mathrm{x}-1}(\mathrm{~s})+2 \mathrm{H}(\text { ads })+\mathrm{O}_{2}(\mathrm{~g}) \rightarrow \mathrm{MnO}_{\mathrm{x}-1}-\mathrm{O}(\mathrm{s})+\mathrm{H}_{2} \mathrm{O}(\mathrm{g})
\end{aligned}
$$

In this mechanism, catalyst efficiency is associated with the number of active surface sites with $\mathrm{Mn}$ atoms susceptible to be cyclically reduced and re-oxidized as shown in equations 2-1 and 2-2. Formic acid can be formed as a byproduct of incomplete oxidation, and may be found in the gas phase or adsorbed to the catalyst. 
In this study, we synthesized novel $\mathrm{MnO}_{\mathrm{x}}$ catalysts $(1<\mathrm{x}<2)$, and evaluated experimentally the efficacy of filters coated with this material with moderately low pressure drops. During FY2010, we focused primarily on the characterization of the materials and the evaluation of their performance in small-scale laboratory studies.

\subsection{Experimental Methods}

\subsubsection{Chemicals}

Sodium permanganate ( $\geq 97 \%)$ and Manganese sulfate monohydrate $(\geq 98 \%)$ were obtained from Sigma Aldrich and used without further purification. Manganese dioxide $(>98 \%)$ was also obtained from Sigma Aldrich to use as a reference in formaldehyde removal tests.

\subsubsection{Preparation of manganese oxide catalysts}

Manganese oxide samples were prepared using a chemical co-precipitation route. Manganese sulfate $\left(\mathrm{MnSO}_{4}\right)$ and sodium permanganate $\left(\mathrm{KMnO}_{4}\right)$ were dissolved in distilled water. To the manganese sulfate aqueous solution, the sodium permanganate solution was added slowly with constant stirring such that the molar ratio of the resulting solution of sodium permanganate to manganese sulfate was maintained at 2:3. This leads to precipitation of an oxide. The resulting black suspension was kept at room temperature for 24 hours. The suspension was then filtered, and the precipitate was washed with deionized water several times to remove any sodium impurities. Three different aliquots of the precipitate were heated in air for 12 hours at 100, 200 and 400 ${ }^{0} \mathrm{C}$, respectively, to prepare three different catalyst materials.

\subsubsection{Catalyst characterization techniques}

\subsubsection{BET surface area analysis}

Brunner Emmet and Teller (BET) surface area was obtained using a Porosimeter (Micromeritics 3000). Nitrogen was used as the sorption gas to study the BET isotherm and obtain surface area and pore volume. About $1 \mathrm{~g}$ of the samples was degassed for a 
period of 12 hours under a stream of nitrogen at $100{ }^{\circ} \mathrm{C}$. The samples were then analyzed for sorption of nitrogen under a liquid nitrogen bath.

\subsubsection{X-ray diffraction}

A small amount of each sample was placed in a mortar. Approximately $1 \mathrm{~mL}$ of hexane was added. The material was ground under hexane. A silicon zero background plate (ZBP) was placed on a warm hotplate, and a few drops of the hexane slurry were applied onto the ZBP. When dry, the ZBP was placed in a holder and examined using a Panalytical X'Pert diffractometer.

Raw x-ray diffraction data were merged (12, 2 hour scans), an empirical background was removed, the $\mathrm{K}$ alpha 2 contribution was stripped, and the scans were smoothed using a Fourier filter. Peaks were selected using the peak picking utility, and phases were determined using a library search by matching utility with all manganese files in the database. Crystallite size for the samples was obtained using the Scherrer equation.

\subsubsection{SEM imaging analysis}

SEM imaging was performed using a Hitachi SE4000 Scanning electron microscope. Samples were mounted on a specimen mount and sputter coated with gold nano-particles before analysis.

\subsubsection{ICP MS analysis}

Manganese oxide samples were analyzed using a Perkin Elmer DRCII Inductively Coupled Plasma - Mass Spectrometer (ICP-MS). To measure the concentrations of $\mathrm{Mg}, \mathrm{K}, \mathrm{Ca}, \mathrm{Cr}$ and $\mathrm{Fe}$, the instrument was used in DRC (Dynamic Reaction Cell) mode using ammonia as reaction gas to remove interferences. Other elements were analyzed in standard mode. Gallium was used as an internal standard. 


\subsubsection{Evaluation of formaldehyde elimination}

\subsubsection{Preparation of supported catalysts}

Formaldehyde removal was studied using a continuous flow system. The catalyst support used in this study was a heating ventilation and air conditioning (HVAC) particle filter. An American Air Filter (AAF) Roll-O-Mat polyester type HVAC filter with a thin tackifier coating was used for loading the manganese oxide catalyst (conditioned at 100 ${ }^{\circ} \mathrm{C}$ ) in this study. The prepared catalyst was ground into a fine powder and transferred into a Petri dish. A $47 \mathrm{~mm}$ cut HVAC filter piece was mounted on an open faced filter holder so that the filter loading side is visible. The filter holder was fitted to the Petri dish holding the manganese oxide. The rear of the filter holder was connected to laboratory house vacuum. Uniform vacuum was applied for a fixed amount of time across the filter surface, allowing for elutriation of manganese dioxide from the Petri dish to the filter surface. The mass of manganese oxide loaded on the filter surface was obtained by weighing the filter before and after loading. The filter was then removed from the open faced filter holder and transferred into a $47-\mathrm{mm}$ custom made alumina filter holder. The procedure was repeated for commercially obtained manganese oxide to compare the performance efficiency between the laboratory prepared and commercially available manganese oxide samples.

\subsubsection{Experimental setup}

Formaldehyde was generated inside a $1-\mathrm{m}^{3}$ chamber using stable diffusive sources. For that purpose, we introduced several $4 \times 4$ square inch specimens of cabinetry obtained in a recent study, and marked as high formaldehyde emitters (Maddalena et al. 2009). Two experiments at different face velocities were conducted to evaluate the efficiency of the catalyst at high and low flows. Air from the chamber was pulled through the filter holder containing the supported manganese oxide catalyst at the rate of $0.1 \mathrm{~L} / \mathrm{min}$ and $30 \mathrm{~L} / \mathrm{min}$ (face velocity $=0.11 \mathrm{~m} / \mathrm{min}$ and $31.4 \mathrm{~m} / \mathrm{min}$ ) (Figure 2-1). Aldehyde samples were collected simultaneously upstream and downstream of the filter holder. 


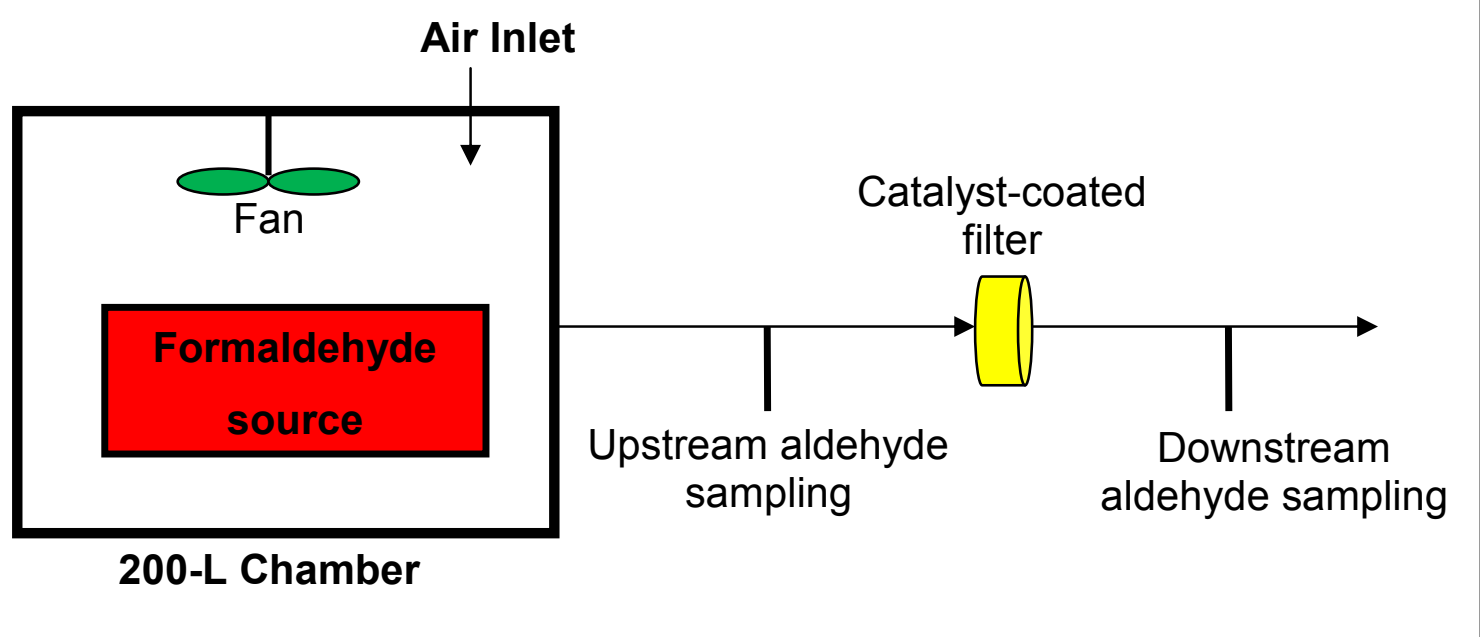

\subsubsection{Sampling and analytical methods}

Integrated volatile carbonyl samples were collected upstream and downstream of the catalyst using dinitrophenyl hydrazine (DNPH)-coated silica samplers (Waters) at the rate of $20 \mathrm{cc} / \mathrm{min}$ using peristaltic pumps. Ambient ozone was scrubbed with potassium iodide scrubbers preceding each DNPH sampler (Waters Sep-pak Ozone scrubber). The concentration value reported in each case corresponds to a timeintegrated average over the sampled period, and is reported at the center of each sampling period. The flow corresponding to each sample was measured using a primary air flow calibrator (Gilibrator $\AA$ ) with a precision greater than $2 \%$.

DNPH cartridges were extracted with 2-mL aliquots acetonitrile, and the extracts were analyzed by HPLC with UV detection $\left(\lambda_{\max }=360 \mathrm{~nm}\right)$. A calibration curve for quantification was carried out using authentic standards of the DNPH hydrazone of formaldehyde, acetaldehyde and acetone.

\subsubsection{Evaluation of the extent of mineralization}

Carbon dioxide levels produced as a final byproduct of formaldehyde mineralization were estimated using a mid-IR Picaro $\mathrm{iCO}_{2}$ analyzer, CBDS 07. Ultrahigh purity nitrogen and oxygen (99.999\% pure) (Alliance Gas) with minimal $\mathrm{CO}_{2}$ background levels $(<1 \mathrm{ppb})$ were used for this evaluation. A gas stream was connected to a formaldehyde source $(20 \mathrm{ml}$ of $37 \%$ aqueous formaldehyde solution in a $100 \mathrm{ml}$ beaker, 
placed inside a 4-L stainless steel flow cell). The net flow of gas mixture through the flow cell was maintained at $8 \mathrm{~L} / \mathrm{min}$ and the nitrogen to oxygen ratio was $\sim 7: 3$. The upstream and downstream gas samples were collected in two 5-L Mylar bags for carbon dioxide analysis. Formaldehyde present in upstream and downstream samples was stripped using DNPH-coated silica cartridges (Waters Sep-pak) to avoid spectral interference with the $\mathrm{iCO}_{2}$ analyzer. These cartridges were subsequently extracted with acetonitrile solution for aldehyde analysis. In order to analyze the possibility of partial oxidation by-products, tests were also conducted to identify the formation of formic acid. Upstream and downstream formic acid gas samples were collected in a $0.01 \mathrm{~N}$ sodium hydroxide solution using a glass impinge and the concentration estimates were obtained using Ion Chromatography (Dionex ICS 2000). Standards were prepared using 1g/L sodium formate solution (Sigma Aldrich, Formate standard for IC) to identify and quantify formic acid if any present.

\subsection{Results and Discussion}

\subsubsection{Catalyst characterization}

\subsubsection{BET surface area analysis}

BET surface area measurements obtained for the different materials tested in this study are listed in Table 2-1.

Table 2-1 BET surface area of different ceiling tile materials.

\begin{tabular}{|c|c|}
\hline Ceiling Tile & BET Surface area $\mathbf{~ m}^{2} / \mathbf{g}$ \\
\hline LBNL MnO $_{x} 100^{\circ} \mathrm{C}$ & 149 \\
\hline $\mathrm{LBNL} \mathrm{MnO}_{x} 200^{\circ} \mathrm{C}$ & 103 \\
\hline $\mathrm{LBNL} \mathrm{MnO}_{\mathrm{x}} 400^{\circ} \mathrm{C}$ & 93 \\
\hline $\mathrm{MnO}_{2}$ commercial & 0.4 \\
\hline
\end{tabular}

It should be noted that the BET surface area of commercial manganese oxide is much lower than the BET surface area of the manganese oxide prepared in the lab. 
Further, it was also observed that the BET surface area of the manganese oxide was inversely proportional to the temperature of curing.

\subsubsection{X-Ray diffraction analysis}

Results of X-Ray diffraction for the different preparations of manganese oxide are shown in Figure 2-2, Figure 2-3, and Figure 2-4. Table 2-2 shows the crystallite composition of the bulk phase of the manganese oxide samples. For the samples treated at 100 and $200{ }^{\circ} \mathrm{C}$, the X-ray diffraction spectra show combinations of high and low intense characteristics of Nsutite and Cryptomelane phases of manganese oxide. Cryptomelane was the best match for the samples treated at 100 and $200{ }^{\circ} \mathrm{C}$ but did not match all lines. Nsutite was found to best correspond the unmatched lines with the best agreement on intensities. The sample treated at $400{ }^{\circ} \mathrm{C}$ was well reproduced by the pyrolusite signatures.

X-ray diffraction spectra of manganese oxide sample obtained after reaction with formaldehyde was also obtained (Sample reacted for 42 days, formaldehyde reacted $=$ $9.2 \mu \mathrm{g} / \mathrm{m}^{2}$ of catalyst surface). It was found that although the sample maintained the same crystal structure property as that of the unreacted manganese oxide, the X-ray diffraction peaks of Nsutite and Cryptomelane were shifted showing a reduction in bulk phase of the catalyst causing an increase in the crystal spacing $(d=2.42 \mathrm{~A})$. The crystallite sizes were observed to be between $59 \mathrm{~A}$ to $110 \mathrm{~A}$.

Table 2-2 Composition of manganese oxide prepared in the laboratory

\begin{tabular}{|c|c|c|}
\hline Material ID & Compound Name & Chemical Formula \\
\hline \multirow[t]{2}{*}{ LBNL $\mathrm{MnO}_{x}, 100^{\circ} \mathrm{C}$} & Nsutite & $\begin{array}{c}\mathrm{Mn}^{4+}{ }_{1-\mathrm{x}} \mathrm{Mn}^{2+}{ }_{\mathrm{x}} \mathrm{O}_{2-2 \mathrm{x}}(\mathrm{OH})_{2 \mathrm{x}} \\
\quad \text { where } \mathrm{x}=0.06-0.07, \\
\text { corresponding to a mixture of } \\
12.20 \% \mathrm{MnO} / 84.71 \% \mathrm{MnO}_{2}\end{array}$ \\
\hline & Cryptomelane & $\mathrm{KMn}^{4+}{ }_{6} \mathrm{Mn}^{2+}{ }_{2} \mathrm{O}_{16}$ \\
\hline \multirow[t]{2}{*}{ LBNL $\mathrm{MnO}_{\mathrm{x}}, 200^{\circ} \mathrm{C}$} & Nsutite & $\begin{array}{c}\mathrm{Mn}^{4+}{ }_{1-\mathrm{x}} \mathrm{Mn}^{2+}{ }_{\mathrm{x}} \mathrm{O}_{2-2 \mathrm{x}}(\mathrm{OH})_{2 \mathrm{x}} \\
\text { where } \mathrm{x}=0.06-0.07, \\
\text { corresponding to a mixture of } \\
12.20 \% \mathrm{MnO} / 84.71 \% \mathrm{MnO}_{2}\end{array}$ \\
\hline & Cryptomelane & $\mathrm{KMn}^{4+}{ }_{6} \mathrm{Mn}^{2+}{ }_{2} \mathrm{O}_{16}$ \\
\hline \multirow[b]{2}{*}{ LBNL $\mathrm{MnO}_{x}, 400^{\circ} \mathrm{C}$} & Pyrolusite & $\mathrm{Mn} \mathrm{O}_{2}$ \\
\hline & Cryptomelane-Q & $\mathrm{KMn}^{4+}{ }_{6} \mathrm{Mn}^{2+}{ }_{2} \mathrm{O}_{16}$ \\
\hline
\end{tabular}


Figure 2-2 X-Ray Diffraction spectrum of $\mathrm{MnO}_{\mathrm{x}}$ treated at $100{ }^{\circ} \mathrm{C}$

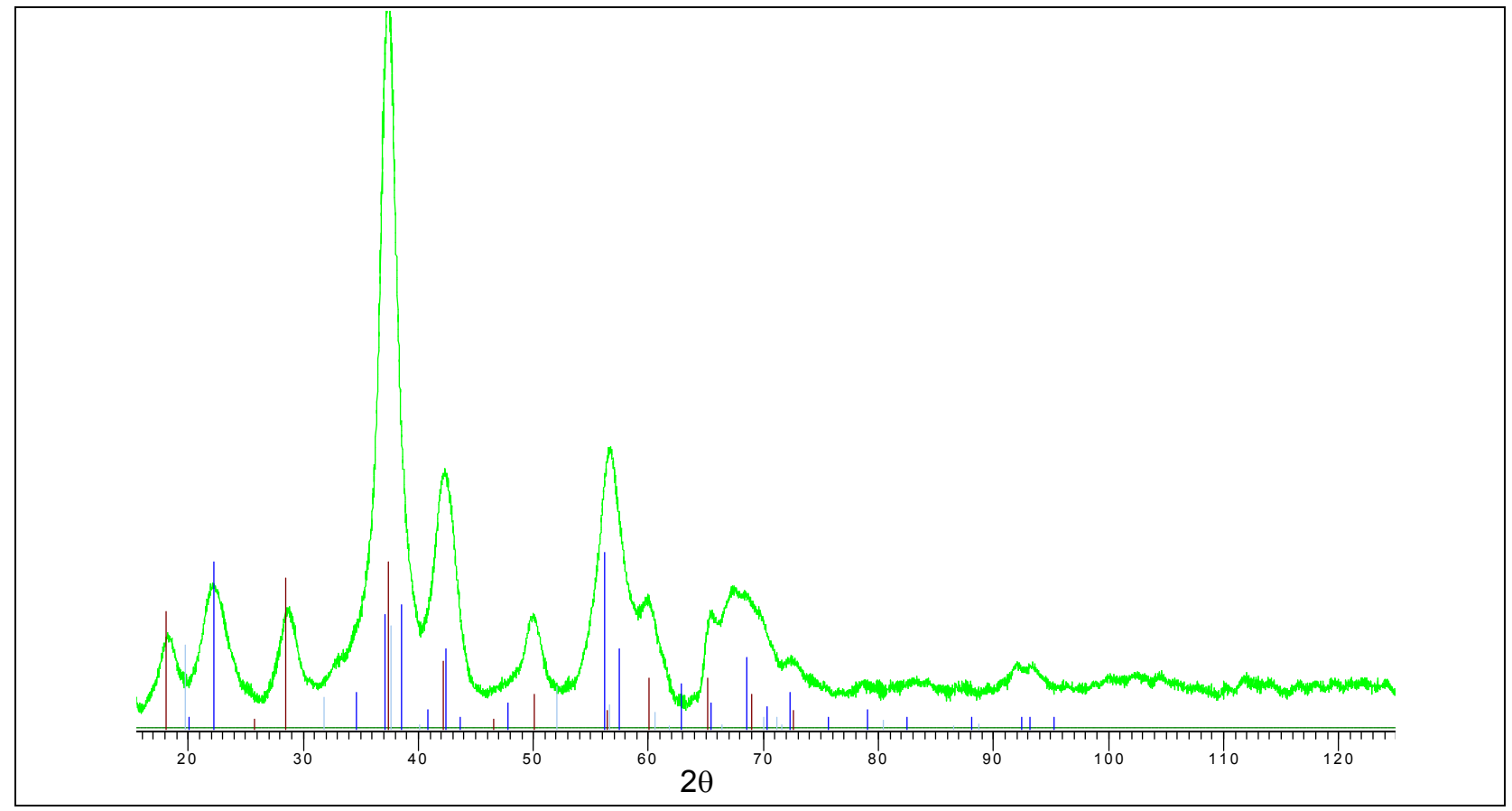

Figure 2-3 X-Ray Diffraction spectrum of $\mathrm{MnO}_{\mathrm{x}}$ treated at $200{ }^{\circ} \mathrm{C}$

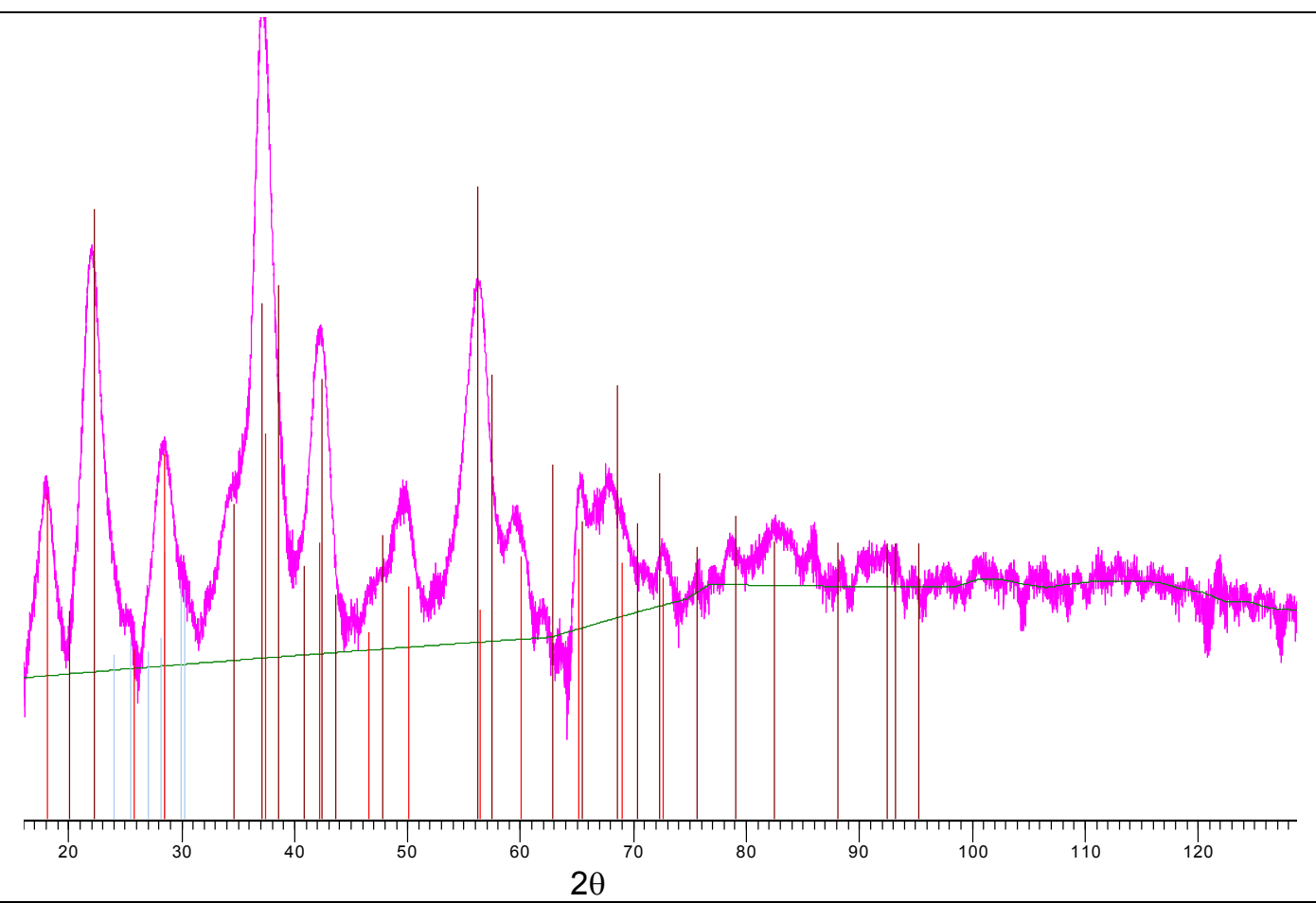




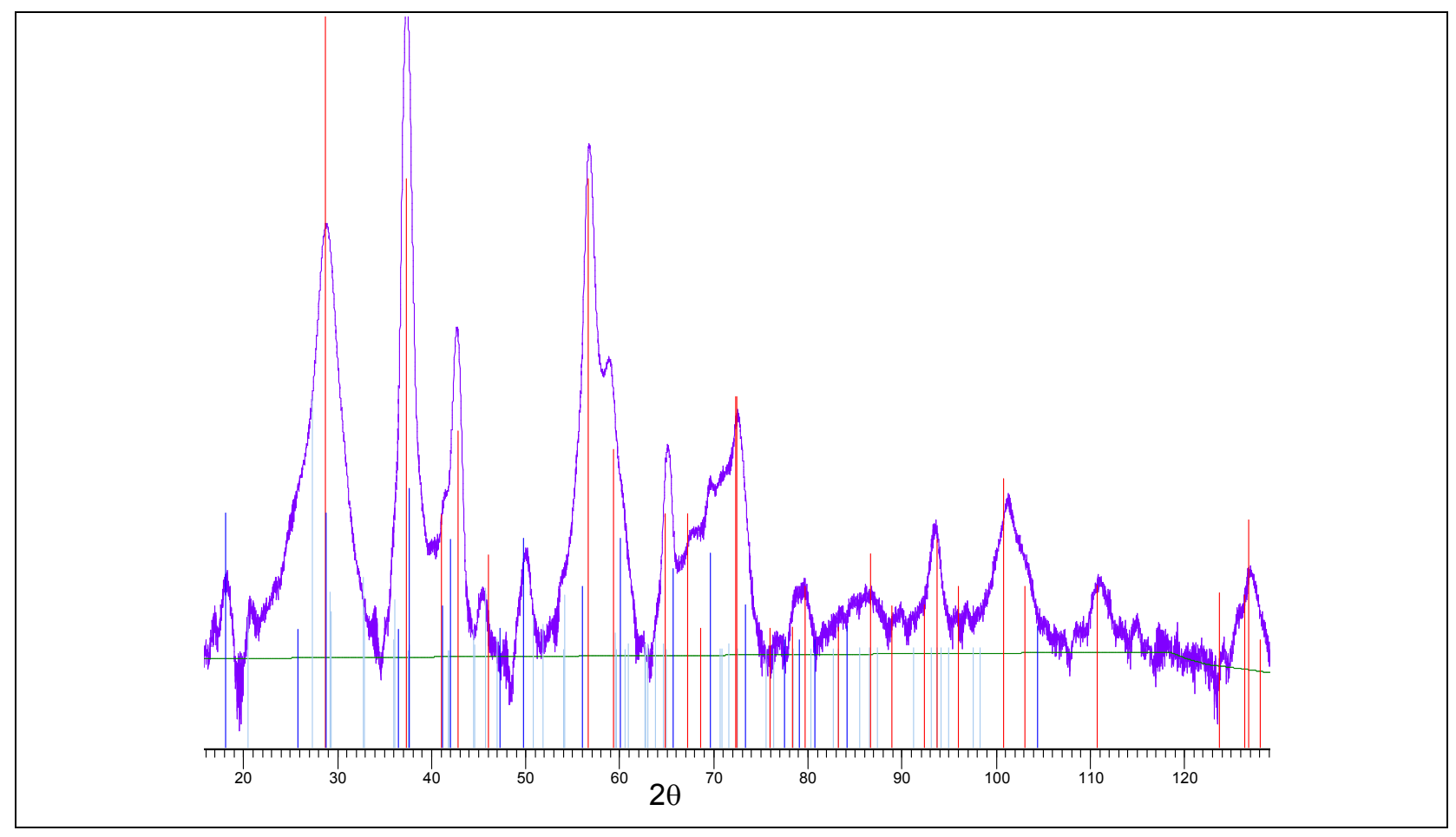

The results of the X-Ray diffraction spectrum show that phase change occurs with temperature. The X-ray spectrum of reacted manganese oxide species show no phase change and hence no significant oxidation state change, further supporting the hypothesis that manganese oxide acts as a catalyst and does not undergo any permanent change with the oxidation reaction of the surface reacting species.

\subsubsection{SEM surface analysis}

Figure 2-5 (a), (b), and (c) show the scanning electron microscopy (SEM) images of manganese oxide heat treated at 100,200 and $400{ }^{\circ} \mathrm{C}$ respectively. Figure 2-5 (d) shows the SEM image of commercially available $\mathrm{MnO}_{2}$ (Sigma Aldrich). It was found that the manganese oxide samples synthesized in the lab were highly porous and had monodisperse nanospherical particles with diameter smaller than $50 \mathrm{~nm}$. The commercially available manganese oxide was found to be crystalline and had particles 
with well defined crystal shape and size greater than $2 \mu \mathrm{m}$. It can be seen from SEM images of the laboratory synthesized manganese oxide that each nanospherical particle consisted of platelets that were aligned perpendicular to the spherical surface which is very similar to a honeycomb structure (Yuan et al., 2005, Yuan et al., 2003, Zhong et al., 2004).

Figure 2-5. SEM Images of manganese oxide particles synthesized and treated at (a) $100{ }^{\circ} \mathrm{C}$; (b) $200{ }^{\circ} \mathrm{C}$; (c) $400{ }^{\circ} \mathrm{C}$; and (d) commercially available $\mathrm{MnO}_{2}$.

(a)

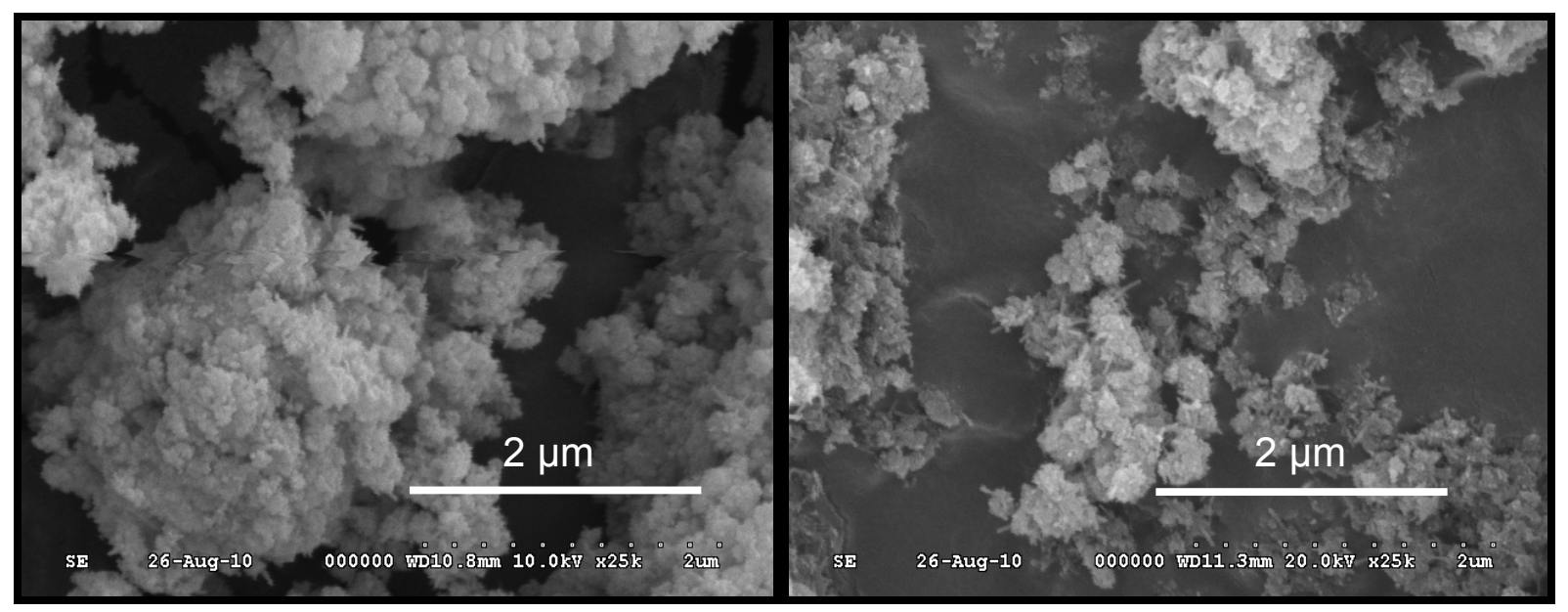

(c)

(b)

(d)

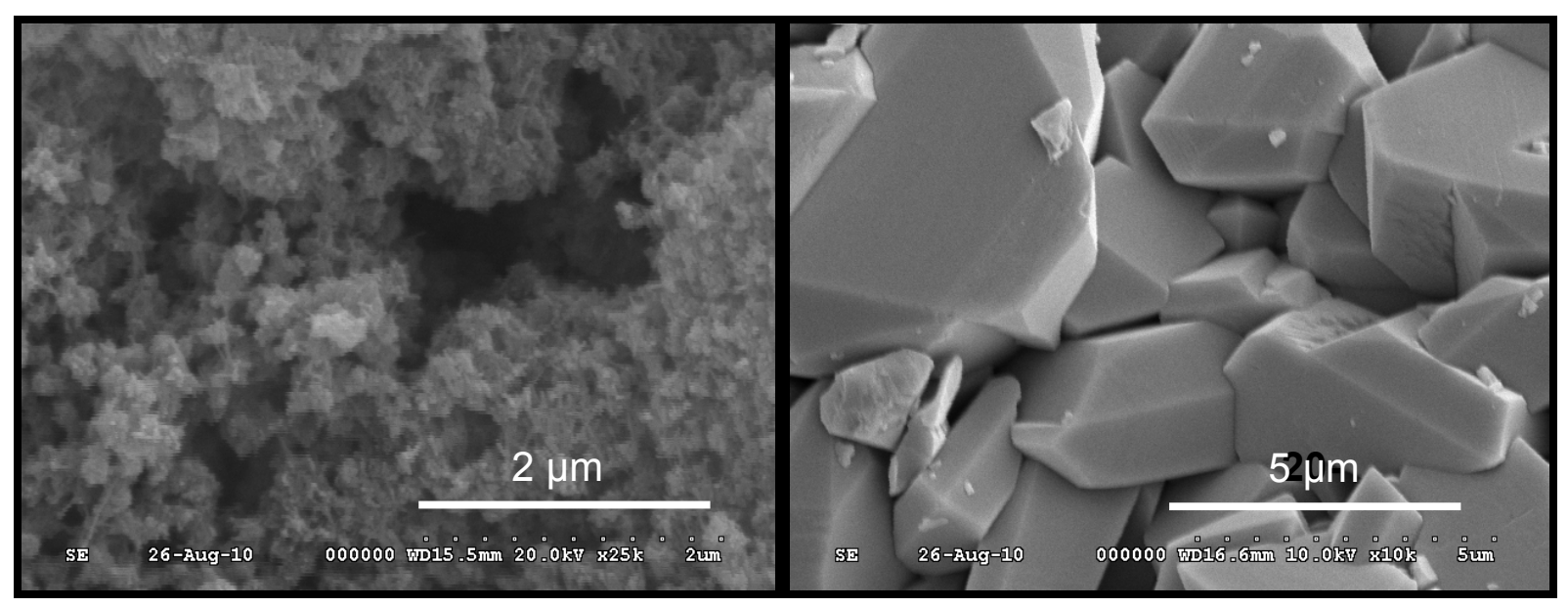




\subsubsection{Determination of empirical formulae}

The results from ICP-MS analysis are shown in Table 2-3. Analysis was performed on manganese oxide sample treated at 100, 200 and $400^{\circ} \mathrm{C}$. The results are in accordance with those from X-ray diffraction studies. We identified minor constituents such as sodium and potassium, as well as other impurities such as iron, and other metals, present in trace quantities. Using the ICP-MS data the empirical formula, mineral allotropic form and the oxidation state of manganese in the sample were also determined. The manganese oxide synthesized from the precipitation method used in this study hosts water molecules in the void spaces of the crystal structure under ambient conditions. The SEM results for these samples (Section 2.3.1.3) show the honeycomb structure of the synthesized manganese oxide suggesting the presence of voids that can house water in the interstitial spaces. Blish and Post (1989) have conducted studies on the thermal evolution of water and have observed the presence of water in the porous structures of manganese oxide. Further, they have observed that with increasing the temperature of curing of manganese oxide, the water content decreased and was reduced drastically at $500{ }^{\circ} \mathrm{C}$. Additionally at higher temperature, oxygen evolution also takes places, leading to structural effects and phase change (Blish and Post, 1989). The X-Ray diffraction results obtained in this study suggest the presence of Nsutite at 100 and $200{ }^{\circ} \mathrm{C}$. Post (1999) and Zwicker et al., (1962) suggest that the Nsutite structure of manganese oxide has large channels leading to water uptake (in the order of $\sim 10 \%$ by mass) and other cations such as sodium, calcium, iron and magnesium in such spaces. The ICP-MS results obtained in this study show the presence of such cation impurities (Table 2-3). The empirical formulae for the different laboratory synthesized manganese oxide were calculated from the ICP-MS results by assuming the presence of water in the interstitial voids. Further, the allotropic forms of manganese oxide as observed from the $X$-Ray diffraction results (Section 2.3.1.2) have been used as the basis to estimate the percentage of each phase present in these samples. The mass fraction of manganese present suggests that $\mathrm{Mn}^{2+}$ and $\mathrm{Mn}^{4+}$ are the most predominant oxidation state of the synthesized material. The dual oxidation states present in the synthesized manganese oxide treated at $100 \mathrm{C}$ and $200{ }^{\circ} \mathrm{C}$ explain the 
active form of these minerals leading to the room temperature oxidation of formaldehyde (Attenburrow et al., 1952; Harfenist et al., 1954). The pores of pyrolusite (the predominant form in samples treated at $400{ }^{\circ} \mathrm{C}$ ) are small and hence cannot accommodate higher moisture unlike that of Nsutite (predominantly present in samples treated at 100 and $200^{\circ} \mathrm{C}$ ) further supporting the observation.

Table 2-3. Analysis of manganese oxide sample treated at $100^{\circ} \mathrm{C}$ using ICP-MS

\begin{tabular}{|c|c|c|c|c|}
\hline Sample & $\begin{array}{l}\mathrm{MnO}_{x} \text { and } \mathrm{H}_{2} \mathrm{O} \\
\text { ratios }\end{array}$ & Element & $\begin{array}{l}\text { Mass fraction } \\
\text { present in the } \\
\text { sample } \\
\end{array}$ & $\begin{array}{l}\text { MnOx phase and emperical } \\
\text { formula }\end{array}$ \\
\hline \multirow{4}{*}{$\begin{array}{l}\mathrm{MnO}_{\mathrm{x}} \\
\text { treated at } \\
100 \mathrm{C}\end{array}$} & \multirow{4}{*}{$\begin{array}{l}85 \% \mathrm{MnO}_{\mathrm{x}} \text { and } \\
15 \% \mathrm{H}_{2} \mathrm{O}\end{array}$} & $\mathrm{Mn}$ & 63.04 & \multirow{4}{*}{$\begin{array}{c}94 \% \text { Nsutite } \\
\left(\mathrm{Mn}^{4+}{ }_{0.85} \mathrm{O}_{1.7} \mathrm{Mn}^{2+}{ }_{0.15}(\mathrm{OH})_{0.3}\right) \\
5.3 \% \mathrm{Crryptomelane} \\
\left(\mathrm{KMn}^{4+}{ }_{6} \mathrm{Mn}^{2+}{ }_{2} \mathrm{O}_{16}\right)\end{array}$} \\
\hline & & $\mathrm{Na}$ & 0.35 & \\
\hline & & $\mathrm{K}$ & 0.29 & \\
\hline & & $\mathrm{Fe}$ & 0.03 & \\
\hline \multirow{4}{*}{$\begin{array}{l}\mathrm{MnO}_{\mathrm{x}} \\
\text { treated at } \\
200 \mathrm{C}\end{array}$} & \multirow{4}{*}{$\begin{array}{c}84 \% \mathrm{MnO}_{\mathrm{x}} \text { and } \\
16 \% \mathrm{H}_{2} \mathrm{O}\end{array}$} & $\mathrm{Mn}$ & 63.05 & \multirow{4}{*}{$\begin{array}{c}95 \% \text { Nsutite } \\
\left(\mathrm{Mn}^{4+}{ }_{0.85} \mathrm{O}_{1.7} \mathrm{Mn}^{2+}{ }_{0.15}(\mathrm{OH})_{0.3}\right) \\
4.9 \% \text { Cryptomelane } \\
\left(\mathrm{KMn}_{6}^{4+}{ }_{6} \mathrm{Mn}^{2+}{ }_{2} \mathrm{O}_{16}\right)\end{array}$} \\
\hline & & $\mathrm{Na}$ & 0.37 & \\
\hline & & $\mathrm{K}$ & 0.26 & \\
\hline & & $\mathrm{Fe}$ & 0.04 & \\
\hline \multirow{4}{*}{$\begin{array}{l}\mathrm{MnO}_{\mathrm{x}} \\
\text { treated at } \\
\quad 400 \mathrm{C}\end{array}$} & \multirow{4}{*}{$\begin{array}{l}91 \% \mathrm{MnO}_{\mathrm{x}} \text { and } \\
\quad 9 \% \mathrm{H}_{2} \mathrm{O}\end{array}$} & $\mathrm{Mn}$ & 63.07 & \multirow{4}{*}{$100 \%$ pyrolusite $(\mathrm{Mn} 4+\mathrm{O} 2)$} \\
\hline & & $\mathrm{Na}$ & 0.34 & \\
\hline & & $\mathrm{K}$ & 0.23 & \\
\hline & & $\mathrm{Fe}$ & 0.04 & \\
\hline
\end{tabular}

\subsubsection{Formaldehyde elimination studies}

Formaldehyde removal $\left(\eta_{\mathrm{f}}\right)$ was calculated with equation 2-3 where $C_{\text {in }}$ is the upstream formaldehyde concentration and $C_{\text {out }}$ is the downstream formaldehyde concentration.

$$
\eta_{f}=\left(\frac{C_{\text {in }}-C_{\text {out }}}{C_{\text {in }}}\right) \times 100
$$


Figure 2-6. Percent formaldehyde removal $\eta_{f}$ vs. time.

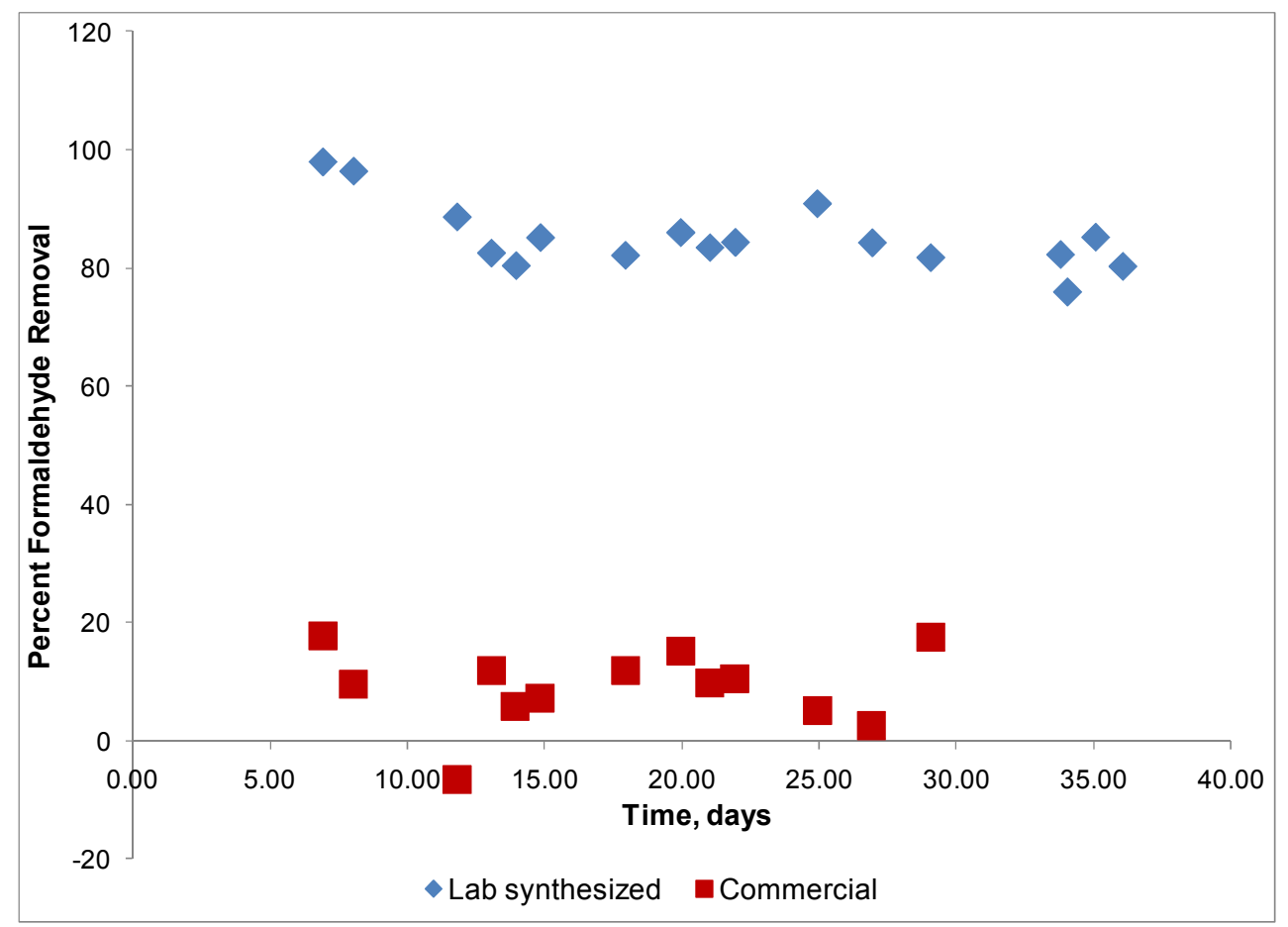

Figure 2-7. Cumulative formaldehyde elimination

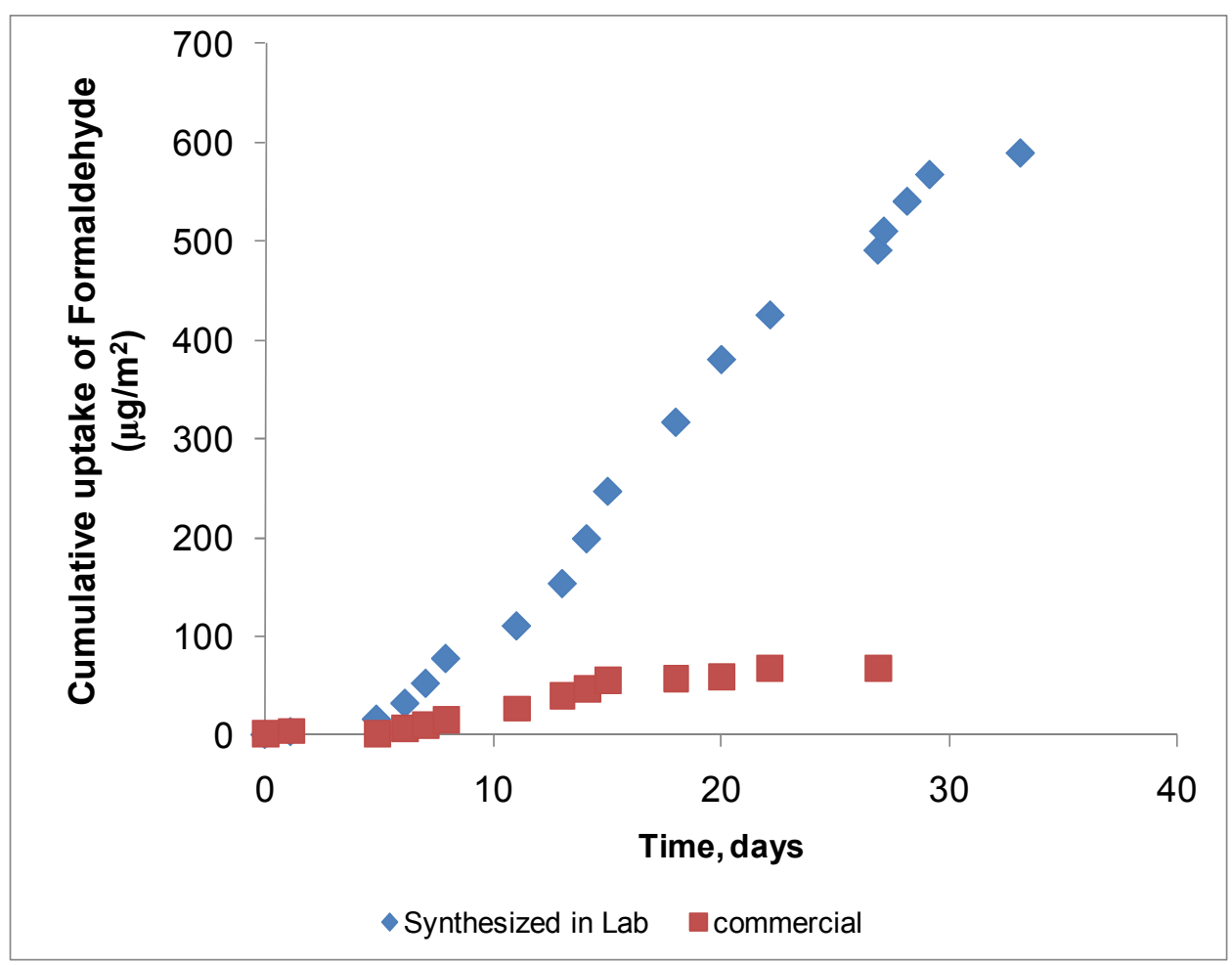


Figure 2-6 shows the formaldehyde removal results obtained for manganese oxide temperature treated at $100{ }^{\circ} \mathrm{C}$ and for the commercial $\mathrm{MnO}_{2}$, when the air passing through the supported catalyst had a low face velocity of $5.7 \times 10^{-2} \mathrm{~m} / \mathrm{min}$. The formaldehyde levels upstream were maintained at $150-200 \mathrm{ppb}$. The mass of laboratory manganese oxide sample loaded on the support was $0.11 \mathrm{gm}$ and the mass of the commercial manganese oxide sample was $0.32 \mathrm{gm}$. It was found that the laboratory made manganese oxide sample performed significantly better than the commercial manganese oxide sample. Figure 2-7 shows the cumulative formaldehyde uptake per unit surface area of the catalysts tested. It was found that the laboratory synthesized manganese oxide performed remarkably better.

Formaldehyde is proposed to be oxidized to $\mathrm{CO}_{2}$ and $\mathrm{H}_{2} \mathrm{O}$ over transitions metal oxides according to the MvK mechanism (Doornkamp and Ponec 2000; Cellier et al. 2006). The complete mineralization of formaldehyde to carbon dioxide and water depends highly on the availability of mobile oxygen species on the surface of the catalyst, Mn-O bond strength and type (Brooks 1965; Brooks 1967; Kobayash.M et al. 1971; Kobayash.M and Kobayash.H 1972; Baltanas et al. 1986, Ciminov and Indovian 1974), and material porosity. The XRD results obtained for laboratory synthesized manganese oxide show the presence of manganese oxide in $\mathrm{Mn}^{2+}$ and $\mathrm{Mn}^{4+}$ oxidation state which determine the availability of bulk oxygen species. These oxidation states of the catalyst material enable higher surface oxygen mobility and hence we observed a good catalytic activity in case of laboratory synthesized manganese oxide.

Figure 2-8 shows the plot of formaldehyde removal results obtained for laboratory synthesized manganese oxide for the higher face velocity $(31.4 \mathrm{~m} / \mathrm{min})$. Results similar to those observed in Figure 2-6 for lower face velocity were obtained. One other major difference other than the face velocity in these experiments was the formaldehyde concentration. The levels of formaldehyde for the experiments at high face velocity were maintained between $30-40 \mathrm{ppb}$, which is much lower than the experiments shown in Figure 2-6 for the low face velocity tests, and closer to the levels found in buildings. A separate test with a high formaldehyde concentration of $150 \mathrm{ppb}$ 
carried out at the same high face velocity of $31.4 \mathrm{~m} / \mathrm{min}$ yielded a high removal efficiency of $\sim 60 \%$.

Figure 2-9 shows the plot comparing the performance of the laboratory synthesized manganese oxide at different face velocities. It was observed that the catalyst performed consistently at both face velocities. The cumulative formaldehyde mass removed increased constantly with time in both cases. This observation is consistent with the results shown in Figure 2-6 and Figure 2-8 where the conversion percent achieved in both cases were $\sim 80-90 \%$. This result shows that manganese oxide-based air cleaning systems can be used successfully in formaldehyde removal.

Figure 2-8. Plot of percent formaldehyde removal vs. time for high face velocity of $31 \mathrm{~m} / \mathrm{min}$.

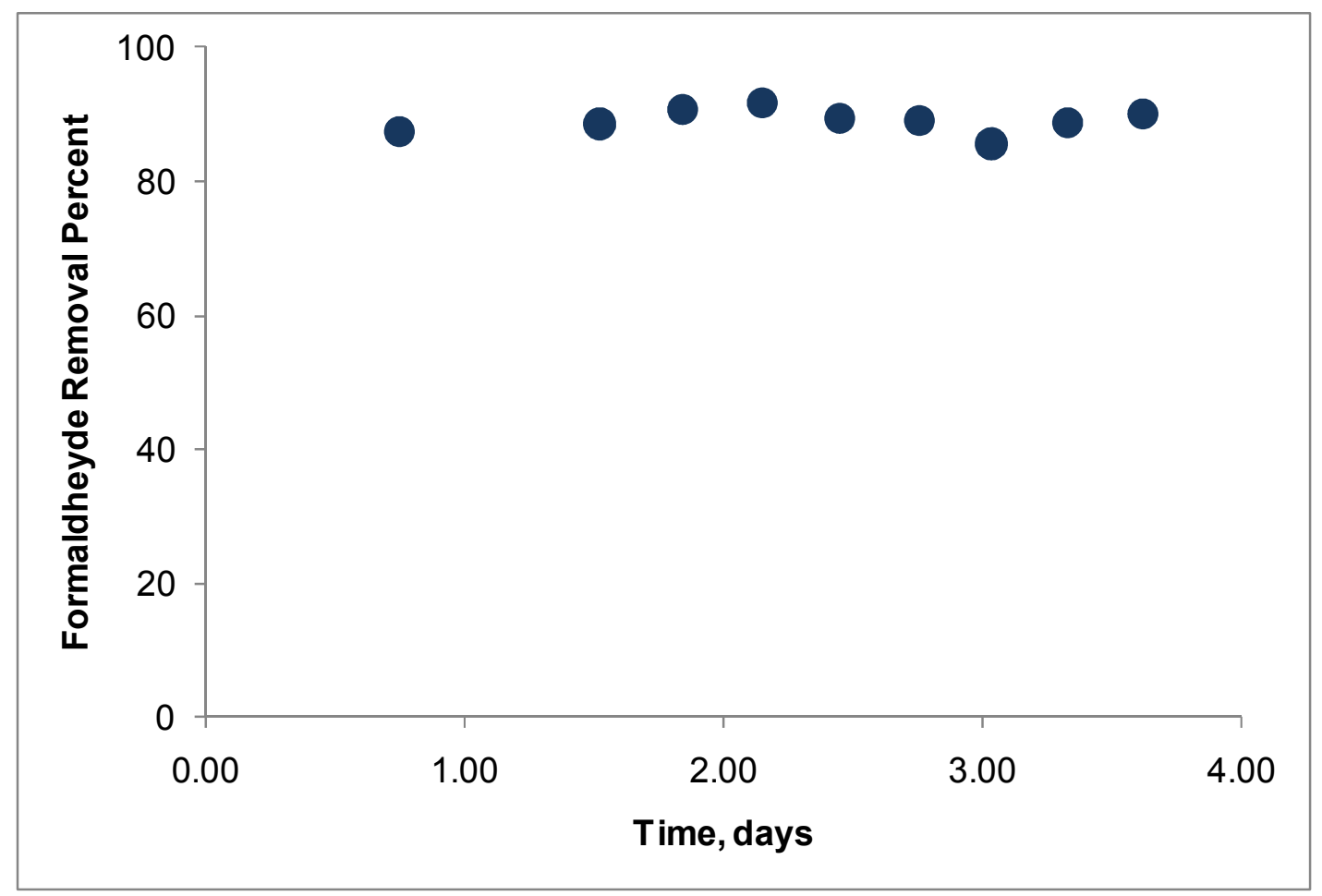


Figure 2-9. Formaldehyde elimination at two different face velocities.

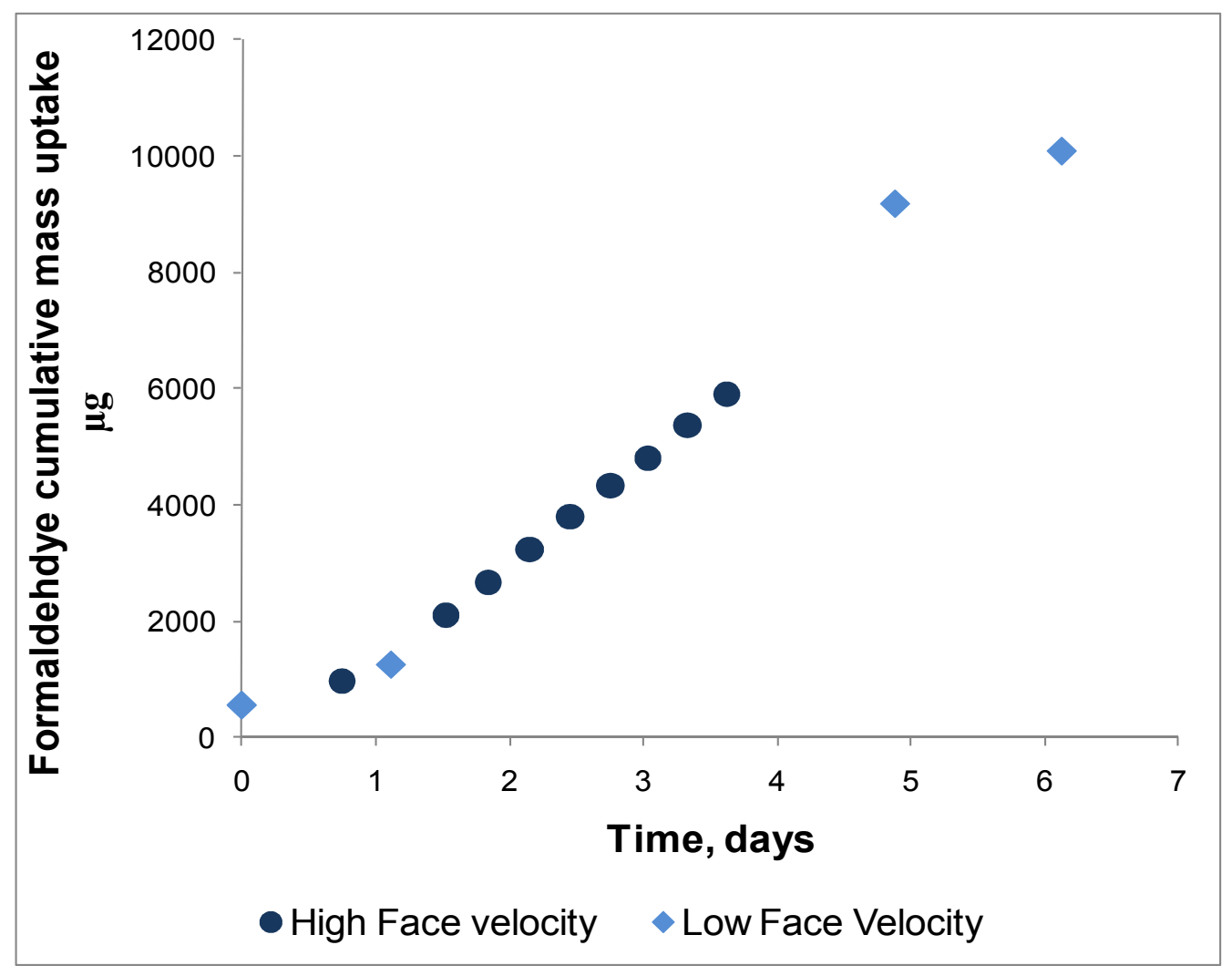

\subsubsection{Mineralization}

The oxidation of formaldehyde on manganese oxide surface is expected to proceed through the MvK mechanism as stated in equations 2-1 and 2-2. The oxidation of formaldehyde on manganese oxide surface leads to mineralization giving rise to carbon dioxide and water. Accordingly, concentration of carbon dioxide released due to the oxidation of formaldehyde was experimentally obtained to verify the mechanism and extent of mineralization. The upstream and downstream formaldehyde and carbon dioxide concentrations are listed in Table 2-4. The carbon dioxide estimation tests were executed at a concentration higher than the indoor levels of formaldehyde by a factor of 300 due to the low sensitivity of the $\mathrm{iCO}_{2}$ analyzer to $\mathrm{ppb}$ levels of carbon dioxide. The extent of mineralization from this reaction was estimated to be $99.6 \pm 7.1 \%$. The results obtained from this study suggest that all of the formaldehyde undergoes mineralization and is in good agreement with the proposed MvK mechanism. 
Table 2-4 Formaldehyde and Carbon-dioxide upstream and downstream concentrations

\begin{tabular}{|c|c|c|}
\hline Compound & $\begin{array}{c}\text { Upstream } \\
\text { Concentration (ppm) }\end{array}$ & $\begin{array}{c}\text { Downstream } \\
\text { Concentration (ppm) }\end{array}$ \\
\hline Formaldehyde & $6.061 \pm 0.16$ & $1.974 \pm 0.05$ \\
\hline Carbon dioxide & $0.04 \pm 0.19$ & $4.11 \pm 0.18$ \\
\hline
\end{tabular}

The upstream and downstream formic acid concentration estimates from ion chromatographic determination show no formic acid. This result thus supports the MvK mechanism for the oxidation of formaldehyde to mineral products, thereby confirming the extent of mineralization obtained from the carbon dioxide estimates shown in Table $2-4$.

\subsubsection{Predicted impact on indoor formaldehyde concentrations}

A simple mass balance model has been developed to analyze the effect of using $\mathrm{MnO}_{\mathrm{x}}$ to remove formaldehyde from indoor air. Scenarios with two different initial ventilation rates were studied to evaluate the performance of manganese oxide when ventilation rates are subsequently reduced.

\subsubsection{Scenario 1: Moderate initial ventilation rates}

Base Case: Air handling system with no manganese oxide filter air cleaning unit and an outdoor air ventilation air exchange rate of $0.8 \mathrm{~h}^{-1}$ and a volume-normalized formaldehyde source emission rate of $6.4 \mathrm{ppb} \mathrm{h}^{-1}$

- Case 1.1: Air handling system with manganese oxide filter air cleaning unit and outdoor air ventilation exchange rate of $0.4 \mathrm{~h}^{-1}$ (50\% reduction in ventilation).

\subsubsection{Scenario 2: High initial ventilation}

Base Case: Air handling system with no manganese oxide filter air cleaning unit and an outdoor air ventilation air exchange rate of $1.2 \mathrm{~h}^{-1}$, and a volume-normalized formaldehyde source emission rate of $6.4 \mathrm{ppb} \mathrm{h}^{-1}$ 
- Case 2.1: Air handling system with manganese oxide filter air cleaning unit and outdoor air ventilation exchange rate of $0.6 \mathrm{~h}^{-1}$ ( $50 \%$ reduction in ventilation).

Figure 2-10 shows the flow diagram of the mass balance model. A formaldehyde air cleaning ratio $(R)$, was defined as the ratio of the indoor formaldehyde concentration with an air handling unit with the manganese oxide filter installed in the system to the concentration of formaldehyde in the room equipped with an air handling unit without the manganese oxide filter and is given in equation 2-4. A lower formaldehyde cleaning ratio denotes a better performing $\mathrm{MnO}_{\mathrm{x}}$ filter unit. $\mathrm{R} \leq 1$, signifies that the air cleaning technology maintains a lower indoor formaldehyde concentration than the base case system with twice the ventilation rate. The air cleaning effectiveness ratio can also be calculated from the air exchange rates and the formaldehyde removal efficiency of the $\mathrm{MnO}_{x}$ system as shown in equation 2-5.

$$
\begin{aligned}
& R=\frac{[C]_{M n O_{x}}}{[C]_{n o-M n O_{x}}} \\
& R=\frac{\left[S_{r}+N_{v, M n O_{x}}(1-\eta)\right] N_{v}}{\left(N_{v}+\eta\left(N_{r}-N_{v, M n O_{x}}\right)\right)\left(S_{r}+N_{v} X_{0}\right)}
\end{aligned}
$$

where $[C]_{n o-M n O x}$ is the indoor concentration of formaldehyde with an air handling unit without manganese oxide catalyst, $[C]_{M n O x}$ is the indoor concentration of formaldehyde with an air handling unit with manganese oxide catalyst, $S_{r}$ is the formaldehyde emission rate source concentration per unit volume, $N_{r}$ is the air exchange rate, $N_{v}$ is the number of air changes with the outdoor air in the scenario without manganese oxide catalyst, $N_{\mathrm{V}-\mathrm{MnOx}}$ is the number of air changes with the outdoor air in the scenario with manganese oxide catalyst, $X_{0}$ is the concentration of formaldehyde entering from outdoors (assumed to be $2 \mathrm{ppb}$ for all our model calculations), and $\eta$ is the removal efficiency of the manganese oxide system for formaldehyde, as determined in this study. 
We estimated that $R=0.18$ for Scenario 1 where the initial ventilation rate was $0.8 \mathrm{~h}^{-1}$ and $R=0.24$ for Scenario 2 where the ventilation air exchange rate of the base case was $1.2 \mathrm{~h}^{-1}$. It can be easily concluded from these values of $R$ that in both the scenarios of low and high ventilation rates, the system equipped with manganese oxide filter and $50 \%$ reduced ventilation maintained a much lower indoor formaldehyde concentration than in the absence of the air cleaner. With negligible pressure drop and anticipated low synthesis and deployment costs, implementing manganese oxide catalysts for formaldehyde abatement in indoor environments is a highly promising technology.

Figure 2-10. Mass Balance Model

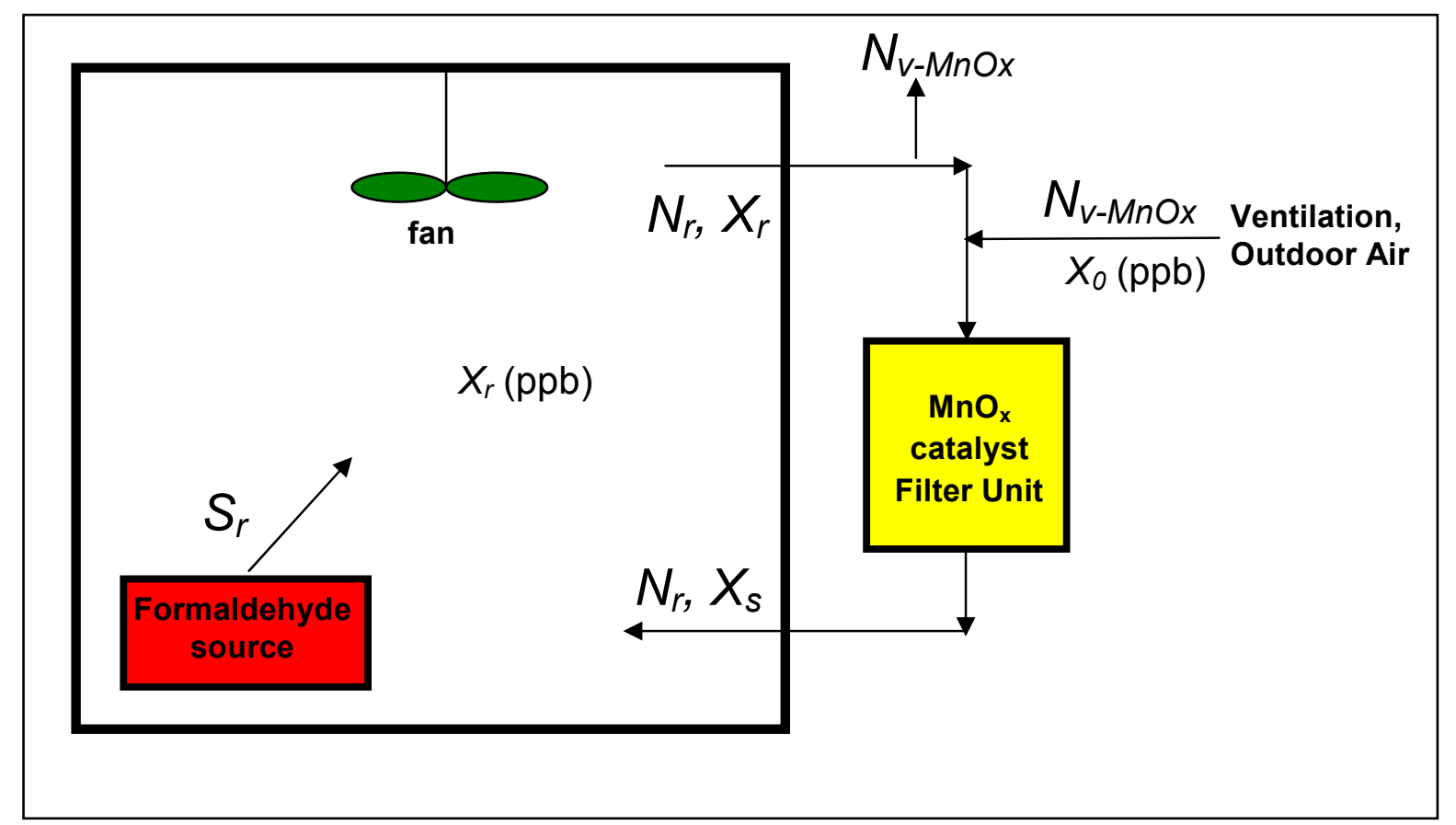




\subsection{Conclusions}

A manganese oxide catalyst was synthesized using inexpensive precursors and a simple process. Relative to the commercial product, the synthesized manganese oxide has a much higher surface area and different crystal size and chemical composition, consistent with superior catalytic performance. The synthesized catalyst, adsorbed on a typical particle filter, removed formaldehyde with a stable $\sim 80 \%$ efficiency at room temperature. Modeling indicated that deployment of this catalyst in the supply airstreams of HVAC systems would substantially reduce indoor formaldehyde concentrations even when ventilation rates are reduced by $50 \%$ to save energy.

\subsection{References}

Ahmed, K. A. M., Q. M. Zeng, K. B. Wu and K. X. Huang (2010). "Mn3O4 nanoplates and nanoparticles: Synthesis, characterization, electrochemical and catalytic properties." Journal of Solid State Chemistry 183(3): 744-751.

Attenburrow, J., Cameron, A. F. B., Chapman, J. H., Evans, R. M., Hems, B. A., Jansen, A. B. A. and Walker, T., (1952) "A synthesis of vitamin A from cyclohexanone", Journal of Chemical Society, 1094-1111.

Baltanas, M. A., A. B. Stiles and J. R. Katzer (1986). "DEVELOPMENT OF SUPPORTED MANGANESE OXIDES FOR PARTIAL OXIDATION COOXIDATION AND OXYGEN AVAILABILITY." Applied Catalysis 20(1-2): 1529.

Benne, K., B. Griffith and e. al (2009). "Assessment of the energy impacts of outside air in the commercial sector." NREL/TP-550-41955. Golden, CO, National Renewable Energy Laboratory. 
Blish, D. and Post, E., (1989), "Thermal behavior of complex, tunnel-structure manganese oxides", American Mineralogist, 74, 177-186,

Brooks, C. S. (1965). "REACTION OF HYDROGEN WITH A NONSTOICHIOMETRIC MANGANESE DIOXIDE." Journal of Catalysis 4(5): 535-\&.

Brooks, C. S. (1967). "KINETICS OF HYDROGEN AND CARBON MONOXIDE OXIDATION OVER A MANGANESE OXIDE." Journal of Catalysis 8(3): 272-\&.

Cellier, C., V. Ruaux, C. Lahousse, P. Grange and E. M. Gaigneaux (2006). "Extent of the participation of lattice oxygen from gamma-MnO2 in VOCs total oxidation: Influence of the VOCs nature." Catalysis Today 117(1-3): 350-355.

Chen, H. M., J. H. He, C. B. Zhang and H. He (2007). "Self-assembly of novel mesoporous manganese oxide nanostructures and their application in oxidative decomposition of formaldehyde." Journal of Physical Chemistry C 111(49): 18033-18038.

Chen, T., H. Y. Dou, X. L. Li, X. F. Tang, J. H. Li and J. M. Hao (2009). "Tunnel structure effect of manganese oxides in complete oxidation of formaldehyde." Microporous and Mesoporous Materials 122(1-3): 270-274.

Ciminov, A, Indovian, V. Catalytic activity of $\mathrm{Mn3}+$ and $\mathrm{Mn} 4+$ ions dispersed in $\mathrm{MgO}$ for CO oxidation, J. Catal 33 (1974) 493

Cogliano, V. J., Y. Grosse, R. A. Baan, K. Straif, M. B. Secretan and F. El Ghissassi (2005). "Meeting report: summary of IARC monographs on formaldehyde, 2butoxyethanol and 1-tert-butoxy-2-propanol." Environ. Health Perspectives 113: 1205-1208.

Destaillats, H., M. M. Lunden, B. C. Singer, B. K. Coleman, A. T. Hodgson, C. J. Weschler and W. W. Nazaroff (2006). "Indoor secondary pollutants from household product emissions in the presence of ozone. A bench scale study." Environ. Sci. Technol. 40: 4421-4428. 
Doornkamp, C. and V. Ponec (2000). "The universal character of the Mars and Van Krevelen mechanism." Journal of Molecular Catalysis a-Chemical 162(1-2): 1932.

Girman, J. R., S. E. Womble and E. L. Ronca (1995). "Developing baseline information on buildings and indoor air quality (BASE 94): Part II - Environmental pollutant measurements and occupant perceptions." Proceedings of Healthy Buildings 95, 3: 1311-1316.

Griffith, B., N. Long and e. al (2008). "Methodology for modeling building energy performance across the commercial sector, ." NREL/TP-550-41956. Golden, Co. National Renewable Energy Laboratory.

Harfenist, M., Bavley, A., and Lazier, W. A., (1954), "The oxidation of allyl and benzyl alcohols to the aldehydes", Journal of Organic Chemistry, 19, 1608-1616

Hodgson, A. T., D. Beal and J. E. R. Mcllyaine (2002). "Sources of formaldehyde, other aldehydes and terpenes in a new manufactured house." Indoor Air 12: 235-242.

Hodgson, A. T. and H. Levin (2003). Volatile organic compounds in indoor air: a review of concentrations measured in North America since 1990. Berkeley, California, Lawrence Berkeley National Laboratory: LBNL Report 51715.

Kobayashi .M and Kobayashi .H (1972). "Application of transient-response method to study of heterogeneous catalysis .1. Nature of catalytically active oxygen on manganese-dioxide for oxidation of carbon-monoxide at low-temperatures." Journal of Catalysis 27(1): 100-\&.

Kobayashi, M, Matsumoto, .H and Kobayashi H (1971). "Distribution of oxidation power of surface oxygen species on manganese dioxide during oxidation of carbon monoxide." Journal of Catalysis 21(1): 48-\&. 
Maddalena, R., M. Russell, D. P. Sullivan and M. G. Apte (2009). "Formaldehyde and Other Volatile Organic Chemical Emissions in Four FEMA Temporary Housing Units." Environmental Science \& Technology 43(15): 5626-5632.

Mendell, M. J. (2007). "Indoor residential chemical emission as risk factors for respiratory and allergic effects in children: a review." Indoor Air 17: 259-277.

NIOSH, (1992) NIOSH recommendations for occupational safety and health. Compendium of policy documents and statements. DHHS (NIOSH) Publication No. 92-100. http://www.cdc.gov/niosh/pdfs/92-100-c.pdf, National Institute for Occupational Safety and Health

Prasad, V. S. and M. Chaudhuri (1995). "removal of bacteria and turbidity from water by chemically treated manganese and iron-ores." Journal of Water Supply Research and Technology-Aqua 44(2): 80-82.

Post, J. E. (1999). "Manganese oxide minerals: Crystal structures and economic and environmental significance." Proceedings of the National Academy of Sciences of the United States of America 96(7): 3447-3454.

Sekine, Y. (2002). "Oxidative decomposition of formaldehyde by metal oxides at room temperature." Atmospheric Environment 36(35): 5543-5547.

Sekine, Y. and A. Nishimura (2001). "Removal of formaldehyde from indoor air by passive type air-cleaning materials." Atmospheric Environment 35(11): 20012007.

Singer, B. C., H. Destaillats, A. T. Hodgson and W. W. Nazaroff (2006). "Cleaning products and air fresheners: emissions and resulting concentrations of glycol ethers and terpenoids." Indoor Air 16: 179-191.

Tang, X. F., J. L. Chen, X. M. Huang, Y. Xu and W. J. Shen (2008). "Pt/MnOx-CeO2 catalysts for the complete oxidation of formaldehyde at ambient temperature." Applied Catalysis B-Environmental 81(1-2): 115-121. 
Tang, X. F., J. H. Li and J. M. Hao (2010). "Significant enhancement of catalytic activities of manganese oxide octahedral molecular sieve by marginal amount of doping vanadium." Catalysis Communications 11(10): 871-875.

Tang, X. F., Y. G. Li, X. M. Huang, Y. D. Xu, H. Q. Zhu, J. G. Wang and W. J. Shen (2006). "MnOx-CeO2 mixed oxide catalysts for complete oxidation of formaldehyde: Effect of preparation method and calcination temperature." Applied Catalysis B-Environmental 62(3-4): 265-273.

USEPA (2003). A standardized EPA protocol for characterizing indoor air quality in large office buildings. Washington DC.

Wen, Y. R., X. Tang, J. H. Li, J. M. Hao, L. S. Wei and X. F. Tang (2009). "Impact of synthesis method on catalytic performance of $\mathrm{MnOx}-\mathrm{SnO} 2$ for controlling formaldehyde emission." Catalysis Communications 10(8): 1157-1160.

Xu, Q., Y. Zhang, J. Mo, R. Ke and S. Kang (2008). "Research of formaldehyde removal by room temperature thermo-catalytic oxidation reactor." Proceedings of Indoor Air 2008 Paper ID 692, Copenhagen, Denmark.

Yuan, J. K.; Li, W. N.; Gomez, S.; Suib, S. L., Shape-Controlled Synthesis of Manganese Oxide Octahedral Molecular Sieve Three-Dimensional Nanostructures, J. Am. Chem. Soc. 2005, 127, 14184.

Yuan, J.; Laubernds, K.; Zhang, Q.; Suib, S. L., Self-Assembly of Microporous Manganese Oxide Octahedral Molecular Sieve Hexagonal Flakes into Mesoporous Hollow Nanospheres, J. Am. Chem. Soc. 2003, 125, 4966

Zwicker W K, Meijer W O J G, Jaffe H W, (1962), "Nsutite a widespread manganese oxide mineral", American Mineralogist 47, 246-266.

Zhong, L.; Hu, J.; Liang, H.; Cao, A.; Song, W.; Wan, L. Self-Assembled 3D Flowerlike Iron Oxide Nanostructures and Their Application in Water Treatment, AdV. Mater. 2006, 18, 2426. 


\section{Evaluation of passive formaldehyde removal by ceiling tile and wallboard}

\subsection{Introduction}

Reductions in outdoor air ventilation rates are an attractive and very easily implemented means of reducing the energy consumed in buildings. As discussed in the previous chapters, substantial reductions in ventilation rates, without compensating measures, will degrade indoor air quality. Effective and energy efficient air cleaning systems for volatile organic compounds would enable ventilation rates to be reduced to save energy. Formaldehyde is a key pollutant that poses substantial health risks for which air cleaning technologies are particularly critical. Formaldehyde is a major additive in building materials as it is used to enhance and preserve desirable properties. Pressed wood products such as particle board can be a dominant source of formaldehyde indoors. Formaldehyde is also a by-product of smoking, of incomplete combustion and a byproduct of ozone-initiated indoor chemistry.

Zeolite-containing ceiling tiles have recently been introduced into the European market for indoor formaldehyde control by the German manufacturer Knauf. Zeolites are highly porous aluminosilicates with strong affinity for certain gases and organic vapors, including formaldehyde (Qian et al. 2001; Aguado et al. 2004). Research has shown that formaldehyde adsorbs strongly to zeolites, where its oxidation can be catalyzed (Okachi and Onaka 2004; Kukulska-Zajac and Datka 2007; Gora-Marek and Datka 2008). Formaldehyde sorption and desorption studies (Matthews et al. 1987) demonstrate that gypsum board has a substantial storage capacity for sorbed formaldehyde vapor that buffers sudden changes in formaldehyde concentration in the surrounding atmosphere but appears to cause only a minor, permanent loss mechanism for formaldehyde. Because there is a very large surface area of ceiling tiles and wallboard in commercial buildings, they are well suited for use in passive air cleaning 
applications, with no energy penalty. However, we have not been able to identify any prior studies that actually document the practical potential of these products.

In some buildings, air cleaning that is effective only for formaldehyde (which is classified as a human carcinogen) may enable modest reductions in ventilation rates. However, in other situations formaldehyde air cleaning systems would be used in conjunction with air cleaning or source control measures for other VOCs.

\subsection{Materials and Methods}

\subsubsection{Experimental design}

The following criteria were followed in the design of our experiments:

\subsubsection{Surface area of ceiling tile per unit air volume}

In a typical room, the ceiling tile area equals the floor area, the height of the ceiling tile above the floor is $2.74 \mathrm{~m}$ and the height of the plenum space above the ceiling tile is $1 \mathrm{~m}$. The ceiling area per unit air volume is then $1 \mathrm{~m}^{2}$ per $3.74 \mathrm{~m}^{3}$, or 0.267 $\mathrm{m}^{-1}$. This calculation considers only one surface of the ceiling tile, but in reality both the upper and lower surfaces of the ceiling tile are exposed to the indoor air.

\subsubsection{Residence time}

The average age of air $(\tau)$ when it leaves a ventilated room equals $V / Q$ where $V$ is the indoor volume and $Q$ is the outdoor air flow rate. This remains true regardless of the indoor air flow pattern or the extent of mechanical recirculation. In a typical office setting, $\tau$ is approximately $1 \mathrm{~h}$ during the period of mechanical ventilation (e.g., 6:00 am to $6: 00 \mathrm{pm}$ ) and $\tau$ has a larger value (e.g., $5 \mathrm{~h}$ ) when the mechanical ventilation is turned off. In the experimental flow cells, $\tau$ is determined by the airflow rate through the chambers per unit chamber volume. To match the residence times in a ventilated room, we ventilated the flow cells at $1 \mathrm{~h}^{-1}$. 


\subsubsection{Composition and concentrations of pollutants in the air}

By ventilating the chambers with air from a real indoor space, we conducted tests with realistic mixtures of pollutants. We enriched the air in formaldehyde (our target compound) by addition of formaldehyde sources upstream of the flow cells.

\subsubsection{Mass transfer coefficients}

The convective mass transfer coefficients may affect the formaldehyde removal rates, if other factors are not limiting; however, it is possible that transport within the ceiling tile or chemical reaction rates are limiting. The convective mass transfer coefficients in a real room depend on the air velocities (driven by mechanical ventilation, buoyancy, etc) and turbulence intensity. Delivery of supply air from ceiling-mounted diffusers may increase the mass transfer coefficients at ceiling tiles. Our small flow cells may have lower average velocities and turbulence intensities than real rooms because of the lack of temperature gradients causing buoyancy-driven air movement, the absence of ceiling mounted supply diffusers, and because of smaller scale of the chambers. In order to counteract these effects, and to operate under ideal mixing and maximum mass transfer conditions, we introduced a small electric fan in each flow cell.

\subsubsection{Temperature and humidity}

By ventilating the chambers with air from a real indoor space, we conducted tests with realistic temporal profiles of humidity and temperature, in the range $18-22{ }^{\circ} \mathrm{C}$ and $40-60 \% \mathrm{RH}$, respectively.

\subsubsection{Indoor surface materials}

Five different types of indoor surface materials were studied to understand the removal of formaldehyde in indoor air. The properties, make, manufacturers and the acronyms used are stated in Table 1-3. The product manufactured by Knauf is the one marketed specifically as improving indoor air quality due to its purported formaldehyde removal capacity. Figure 3-1 illustrates these five materials. 
Table 3-1 Indoor surface materials analyzed in this study

\begin{tabular}{|c|c|c|c|c|}
\hline Type & Manufacturer & Composition of core material(s) & Application & Acronym \\
\hline Sheetrock $®$ & USG & Gypsum & wallboard & G-WB1 \\
\hline Cleaneo Akustik & Knauf & Gypsum with Zeolite mineral & $\begin{array}{c}\text { ceiling tile, } \\
\text { wallboard }\end{array}$ & G+Z-CT1 \\
\hline $\begin{array}{c}\text { Cortega Square } \\
\text { Lay-in }\end{array}$ & Armstrong & Wet formed mineral fiber & ceiling tile & MF-CT1 \\
\hline $\begin{array}{c}\text { Clean Room } \\
\text { ClimaPlus }\end{array}$ & USG & $\begin{array}{c}\text { Water felted mineral fiber with } \\
\text { smooth vinyl finish }\end{array}$ & ceiling tile & MF-CT2 \\
\hline $\begin{array}{c}\text { Fiber Acoustical } \\
\text { Tile }\end{array}$ & $\begin{array}{c}\text { Hutting Building } \\
\text { Products }\end{array}$ & Mineral fiber with holes & ceiling tile & MF-CT3 \\
\hline
\end{tabular}

Figure 3-1 Materials studied in this task

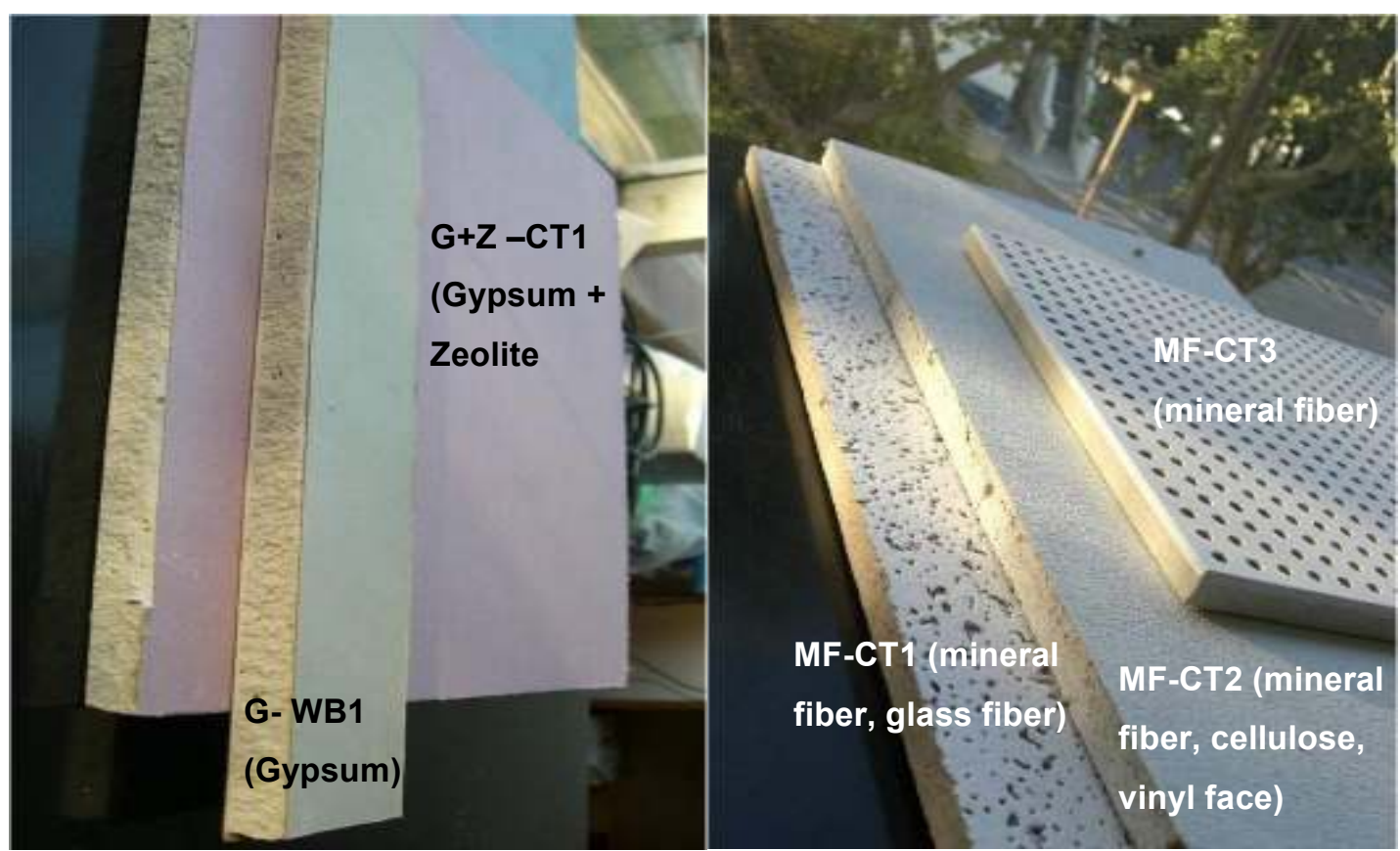

\subsubsection{Experimental setup}

The five different kinds of indoor surface materials were tested for their ability to remove formaldehyde using a $1-\mathrm{m}^{3}$ custom built Teflon coated gypsum chamber (Destaillats et al. 2006). A diagram of the experimental setup is shown in Figure 3-2. 
Formaldehyde was generated inside the chamber using stable diffusive sources. For that purpose, we introduced several $10.2 \mathrm{~cm} \times 10.2 \mathrm{~cm}$ specimens of cabinetry obtained in a recent study, and marked as high formaldehyde emitters (Maddalena et al. 2009). The indoor surface samples were cut in $10 \times 10 \mathrm{~cm}$ squares, and the edges were taped using aluminum tape. Each sample was weighed and placed inside a separate 4-L stainless-steel flow cell, which in turn were placed inside the $1-\mathrm{m}^{3}$ chamber. The bottom of each flow cell was fitted with a quarter-inch Swagelock fitting coupled to a quarter inch tubing connected to a peristaltic pump pulling air from the flow cell at a constant rate. Integrated aldehyde samples were collected downstream of each flow cell at periodic intervals. Each flow cell had 1/8 inch inlet on the top, drawing air directly from the interior of the $1-\mathrm{m}^{3}$ chamber. Each sample was placed on a steel grid inside the flow cell to enable uniform exposure to pollutants. The flow cells and the chamber were fitted with small fans to ensure uniform mixing of the pollutant air. The $\mathrm{RH}$ and temperature were monitored using a $\mathrm{HOBO} \otimes$ data logger downstream of the chamber.

\section{Figure 3-2. Experimental setup}

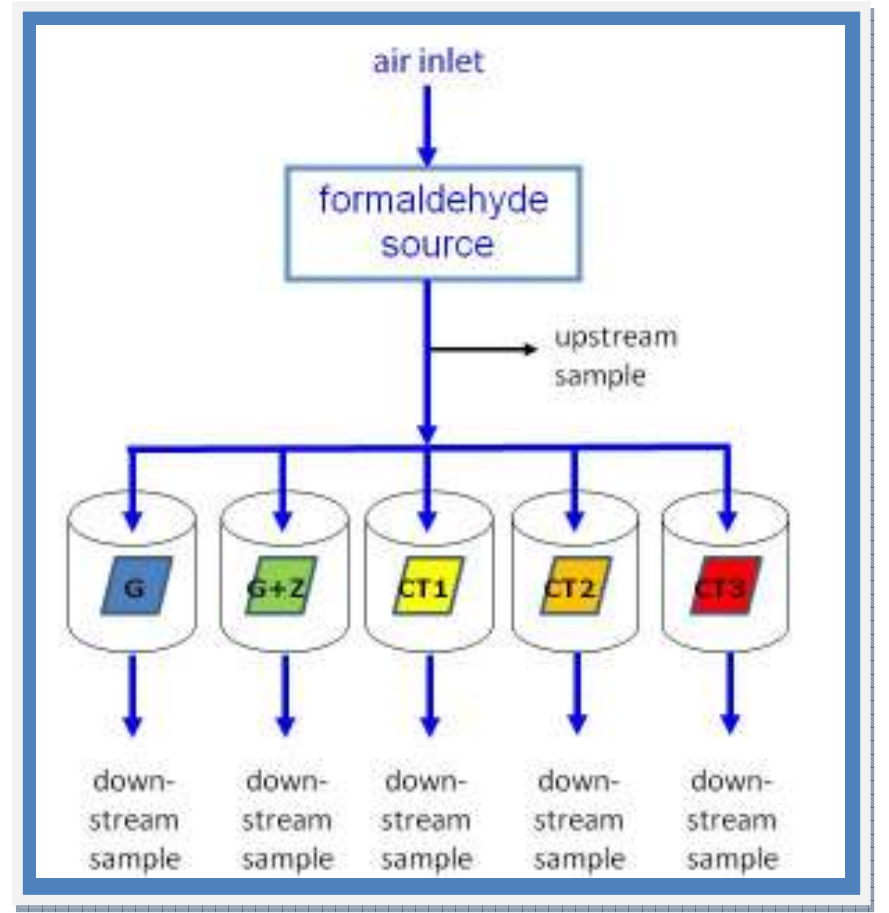


Formaldehyde removal tests were performed with sampling flow rates to each flow cell maintained at $50 \mathrm{cc} / \mathrm{min}$. The total flow of air circulating in the $1-\mathrm{m}^{3}$ chamber was maintained at $\sim 300 \mathrm{cc} / \mathrm{min}$. The upstream formaldehyde concentration (measured directly in the interior of the $1-\mathrm{m}^{3}$ chamber was maintained at $50-60 \mathrm{ppb}$. The formaldehyde concentrations in each flow cell were measured periodically over a period of 5 weeks, after which the formaldehyde sources were removed and the off gassing of formaldehyde from the samples was studied to estimate the formaldehyde release of the ceiling tiles back into ambient air. During the off gassing test, aldehyde samples were collected for all the flow cells and the $1-\mathrm{m}^{3}$ chamber as described above.

\subsubsection{Sampling and Analytical Methods}

Integrated volatile carbonyl samples were collected in dinitrophenyl hydrazine (DNPH)-coated silica samplers (SepPak, Waters) over a period of typically 24 hours at the rate of $17 \mathrm{cc} / \mathrm{min}$ downstream of each of the flow cells, and one upstream sample from the $1-\mathrm{m}^{3}$ chamber. Ambient ozone was scrubbed prior to sampling using potassium iodide scrubbers (Waters Sep-pak Ozone scrubber). The concentration reported in each case corresponds to a time-integrated average over the sampled period, and is reported at the center time of each sampling period. The flow corresponding to each sample was measured using a primary air flow calibrator (Gilibrator ${ }^{\circledR}$ ) with a precision better than $2 \%$.

DNPH cartridges were extracted with 2-mL aliquots acetonitrile, and the extracts were analyzed by HPLC with UV detection $\left(\lambda_{\max }=360 \mathrm{~nm}\right)$. A calibration curve for quantification was carried out using authentic standards of the DNPH hydrazone of formaldehyde, acetaldehyde and acetone. 


\subsection{Results and Discussion}

\subsubsection{Effective surface area}

The effective surface areas (as defined by the BET isotherm) obtained for the different materials tested in this study are listed in Table 3-2, together with the mass of each material used in the experiment.

Table 3-2. BET surface area of different ceiling tile materials*.

\begin{tabular}{|c|c|c|}
\hline Ceiling Tile & Mass of sample $(\mathbf{g})$ & BET Surface area $\left(\mathbf{m}^{2} / \mathbf{g}\right)$ \\
\hline G-WB1 & 33.1 & 3.74 \\
\hline G+Z-CT1 & 25.5 & 4.56 \\
\hline MF-CT1 & 8.4 & 2.55 \\
\hline MF-CT2 & 15.1 & 0.828 \\
\hline MF-CT3 & 9.6 & 2.10 \\
\hline
\end{tabular}

$\mathrm{G}=$ gypsum, $\mathrm{Z}=$ zeolite, $\mathrm{WB}=$ wall board, $\mathrm{CT}=$ ceiling tile

The BET surface area of all of the samples analyzed in this study is very similar except for MF-CT2 which has a lower surface area.

\subsubsection{Formaldehyde Removal Studies}

Formaldehyde levels were determined in the chamber and flow cells using methods described above. Formaldehyde removal was calculated as the difference between upstream and downstream concentrations, divided by the upstream concentration, multiplied by 100 . Figure 3-3 shows the plot of formaldehyde levels in the chamber throughout the duration of the experiment. 
Figure 3-3. Chamber (upstream) concentrations

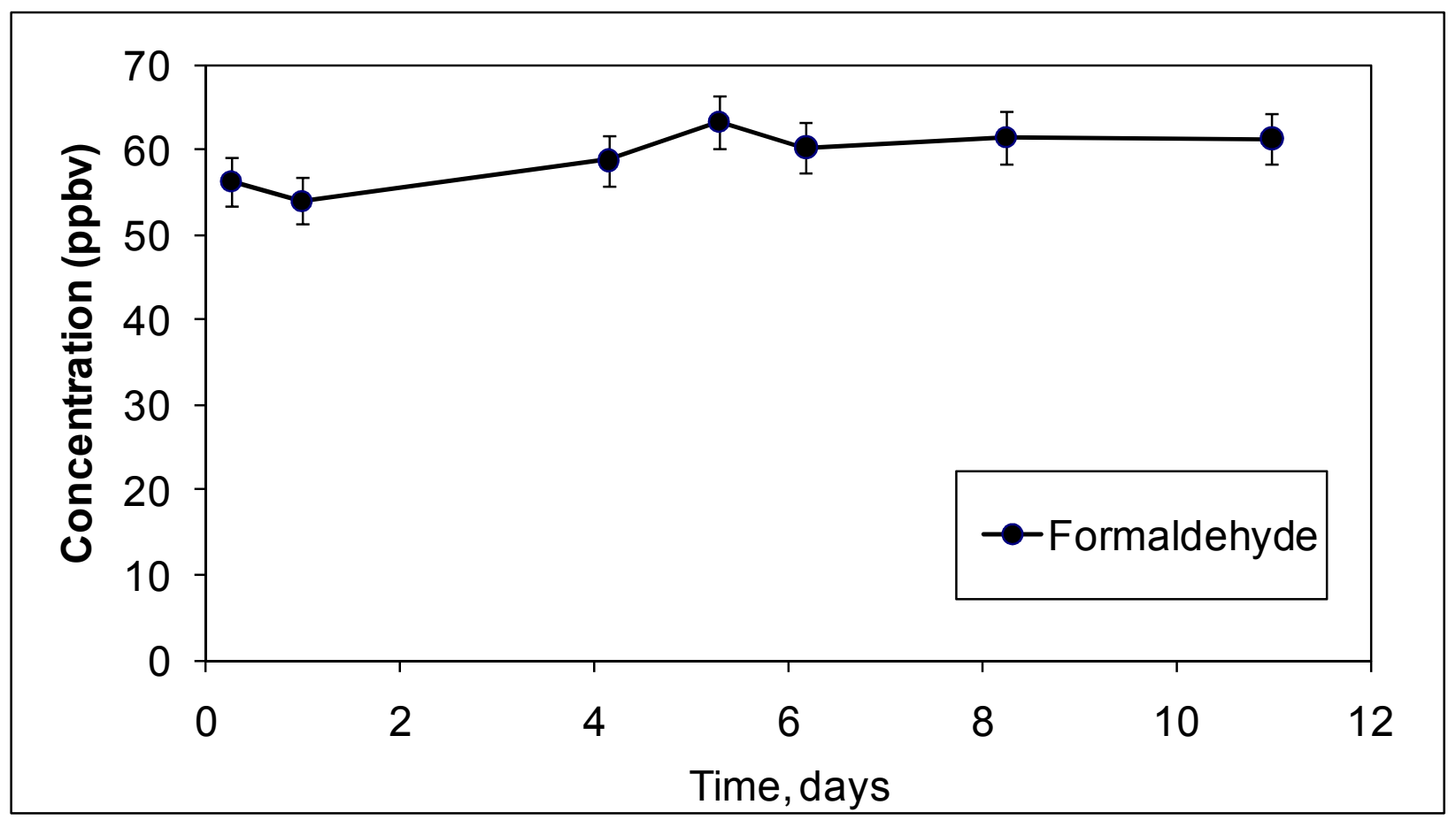

Figure 3-4 shows a plot of the formaldehyde removal percent vs. time for all of the building materials. The green data points in Figure 3-4 show the formaldehyde removal by the G+Z-CT1 material marketed as a product with formaldehyde removal capabilities. The manufacturers claim that this product $(G+Z-C T 1)$ was capable of reducing $\sim 35-40 \%$ indoor formaldehyde levels. The first aldehyde sample showed formaldehyde reduction of $\sim 17 \%$ compared to the chamber levels. Over time, the formaldehyde levels in the flow cell containing the G+Z-CT1 material increased, thereby reducing the formaldehyde removal percent unlike the claims made by the manufacturer. The blue data in Figure 3-4 show the formaldehyde removal percentage of typical gypsum wallboard. Mathews et al (Matthews et al. 1987) developed a single exponential adsorption and desorption model to described formaldehyde sorption on gypsum and estimated a lifetime of $2.9 \pm 0.1$ days. They conducted experiments at 23 ${ }^{\circ} \mathrm{C}, 50 \% \mathrm{RH}$, air exchange to board loading ratio of $0.43 \mathrm{~m} / \mathrm{h}$ and formaldehyde concentrations ranging from 0 to $0.5 \mathrm{mg} / \mathrm{m}^{3}$. We observed a similar behavior in our 
system with formaldehyde adsorption levels reaching equilibrium at the end of 3 days. Formaldehyde removal initially was around $17 \%$, similar to that of G+Z-CT1 sample and decreased rapidly with time, similar to the trend of the G+Z-CT1 material. After the initial stabilization of formaldehyde concentrations in both the G-WB1 and G+Z-CT1 samples, it was found that the formaldehyde levels in the two flow cells containing the materials fluctuated due to cyclic formaldehyde adsorption and desorption.

The ceiling tiles made from mineral fiber ceiling tiles (MF-CT1, MF-CT2 and MFCT3) displayed similar formaldehyde adsorption properties. The formaldehyde removal percentage was comparable to $G$ and $G+Z$ materials and, in some cases (MF-CT3), had significantly better removal. However, it's important to keep in mind that MF-CT3 surfaces were textured, as opposed to all other samples, providing for more total surface area of contact.

The formaldehyde adsorption properties of mineral fibers (MF-CT1, MF-CT2, MFCT3) was correlated with the humidity conditions of the ambient air. It was observed that with a slight increase in humidity, the adsorption of formaldehyde was improved by a factor of 20. Figure 3-5 shows the cumulative formaldehyde mass uptake per unit mass of material. The data shown in Figure 3-5 is in accordance with the data shown in Figure 3-4 showing that mineral fiber based indoor surfaces performed better than gypsum and zeolite based materials. 
Figure 3-4. Formaldehyde percent removal and cumulative uptake for different materials

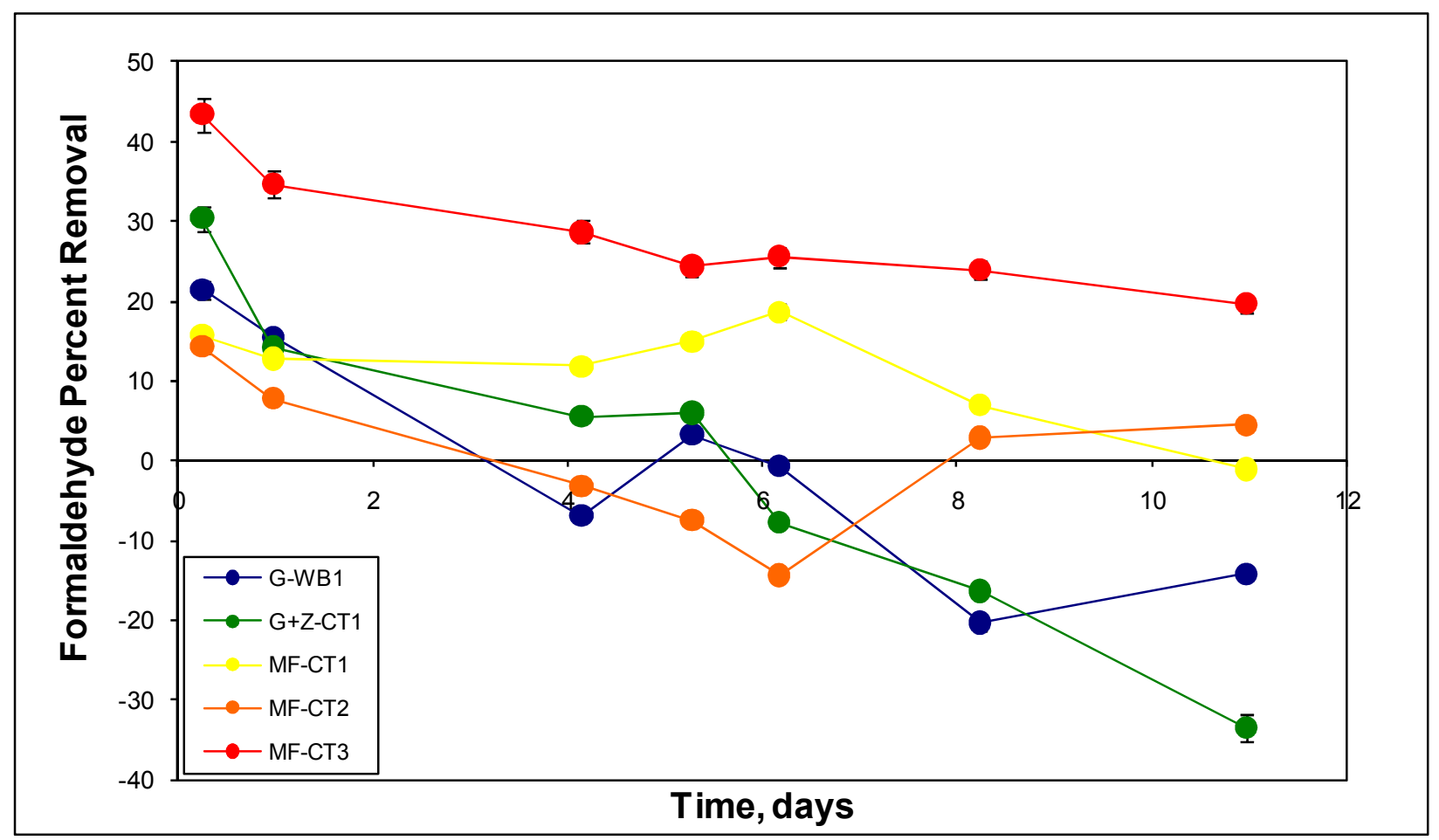

Figure 3-5. Formaldehyde cumulative mass uptake by each material.

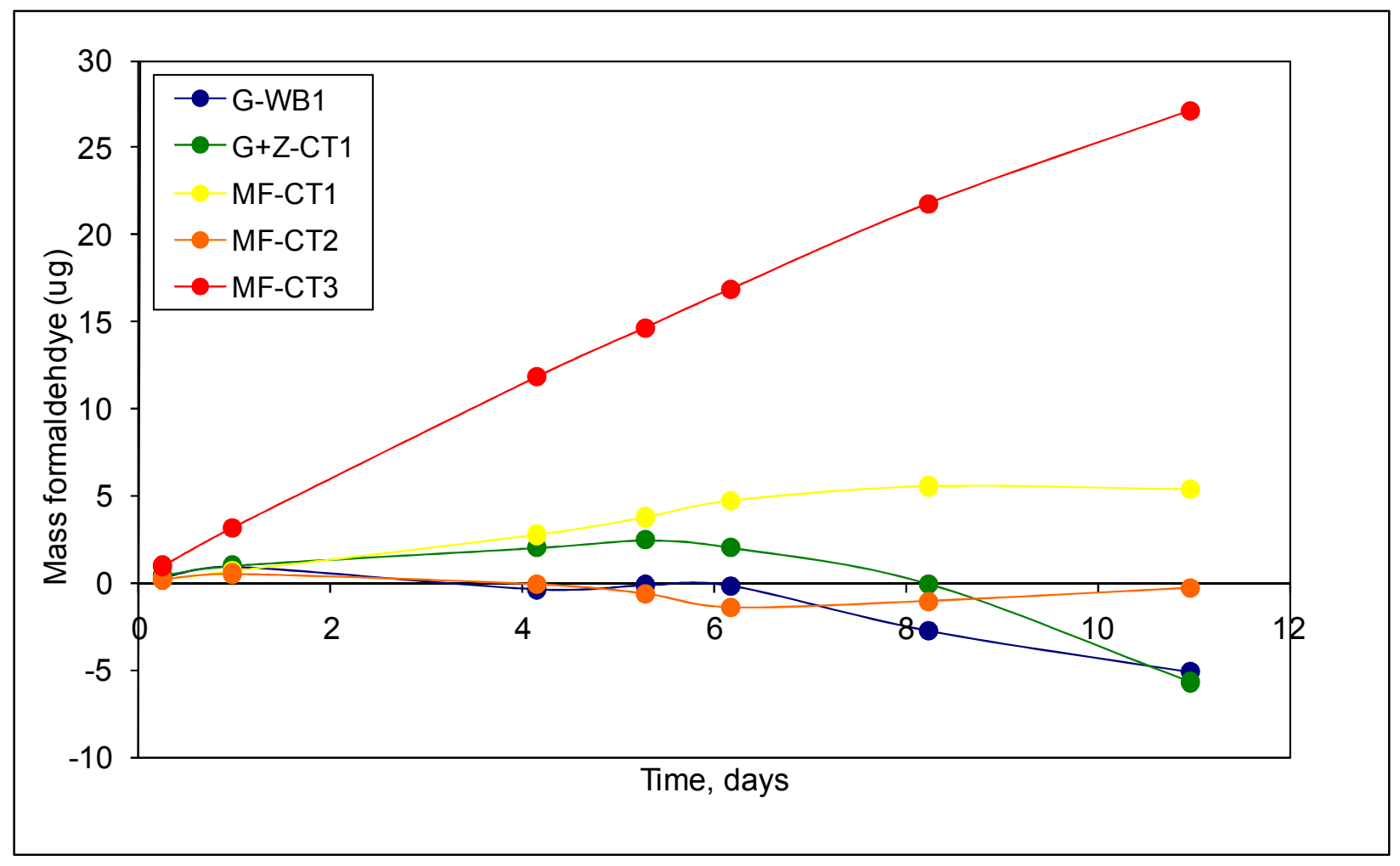




\subsection{Conclusions}

The tests performed in this pilot-scale study indicate, as expected, that each ceiling tile material, and standard gypsum wallboard, adsorbs formaldehyde for a period after initial exposure to formaldehyde, The special indoor surface material (G+Z-CT1) marketed as a product that helps to control indoor formaldehyde levels did not exhibit greater formaldehyde adsorption capabilities than the other materials tested. There was no clear evidence of catalytic formaldehyde destruction by this ceiling tile. The testing was limited in scope and utilized higher formaldehyde levels than typically found in buildings. The tests also involved simultaneous exposure to other typical indoor VOCs which may have limited the rate of formaldehyde removal. While the testing was too limited to support definitive conclusions, the results strongly suggest that the special ceiling tile is not likely to be effective for long-term indoor formaldehyde control.

\subsection{References}

Aguado, S., A. C. Polo, M. P. Bernal, J. Coronas and J. Santamaria (2004). "Removal of pollutants from indoor air using zeolite membranes." J. Membrane Sci. 240: 159166.

Destaillats, H., B. C. Singer, S. K. Lee and L. A. Gundel (2006). "Effect of ozone on nicotine desorption from model surfaces: Evidence for heterogeneous chemistry." Environmental Science \& Technology 40(6): 1799-1805.

Gora-Marek, K. and J. Datka (2008). "The transformation of formaldehyde on CoZSM-5 zeolites." Catalysis Today 137: 466-470.

Kukulska-Zajac, E. and J. Datka (2007). "Transformations of formaldehyde molecules in Cu-ZSM-5 zeolites." J. Phys. Chem. C 111: 3471-3475. 
Maddalena, R., M. Russell, D. P. Sullivan and M. G. Apte (2009). "Formaldehyde and Other Volatile Organic Chemical Emissions in Four FEMA Temporary Housing Units." Environmental Science \& Technology 43(15): 5626-5632.

Matthews, T. G., A. R. Hawthorne and C. V. Thompson (1987). "Formaldehyde sorption and desorption characteristics of gypsum wallboard." Environ. Sci. Technol. 21: 629-634.

Okachi, T. and M. Onaka (2004). "Formaldehyde encapsulated in zeolite: a long-lived, highly activated one-carbon electrophile to carbonyl-ene reactions." J. Amer. Chem. Soc. 126: 2306-2307.

Qian, B., H. Jiang, Y. Sun and Y. Long (2001). "Affinity study of organics on siliceous ferrierite type zeolite." Langmuir 17: 1119-1125. 